\title{
UCRL-TR-228629
}

LAW RENCE LIVERMORE N A TIO N A L LABORATORY

Visible and Infrared Optical Design for the ITER Upper Ports

C.J. Lasnier, L.G. Seppala, K. Morris, M. Groth, M.E. Fenstermacher, S.L. Allen, E. Synakowski, J. Ortiz

March 4, 2007 
This document was prepared as an account of work sponsored by an agency of the United States Government. Neither the United States Government nor the University of California nor any of their employees, makes any warranty, express or implied, or assumes any legal liability or responsibility for the accuracy, completeness, or usefulness of any information, apparatus, product, or process disclosed, or represents that its use would not infringe privately owned rights. Reference herein to any specific commercial product, process, or service by trade name, trademark, manufacturer, or otherwise, does not necessarily constitute or imply its endorsement, recommendation, or favoring by the United States Government or the University of California. The views and opinions of authors expressed herein do not necessarily state or reflect those of the United States Government or the University of California, and shall not be used for advertising or product endorsement purposes.

This work was performed under the auspices of the U.S. Department of Energy by University of California, Lawrence Livermore National Laboratory under Contract W-7405-Eng-48. 


\section{Visible and infrared optical design for the ITER upper ports}

C.J. Lasnier ${ }^{\mathrm{a}}$, L.G. Seppala ${ }^{\mathrm{a}}$, K. Morris ${ }^{a}$,

M. Groth ${ }^{\mathrm{a}}$, M.E. Fenstermachera ${ }^{\mathrm{a}}$ S.L. Allen $^{\mathrm{a}}$, E. Synakowski ${ }^{\mathrm{a}}$, J. Ortiz

\section{aLawrence Livermore National Laboratory}

\section{${ }^{b}$ University of Arizona, Tucson}

This work was performed under the auspices of the U.S. Department of Energy by University of California, Lawrence Livermore National Laboratory under contract No. W-7405-Eng-48. Work supported by the US ITER Project Office. 


\begin{abstract}
This document contains the results of an optical design scoping study of visible-light and infrared optics for the ITER ${ }^{1}$ upper ports, performed by LLNL under contract for the US ITER Project Office. ITER is an international collaboration to build a large fusion energy tokamak with a goal of demonstrating net fusion power for pulses much longer than the energy confinement time. At the time of this report, six of the ITER upper ports are planned to each to contain a camera system for recording visible and infrared light, as well as other diagnostics. The performance specifications for the temporal and spatial resolution of this system are shown in the Section II, Functional Specifications. We acknowledge a debt to Y. Corre and co-authors of the CEA Cadarache report "ITER wide-angle viewing and thermographic and visible system". Several of the concepts used in this design are derived from that CEA report.

The infrared spatial resolution for optics of this design is diffraction-limited by the size of the entrance aperture, at lower resolution than listed in the ITER diagnostic specifications. The size of the entrance aperture is a trade-off between spatial resolution, optics size in the port, and the location of relay optics. The signal-to-noise ratio allows operation at the specified time resolutions.
\end{abstract}




\section{Executive summary}

This report examines the performance specifications for the visible/IR camera systems for the upper ports of ITER and presents optical designs responding to those specifications. The system is required to observe as much of the outer divertor target plate as possible. The visible system is to detect wavelengths of $400-700 \mathrm{~nm}$, with a time resolution of $100 \mathrm{~ms}$. The IR system requires a temperature range of $200-2500{ }^{\circ} \mathrm{C}, 3 \mathrm{~mm}$ spatial resolution, and $20 \mu$ s time resolution for temperature between $1000{ }^{\circ} \mathrm{C}$ and 2500 ${ }^{\circ} \mathrm{C}$. For target temperatures from $200{ }^{\circ} \mathrm{C}$ to $1000{ }^{\circ} \mathrm{C}$ the required time resolution is $2 \mathrm{~ms}$.

In examining the specifications, we find that the IR performance specifications are well chosen to meet the mission objectives of the system. The $3 \mathrm{~mm}$ spatial resolution is consistent with predicted strike point width. However, the $3 \mathrm{~mm}$ resolution requirement with full spatial coverage may be impossible to meet within the dimensions of the port tube and design constraints on relay optics in the port, such as radiation tolerance.

The specified $100 \mathrm{~ms}$ time resolution for visible images is adequate for monitoring integrity of the divertor tiles. For measurement of emission during ELMs and disruptions, it would be desirable to have the same $20 \mu$ s time resolution as the IR system.

The outer target plate cannot be seen from an upper port by looking straight down. Since the target plate is vertical and the port opening is farther outboard, the target is not visible. It is necessary to tilt the field of view in the toroidal direction, $28^{\circ}$ from vertical to view the target. With six views, the camera system on each port must image 60 degrees of the torus for the maximum possible coverage

The reference design for the European camera system on the midplane ports includes various bends in the light path to allow enhanced neutron shielding. For the upper ports, it may be desirable instead to incorporate the optics into a "central tube" that can be installed and removed to allow maintenance of the system without removing the port plug. There is not a detailed reference design for the upper ports. We have developed a design with similarities to the midplane reference design (the " $5 \mathrm{~mm}$ aperture" design, section V.A) as well as a port-filling design (20 mm aperture, section V.B) and a centraltube design (10 $\mathrm{mm}$ aperture in a $360 \mathrm{~mm}$ inside diameter tube, section V.C).

The aperture is a small hole in the first wall tiles at the port location through which the divertor is viewed. Behind the aperture (within the port plug) is an aspherical primary mirror that collects light passing through the aperture. A flat mirror with a hole surrounds the aperture and redirects the light from the primary mirror outward toward the port flange.

The designs we show here do not have relay optics inside the vacuum. This is due to concern about the effects of neutrons on the transmission of refractive optics. It may be that lenses could be used in the outer half of the port plug, particularly since the upper ports do not point toward the core of the plasma where most fusion neutrons will be emitted.

The light for the visible camera is split from the IR beam using a mirror that deflects the center part of the beam to a path through separate vacuum widows optimized for visible light. The IR beam passes also through dedicated windows. Therefore each window material can be chosen for best performance at the required wavelengths. Each beam then enters a Cassegrain telescope followed by a lens relay that carries the light across the port interspace and through the bioshield to the camera. 
The system is diffraction limited by the entrance aperture diameter, provided cameras with enough pixels are used to resolve details. The size of the entrance aperture is limited by the size of the optics needed to form and relay an image (section IV.C). This in turn is limited by the size of the port tube. If the required field of view could be reduced, the image size would be reduced correspondingly as would the required optics size. Alternatively, the entrance aperture size could be increased for better resolution.

We find that the IR system provides enough light even at a $200{ }^{\circ} \mathrm{C}$ target temperature for $\mathrm{S} / \mathrm{N}=256$ at a frame rate of $86 \mathrm{kHz}$, faster than the required $20 \mu \mathrm{s}$ integration time, provided little signal is absorbed in the vacuum windows. Absorption is a concern for thick sapphire windows. Zinc selenide windows provide lower loss but may not be mechanically acceptable for a large window. Another candidate window material is $\mathrm{ZnS}$.

In contrast to the time resolution, the IR spatial resolution in all the designs presented here, fails to meet the specified $3 \mathrm{~mm}$ by a significant margin. Diffraction by the entrance aperture places a limit on spatial resolution as mentioned above. The aperture size is limited by the size of optics that fit in the port plug. Allowing relay lenses inside the port plug, and reducing the required field of view for less than full divertor coverage, would allow increased resolution.

In the case of metallic divertor tiles, or carbon with deposited metal, the emissivity of the surface will be poorly known. This introduces a very large error bar into the calculation of the surface temperature. In this case it is helpful to use a two-color or multi-color IR measurement, where the surface temperature is obtained from the relative shape of the blackbody spectrum rather than the absolute emitted intensity.

Model predictions of $\mathrm{D}_{\alpha}$ and carbon line emission obtained from Andre Kukushkin were used to predict signal levels and limiting frame rates for the visible cameras. We find that signal-to-noise ratios greater than 50 at 5000 frames per second, can be obtained for the emission lines $\mathrm{D}_{\alpha}, \mathrm{CII}$ at $229.8 \mathrm{~nm}$, and CIII at $465 \mathrm{~nm}$. For 20,000 frames/second, only CIII emits enough light for $\mathrm{S} / \mathrm{N}>50$. The radiation intensity of other impurities such as beryllium and tungsten is not available from present modeling codes.

One area of difficulty that awaits further development is availability of fast highresolution cameras. Visible camera detectors are now approaching the required 30004000 pixel resolution across the chip but not yet the necessary speed. The commercial development of visible cameras is proceeding rapidly and we can easily extrapolate that such cameras will be available before ITER operates, although perhaps not before the diagnostic construction begins.

The state of development in IR cameras is less advanced. The largest commercial detectors as of this writing (February 2007) are around 1000 pixels across. There are more specialized semi-custom detectors made of mosaics of smaller detectors that reach the required size. These detectors are normally used in satellites and are likely to be more expensive than commercial items. These arrays are normally read out slowly, so high speed again requires future development.

We also will need more data on radiation effects on optical materials and coatings before the final design of the diagnostic can be accepted or construction can begin. Other remaining issues are explored in section IX. 
Table of contents

Executive summary 3

I. Introduction $\quad 7$

$\begin{array}{lr}\text { II. Functional Specifications } & 14\end{array}$

$\begin{array}{ll}\text { A. Time resolution } & 14\end{array}$

B. Spatial resolution 15

$\begin{array}{ll}\text { C. Other requirements } & 16\end{array}$

$\begin{array}{ll}\text { III. Reference design and central tube concept } & 17\end{array}$

$\begin{array}{ll}\text { IV. General results that apply to all designs } & 19\end{array}$

$\begin{array}{lr}\text { A. Overall viewing geometry } & 19\end{array}$

B. Optical collection head 19

C. Determination of tube size 20

$\begin{array}{ll}\text { D. Projected geometrical pixel size } & 21\end{array}$

E. Effects of diffraction on resolution $\quad 23$

F. Object resolution $\quad 26$

G. Window material $\quad 27$

H. Birefringence of sapphire vacuum windows $\quad 30$

$\begin{array}{ll}\text { I. Radiation damage to optics } & 30\end{array}$

$\begin{array}{ll}\text { 1. Windows and lenses } & 30\end{array}$

2. Mirror substrates and coatings 31

V. Optical designs $\quad 32$

A. $5 \mathrm{~mm}$ aperture $\quad 32$

1. Optical schematic $\quad 32$

2. Effects of diffraction on resolution $\quad 35$

3. Camera telescope $\quad 35$

4. Sapphire vacuum windows $\quad 36$

5. Optical design parameters $\quad 36$

B. $20 \mathrm{~mm}$ aperture $\quad 40$

1. Optical layout 40

2. Optical collection head 41

3. Effects of diffraction on resolution $\quad 42$

4. Optical design parameters $\quad 42$

5. Detailed schematics of the optical train 43

6. Sapphire vacuum windows $\quad 49$

7. Optical performance 49

8. Drawings of the system $\quad 54$

C. $10 \mathrm{~mm}$ aperture in $360 \mathrm{~mm}$ tube $\quad 63$

1. Optical schematic $\quad 63$

2. Optical resolution 63

3. Optical performance $\quad 64$

4. Optical design details $\quad 65$

5. Physical layout $\quad 67$

VI. Consultation with European experts 
VII. Estimates of system signal-to-noise ratios and limiting frame rates

A. Estimating radiated power from a target reaching a detector pixel

B. Estimating radiated blackbody power on an IR camera pixel

C. Signal-to-noise ratios for IR $\quad 77$

$\begin{array}{ll}\text { D. Transmission losses } & 78\end{array}$

$\begin{array}{lr}\text { E. Self-emitted light } & 80\end{array}$

$\begin{array}{ll}\text { 1. IR } & 80\end{array}$

2. Visible $\quad 81$

F. Visible system signal-to-noise estimates $\quad 81$

$\begin{array}{ll}\text { VIII. Calibration } & 84\end{array}$

$\begin{array}{lr}\text { A. IR calibration } & 84\end{array}$

B. Visible system calibration $\quad 85$

IX. High-priority R\& D issues $\quad 85$

A. Large detector for IR, 3000-4000 pixels wide, $18 \mathrm{~mm}$ pixels 85

B. Large visible detector, 3300 pixels, $4 \mathrm{~cm}$ long 85

C. Durability of rhodium-coated mirrors under ion bombardment $\quad 86$

D. Durability of visible and IR anti-reflection coatings in high neutron environments $\quad 86$

E. Dependence of IR transmission on neutron fluence for $\mathrm{ZnSe}$ and Ge $\quad 86$

F. Fluorescent emission from optics $\quad 86$

G. Calibration of the visible system 86

H. Rejection of microwave power from gyrotrons $\quad 87$

I. Acquisition, processing, and storage, and analysis of data 87

$\begin{array}{ll}X . \text { Concluding comments } & 88\end{array}$ 


\section{Introduction}

The planned ITER device is a large tokamak intended to produce net fusion power output (Fig. 1) $)^{3}$. As a consequence of the large power density, the temperature of plasma facing components must be monitored to avoid overheating of surfaces exposed to plasma. One critical area is the outer strike plate of the divertor. To monitor the temperature of this surface, thermographic video imaging systems are planned to view the divertor outer target from six upper ports, with one system for each port. Each thermographic system is combined with a visible-light imaging system, which will be used with narrow-band filters to measure the intensity and distribution of hydrogenic and impurity line emission. Both the infrared and visible systems will also be used to monitor the integrity of plasma facing components.

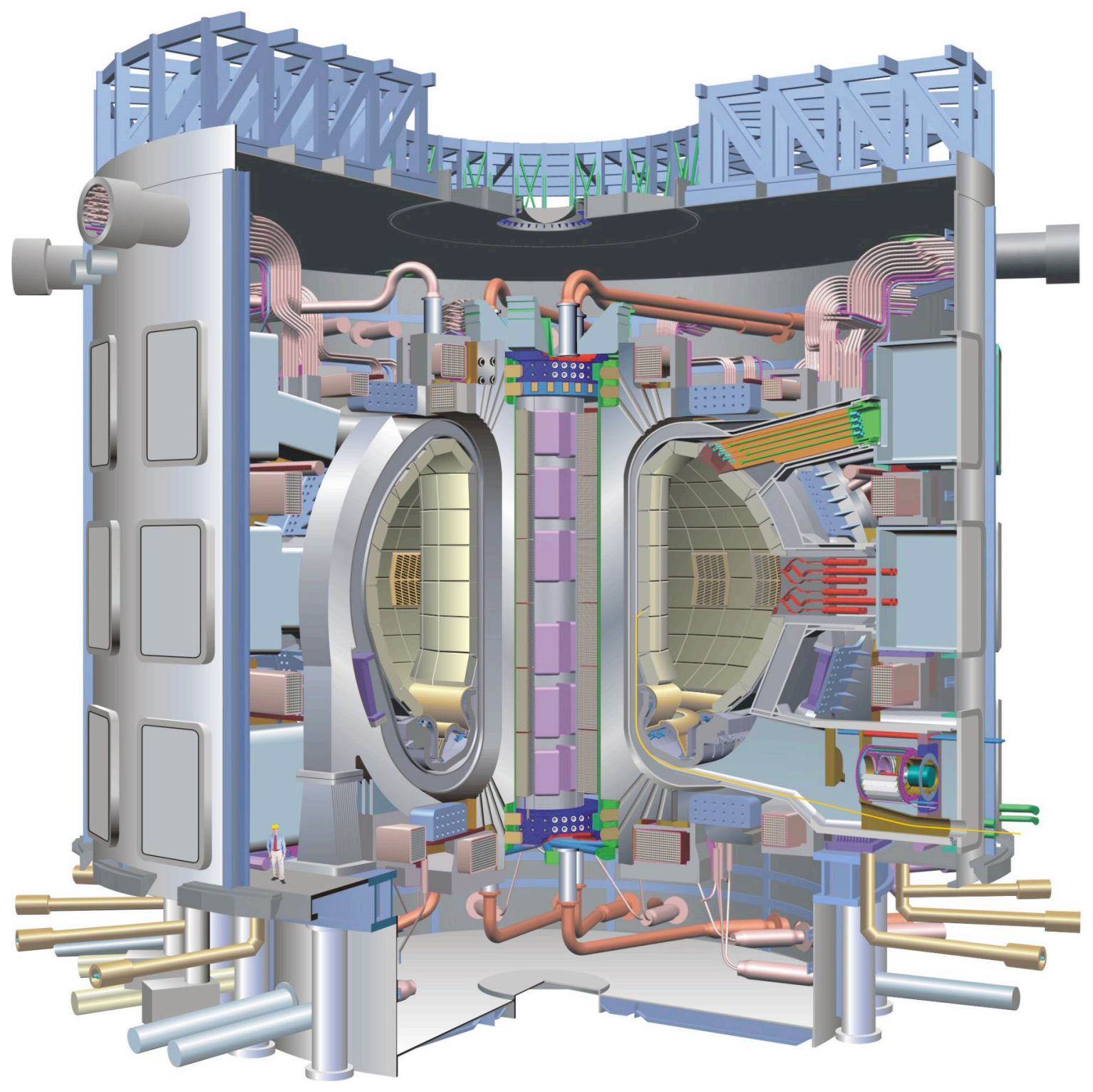

Fig. 1 The ITER tokamak design ${ }^{1}$. 
The goal of the camera systems in the upper port is to monitor the outer target plate, where the outer strike point of the plasma strikes the divertor. An ITER crosssection is shown in Fig. $2^{4}$. Because of the possibility of toroidal asymmetry, the goal is to watch the entire outer strike point all the time during plasma operation. For that reason the designs discussed here were optimized to view as much of the outer target plate as possible, which is $95 \%$ coverage. Because the outer target plate is nearly vertical, the cameras cannot see this plate by looking straight down from an upper port, and the view from each camera must be tilted in the toroidal direction. Some areas remain inaccessible, so coverage is not $100 \%$.

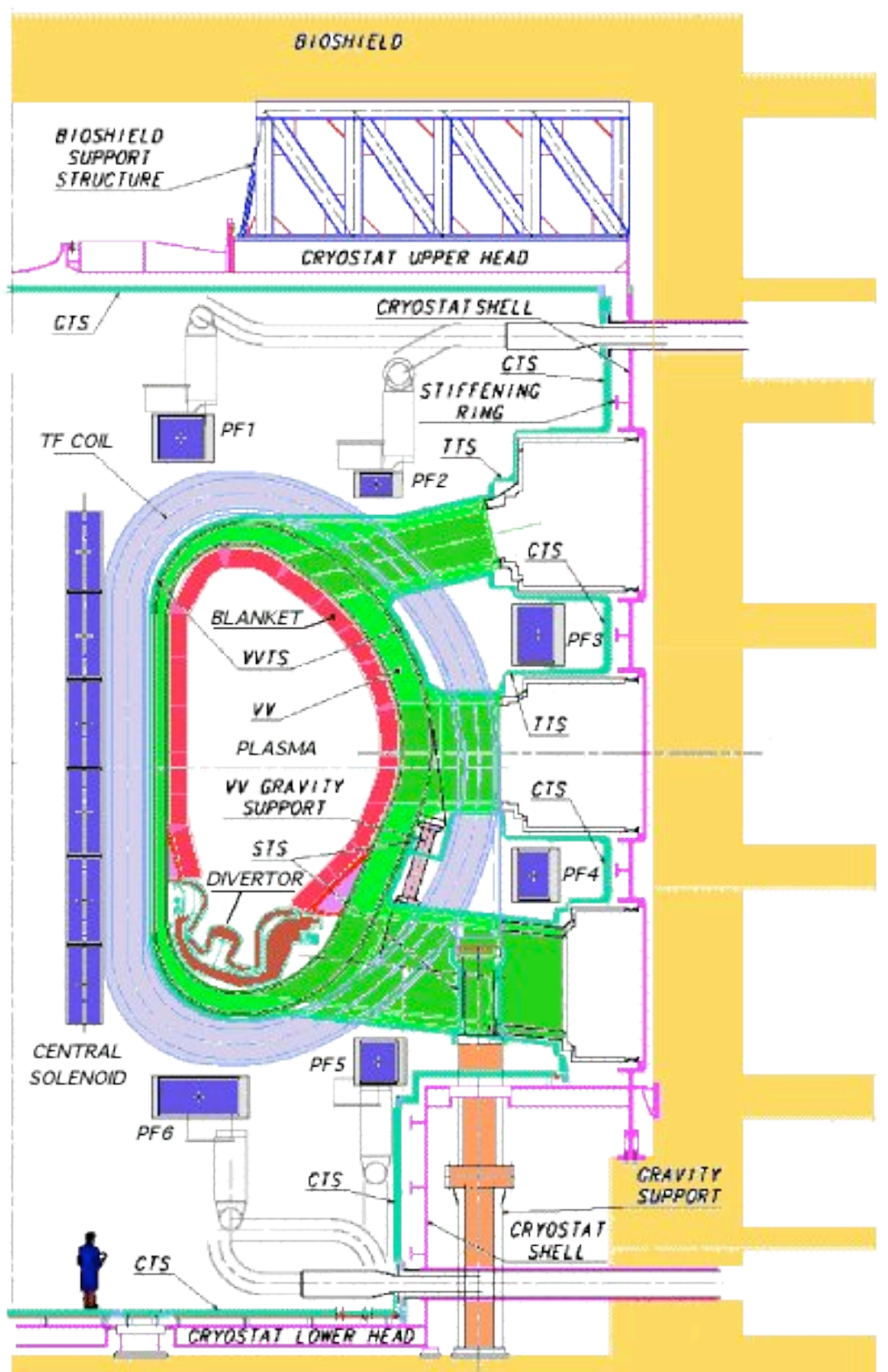

Fig. 2 ITER cross-section 
The field of view is shown in Fig. 3, in a cut-away view from above the tokamak.

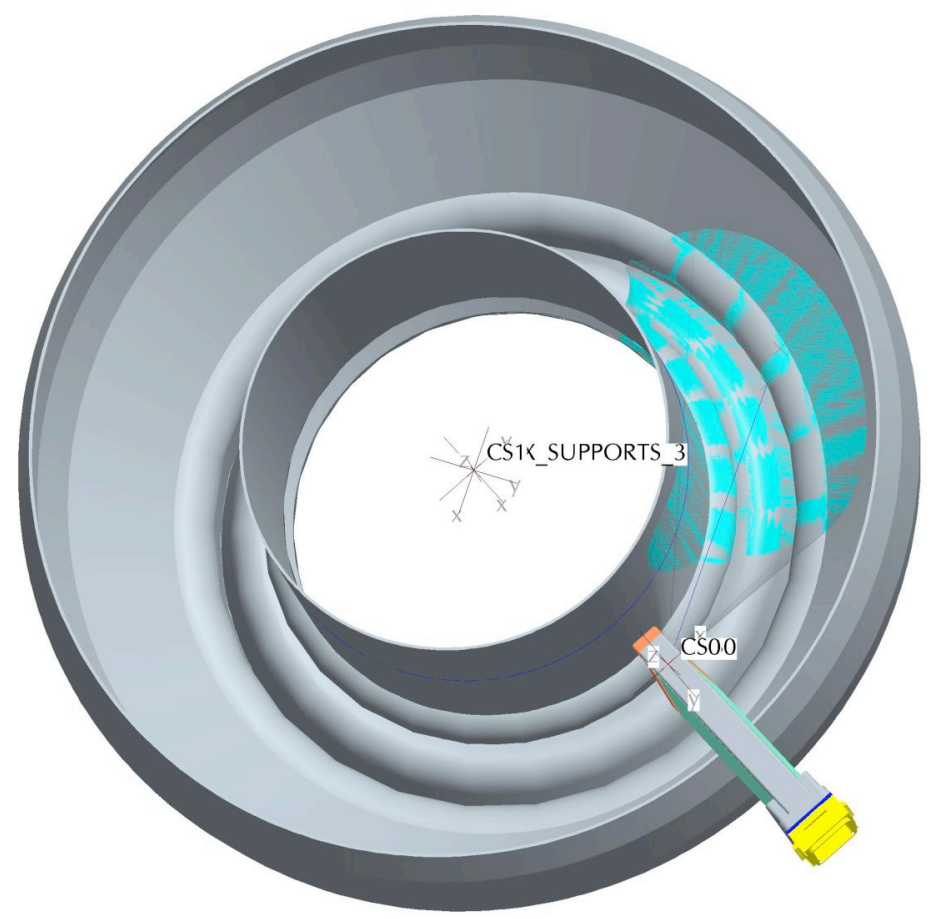

Fig. 3 The field of view from one camera location. Some of the highlighted areas are blocked by the inner wall, as shown in fig. 4 .

Fig. 4 shows the view along the line of sight from an upper port, with the obscuration by the inner wall, and showing a port tube. This view also shows parts of the view of the outer target. The inner target plate is not seen and will be viewed by the European camera systems in the equatorial ports. Fig. 5 shows the same view as Fig. 5, without the port tube, so that the outer target plate can be seen.

Fig. 6 shows a further illustration of the areas of coverage, with a red curve showing a poloidal cross-section of the outer target plate. Very little of the inner target plate is visible from the upper ports regardless of how the viewing angle is chosen. Fig. 7 shows the views using all 6 upper ports.

A visible and an infrared imaging system share a plasma facing aperture in each of the six upper ports. Visible and infrared light pass through the aperture, are collected by an aspheric mirror, reflect off a large flat secondary mirror with a hole for the entrance aperture, and are relayed out of the port plug through vacuum windows. The light then passes through the region outside the port flange, called the "port 
interspace", and through the bioshield (see Fig. 2), where the light is captured by cameras.

The spatial resolution is limited by diffraction of light by the aperture. The size of the aperture maps to the size of the optics, which also increase in size due to a requirement for no relay lenses inside the port plug vacuum (to reduce problems due to radiation damage). The further the image has to travel without a relay lens, the larger the optics need to be. We avoid reflective relay optics due to problems with throughput and/or maintaining critical alignment to preserve image quality.

The figures discussed above show the required field of view independent of any optical design.

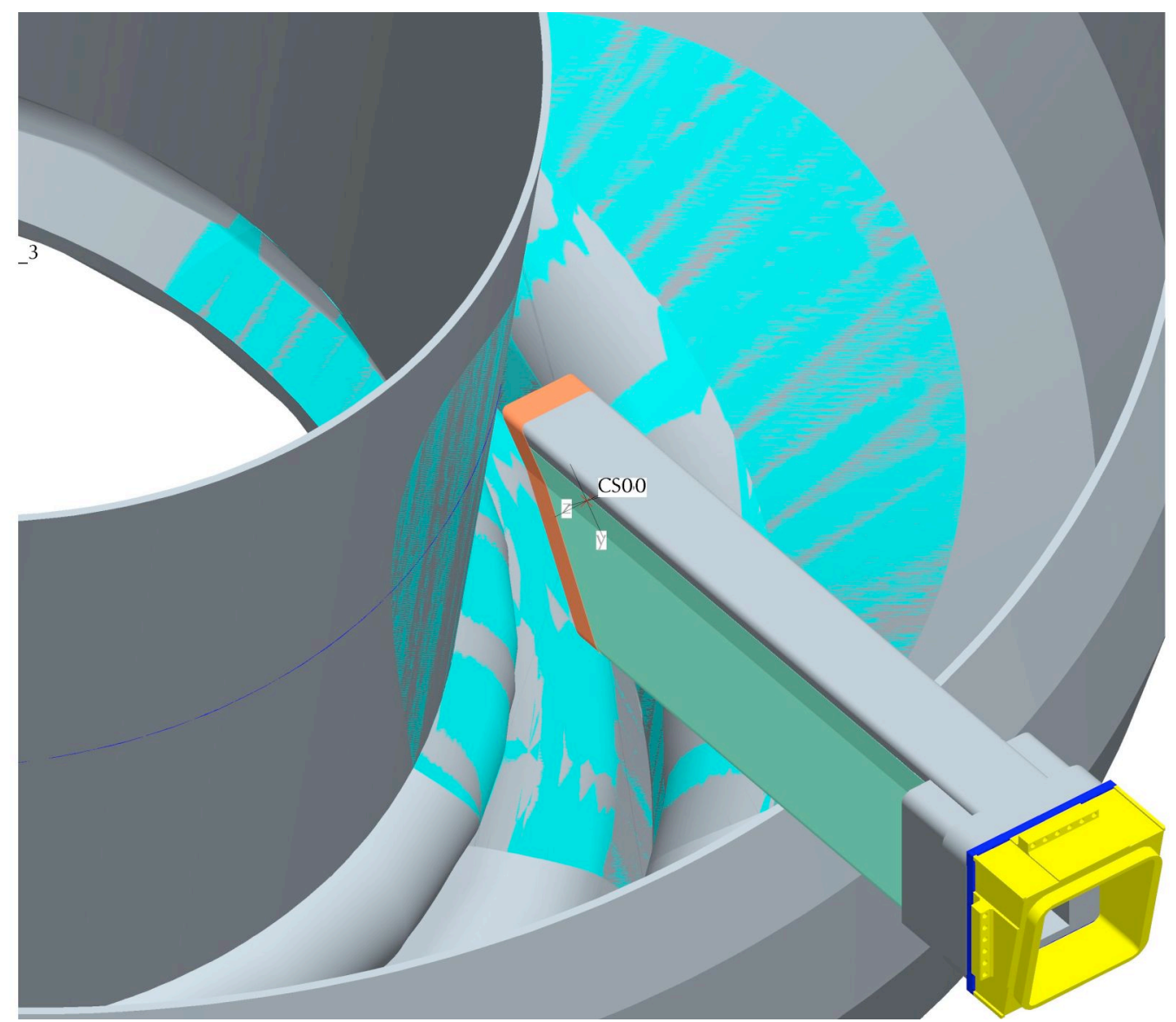

Fig. 4. A view along the line of sight from an upper port, with a port tube shown. Note that the highlighted areas obscured by the centerpost are not visible to the camera. 


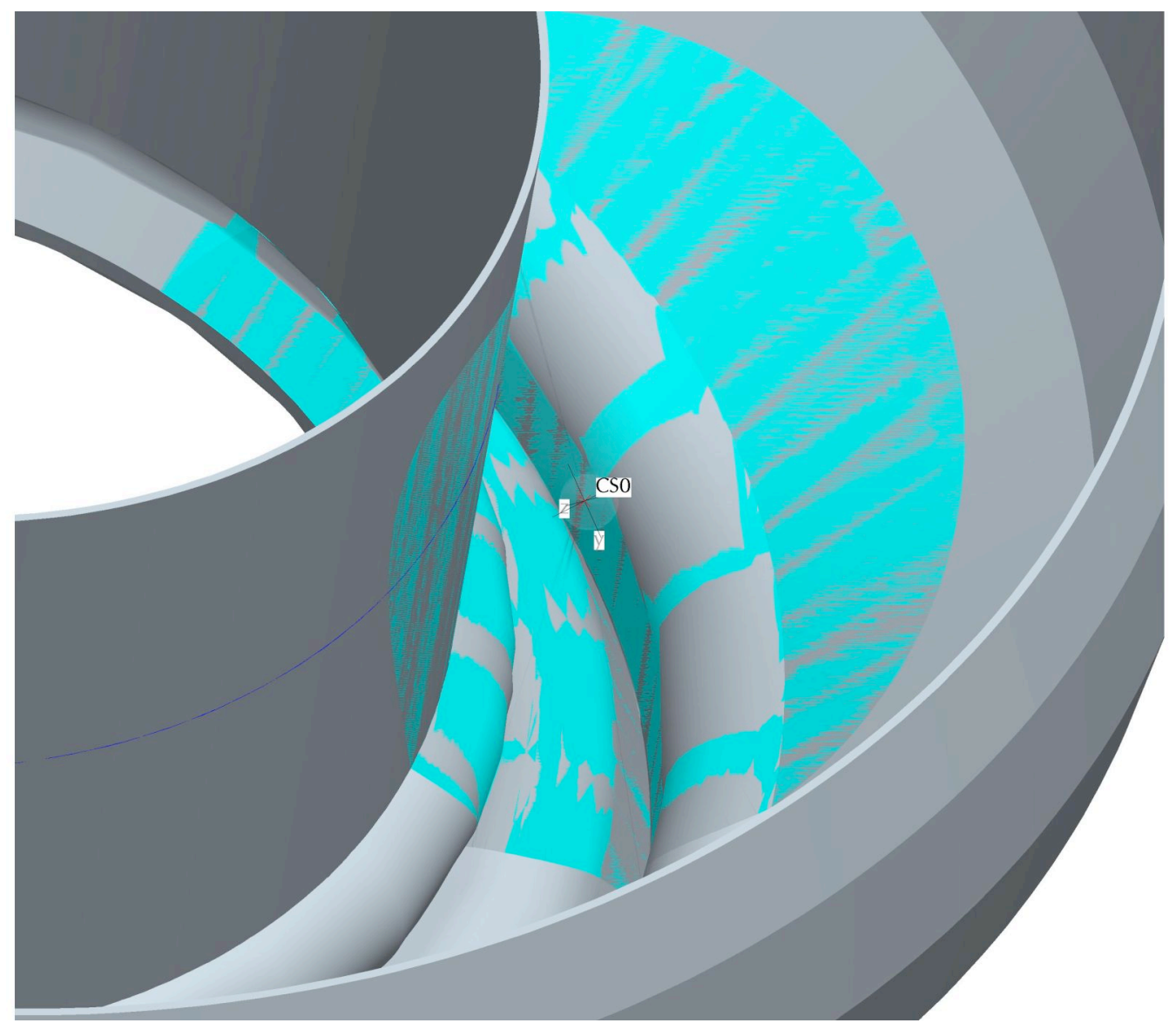

Fig. 5. The same view as Fig. 4 with the port tube not shown, with the outer target plate visible. The cross-hair is on the outer target plate. 


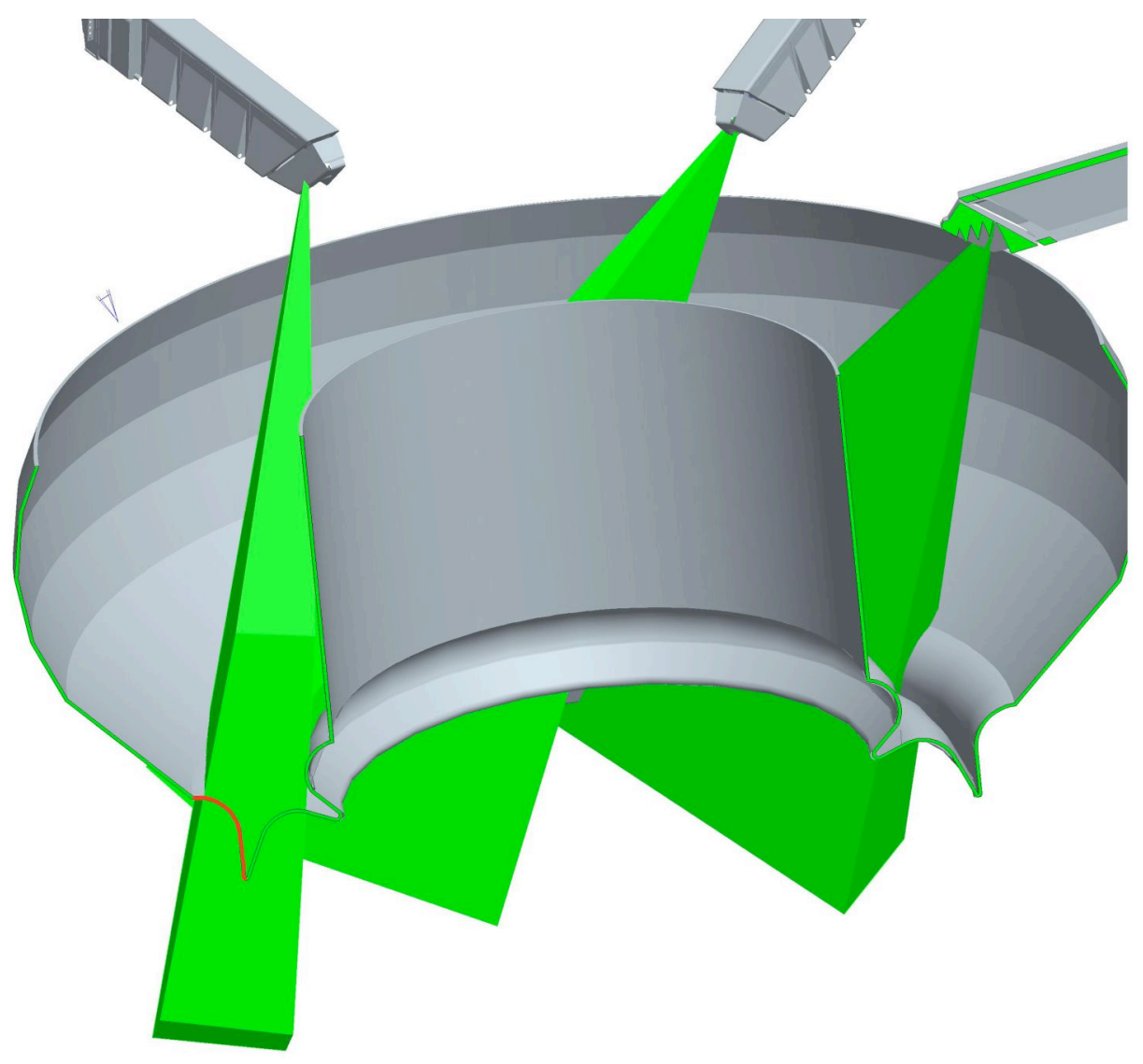

Fig. 6 Further illustration of the areas of coverage. The red curve shows a poloidal crosssection of the outer target plate. The inner target plate is mainly invisible from the upper ports. 


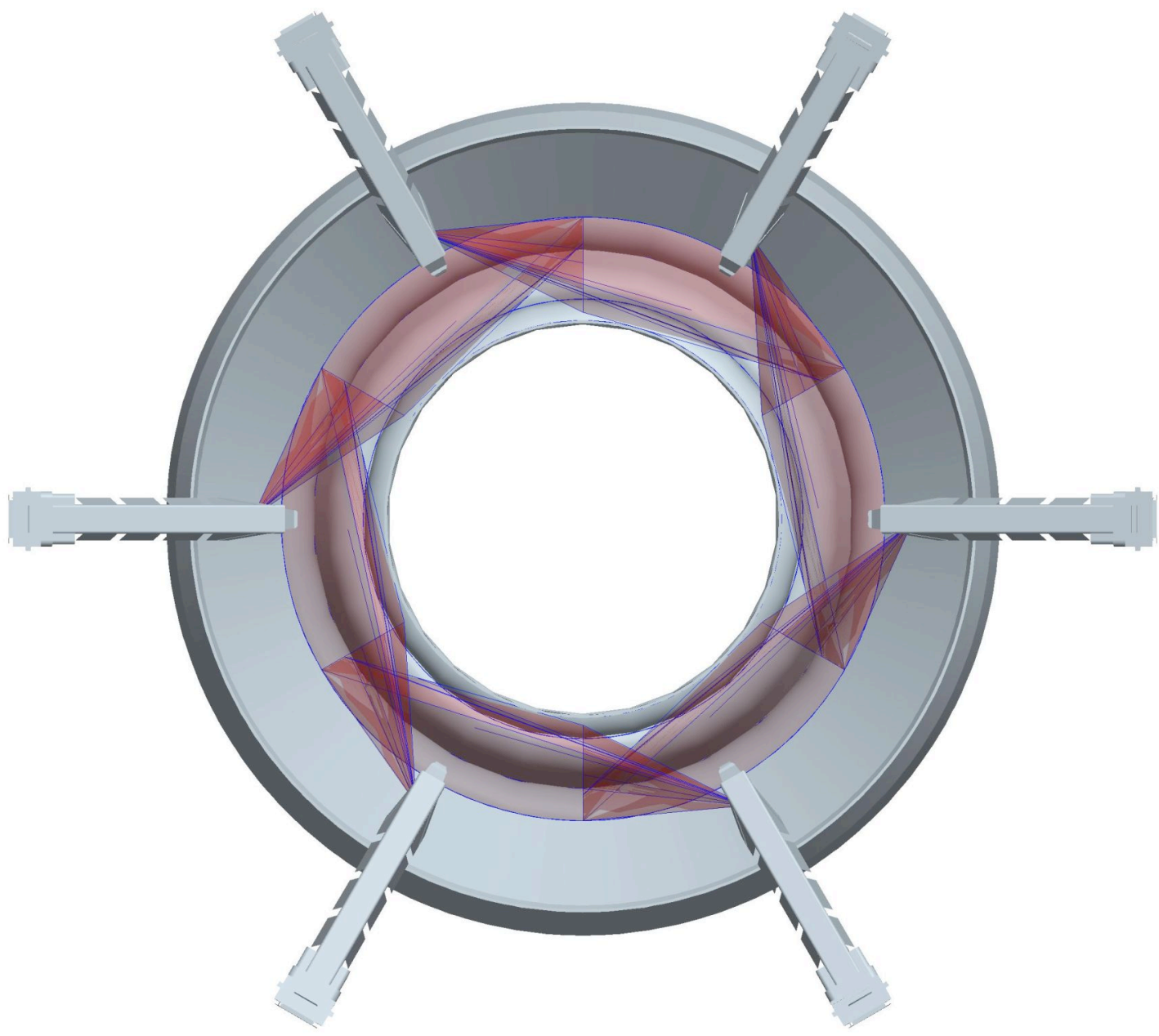

Fig. 7 Views from 6 upper ports covering as much of the outer target plate as possible. In this design the toroidal tilt is in the opposite direction, which is equivalent. 


\section{Functional Specifications}

Performance specifications for visible and infrared camera systems were developed by the ITER organization for time and spatial resolution, spatial coverage, and wavelength coverage of the visible system. Those specifications are given in Table 1 .

\begin{tabular}{|c|c|c|c|c|c|c|}
\hline \multirow[b]{2}{*}{ MEASUREMENT } & \multirow[b]{2}{*}{ PARAMETER } & \multirow[b]{2}{*}{ CONDITION } & \multirow[b]{2}{*}{$\begin{array}{l}\text { RANGE or } \\
\text { COVERAGE }\end{array}$} & \multicolumn{2}{|c|}{ RESOLUTION } & \multirow[b]{2}{*}{ ACCURACY } \\
\hline & & & & $\begin{array}{c}\text { Time or } \\
\text { Freq. }\end{array}$ & $\begin{array}{l}\text { Spatial or } \\
\text { Wave No. }\end{array}$ & \\
\hline \multirow{2}{*}{$\begin{array}{l}\text { 17. First Wall (FW) } \\
\text { Visible Image \& } \\
\text { Wall Temperature } \\
\end{array}$} & FW image & & TBD & $100 \mathrm{~ms}$ & TBD & - \\
\hline & $\begin{array}{l}\text { FW surface } \\
\text { temperature }\end{array}$ & & $200-1500^{\circ} \mathrm{C}$ & $10 \mathrm{~ms}$ & TBD & $20^{\circ} \mathrm{C}$ \\
\hline \multirow{4}{*}{$\begin{array}{l}\text { 38. Heat Loading } \\
\text { Profile in Divertor }\end{array}$} & \multirow{2}{*}{$\begin{array}{l}\text { Surface } \\
\text { temperature }\end{array}$} & & $200-1000^{\circ} \mathrm{C}$ & $2 \mathrm{~ms}$ & $3 \mathrm{~mm}$ & $10 \%$ \\
\hline & & & $1000-2500^{\circ} \mathrm{C}$ & $20 \times 10^{-6} \mathrm{~s}$ & $3 \mathrm{~mm}$ & $10 \%$ \\
\hline & \multirow[t]{2}{*}{ Power load } & Default & $\begin{array}{c}\text { TBD - 25 } \\
\mathrm{MW} / \mathrm{m}^{2} \\
\end{array}$ & $2 \mathrm{~ms}$ & $3 \mathrm{~mm}$ & $10 \%$ \\
\hline & & Disruption & TBD - 5 GW/m $/ \mathrm{m}^{2}$ & $0.1 \mathrm{~ms}$ & TBD & $20 \%$ \\
\hline
\end{tabular}

Table 1. Functional specifications of ITER upper port visible and IR camera systems.

\section{A. Time resolution}

The first time resolution requirement is for the system to detect excessive surface temperature in time to prevent severe damage. The $2 \mathrm{~ms}$ time resolution listed in Table I is likely adequate for measuring the time-averaged temperature (not resolving ELMs), considering the time scale on which a response to off-normal conditions could be made.

To monitor surface temperature excursions during ELMs, the higher $20 \mu \mathrm{s}$ time resolution listed is highly desirable.

The time resolution quoted for power load during disruptions is $100 \mu$ s. Since the power load will be calculated from the surface temperatures, the same time resolution applies to both the power and temperature. It is sometimes desirable to smooth the calculated power results, in which case a $20 \mu$ s time resolution in temperature can be consistent with the $100 \mu$ s resolution for power. The specified time resolutions for the infrared system are appropriate for both operational safety monitoring and physics measurements.

The most significant problem for very fast heat flux measurements is not a characteristic of the camera or optics, but of the surface being measured. It is suspected that first-wall surfaces in tokamaks may accumulate a poorly-adhered layer of material which may have a different thermal capacity and conductance, and a different emissivity for infrared light, than the bulk material, and therefore may heat and cool more quickly with smaller amounts of heat ${ }^{5}$. Since the properties of this material are unknown and heat flux calculations from measured infrared emission depend on the properties of the material, heat flux calculations will give wrong results.

Thermographic surface temperature measurements as a means of assuring tokamak safety are also less reliable for surfaces covered with such layers. A surface layer might heat rapidly to a very high temperature after absorbing a small amount of heat, which would appear as an over-temperature condition. The response might be to 
terminate the discharge, although in reality the surface of the bulk material did not reach a dangerous temperature and none of it was ablated.

The possible anomalous surface layers are problem in areas of net deposition, which we expect in cooler areas and not at the outer strike point. Any such layers in an area of high heat flux would be quickly eroded. Since it is in the hottest areas that we need to critically monitor the temperature, and not the cooler areas, the problem introduced by surface layers to first-wall safety monitoring is less severe than might be first thought. We expect that ITER will run nearly the same discharges with the same plasma shapes for extended periods, so the hot areas will always be hot during discharges. This differs from present-day tokamaks in which the strike points may hit different areas on different days depending on what experiments are chosen. Confusion may still arise when transient events such as disruptions deposit large amounts of heat in areas that normally receive little. These areas can then appear to be dangerously hot even if the tiles are in no danger.

The 100-ms time resolution specified for the visible-light first-wall image is perhaps adequate for quality assurance purposes, such as watching for broken tiles. For physics measurement of properties of ELMs, much higher time resolution is desirable- as fast or faster than the infrared cameras. The optical throughput for at least the brightest emission lines will be adequate for high speed imaging, so the main impact of a speed increase would be to require faster cameras and data acquisition, with larger amounts of required data. It may be argued that not all six ports require a high-speed visible camera, and some cameras could be slower and less expensive.

\section{B. Spatial resolution}

The spatial resolution for the IR system is specified in Table I as $3 \mathrm{~mm}$ everywhere in the divertor. Since the ITER divertor surface area is about $40 \mathrm{~m}^{2}$, we need about 4.4 million pixels, assuming that only divertor plates appear in the images. In practice the image of the divertor plates is an irregular shape that does not completely fill a rectangular detector, so the required number of pixels is even higher. Currently available commercial cameras are typically $640 \times 480$ pixels $(0.3$ Mpixels $)$, so we see immediately that substantially more than 15 such cameras would be required to provide coverage of the divertor at $3 \mathrm{~mm}$ resolution. We hope that higher-resolution IR cameras continue to be developed, as pointed out in the CEA report ${ }^{2}$. Recent progress has slowed compared to the original CEA projection. Special-purpose custom-made detectors exist at higher resolution for astronomy and satellites. Commercial products would be certainly less expensive and possibly more reliable.

There would be an advantage in delaying the purchase of most of the IR cameras until shortly before they are to be put into use, so as the take advantage of up-to-date technology.

As shown is succeeding sections, the $3 \mathrm{~mm}$ resolution requirement is difficult to meet for other reasons, including the physical constraints of the port tube, and a requirement that relay lenses may not be used inside the port plug due to loss of transparency from radiation damage.

The $3 \mathrm{~mm}$ spatial resolution requirement does have a physical basis. Fig. 8 shows a predicted divertor heat flux profile, calculated for the ITER base case by G. D. Porter using the UEdge code ${ }^{6}$. It may be seen that if the resolution is much poorer 
than $3 \mathrm{~mm}$, the peak of the heat flux profile (and the surface temperature profile) will not be well resolved and the peak temperature measurement will be an underestimate. of the true maximum temperature.

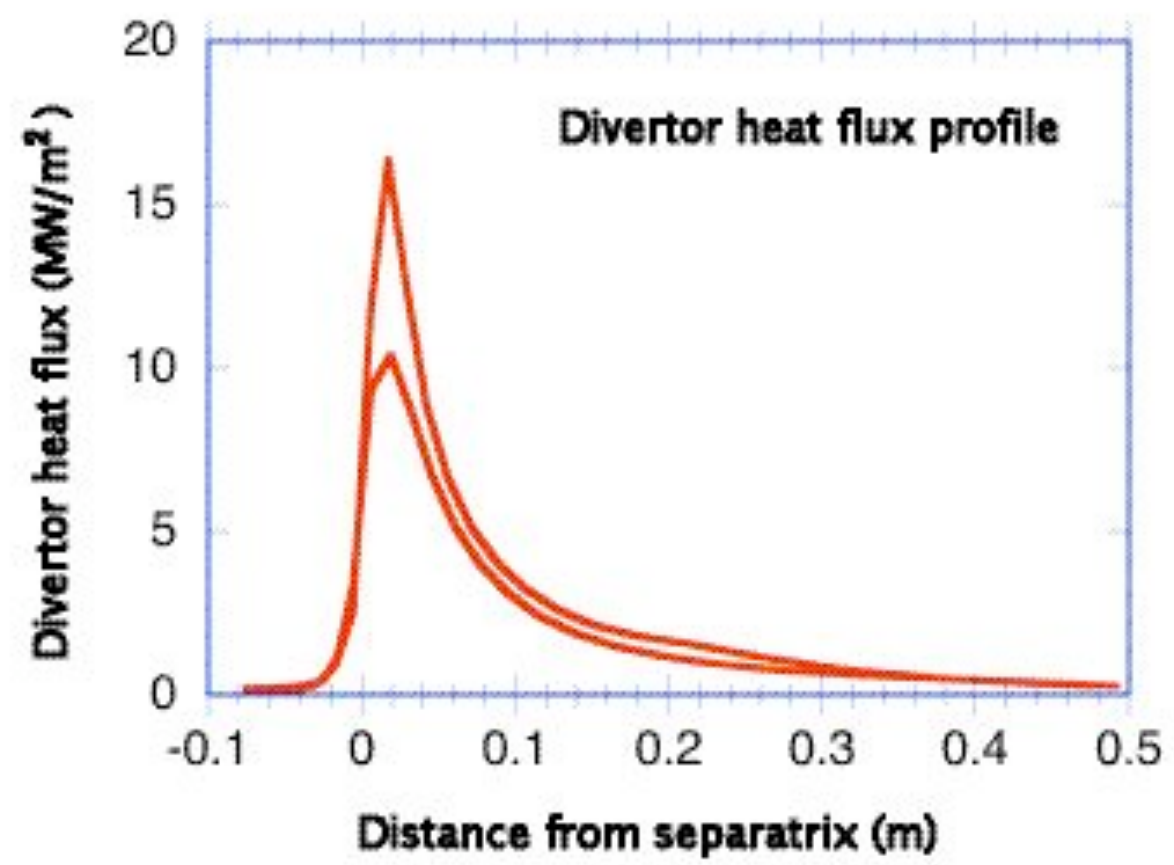

Fig. 8 Divertor heat flux profile predicted using UEdge code.

The spatial resolution of the visible camera system is not given in the current specification. High spatial resolution is easier to achieve in visible wavelengths than infrared, partly because the shorter wavelength is less affected by diffraction, and also because high-resolution cameras are commercially available now. In practice the visible optical resolution ends up being similar to the IR resolution, for the designs we consider here.

\section{Other requirements}

For safe containment of tritium, every vacuum window is required to be a double window with a pumpable space in between. This has a side effect of increased absorption and reflection in the windows for optical diagnostics.

No lenses are used here in the port plug due to reduction of transmission due to radiation damage. Optics in the port plug will require cooling, particularly the first two mirrors closest to the plasma. 


\section{Reference design and central tube concept}

The designs we consider here are based on some of the concepts used in the CEA design ${ }^{2}$, such as a small plasma-facing aperture to view through, an aspheric primary mirror, and a large flat secondary mirror with a hole through which the beam passes. The relay optics are quite different and the visible/infrared splitting is somewhat different.

The so-called reference design is shown in Fig. 9. This is actually a concept rather than a design, and includes a "dogleg" (displacing the beam with mirrors) to block streaming neutrons from the plasma. The optics depicted in the figure are in fact far too small to be consistent with the specified field of view and spatial resolution. We have retained the dogleg concept, which is widely used in other ITER diagnostic designs.

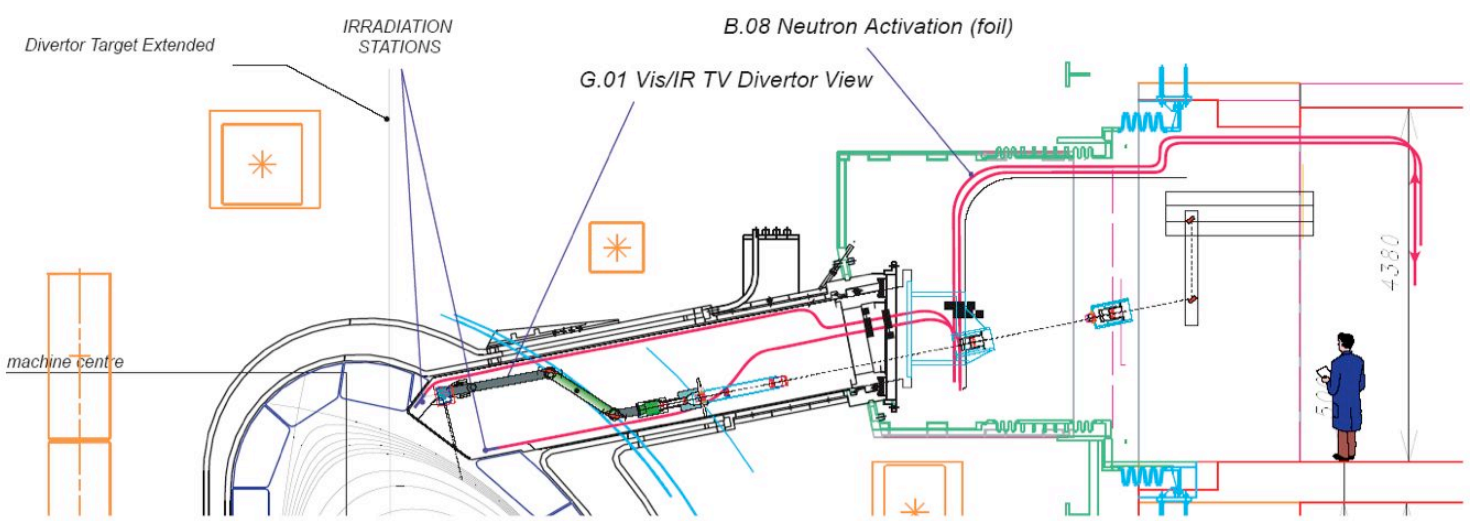

Fig. 9 Reference design for upper port camera optics.

The CEA report ${ }^{2}$ shows a fully developed optical design appropriate for a midplane port. The design for an upper port must differ from this because of different port size and geometry, longer object distance, and somewhat different mission of viewing the outer target plate.

One of the design goals is to produce an endoscope that can be inserted into the port plug and withdrawn without removing the port plug. This can be accomplished using a "central tube", that is, incorporating all the optics in a straight tube which ideally can be installed from outside the bioshield, which is the wall roughly centered at the pink dashed vertical line in Fig. 9.

The central tube concept is depicted in Fig. 10. Components inside the port plug, particularly the first two mirrors, would require cooling. In one version of the central tube concept, cooling is accomplished using a double-walled tube with cooling water flowing between the inner and outer tube. 


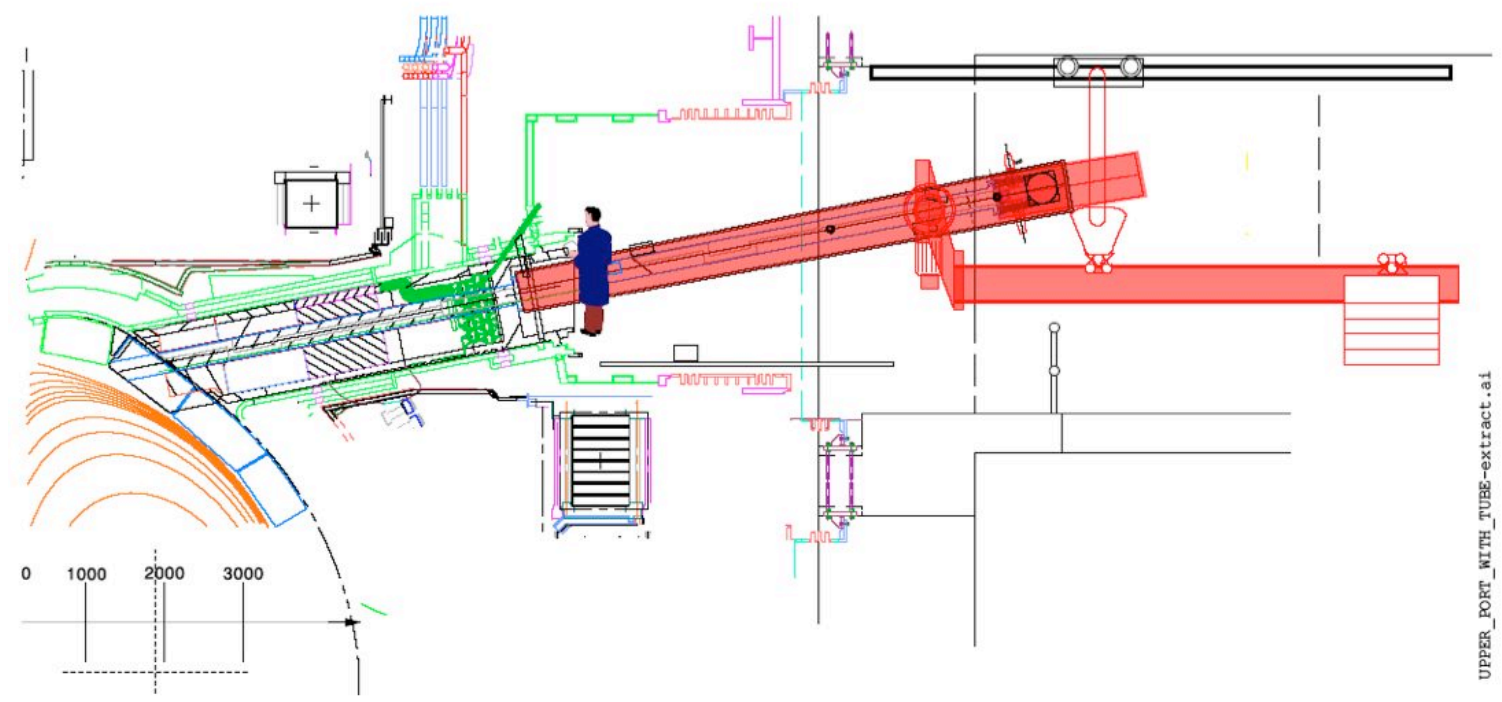

Fig. 10. The central tube concept for an upper port, with handling equipment. 


\section{General results that apply to all designs}

\section{A. Overall viewing geometry}

The overall viewing geometry for an upper port is shown in Fig. 11. The angles shown are those needed for maximum coverage of the outer target using six upper ports.

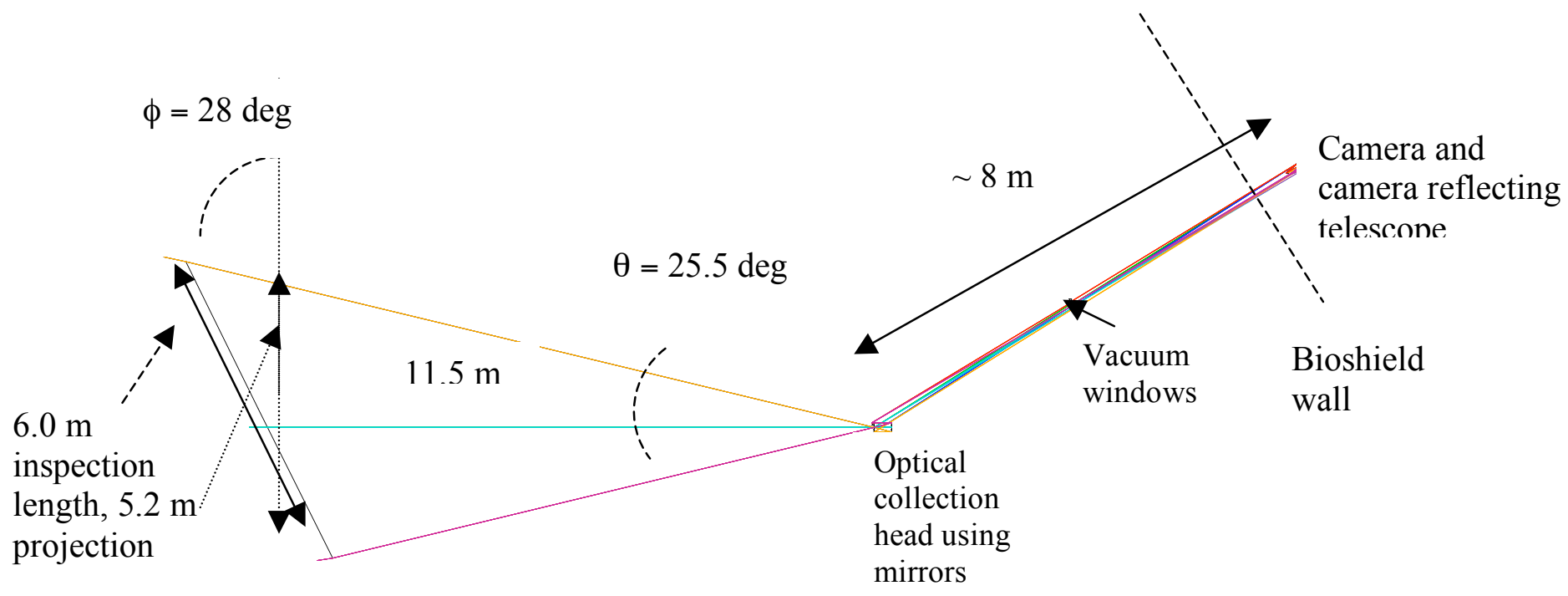

Fig. 11 Viewing geometry for an upper port. The diagram lies in a vertical plane.

\section{B. Optical collection head}

The optical collection head (Fig. 12) is a single concave elliptical mirror that images the small entrance hole further up toward the bioshield wall. For sufficiently small entrance holes and large tube sizes, this image point can lie beyond the bioshield wall. At this location beyond the wall, a simple two-mirror telescope can image the ITER wall onto a detector. The second flat mirror of the collection head has the entrance hole in it and simply directs the collected light away from the first focusing mirror. 


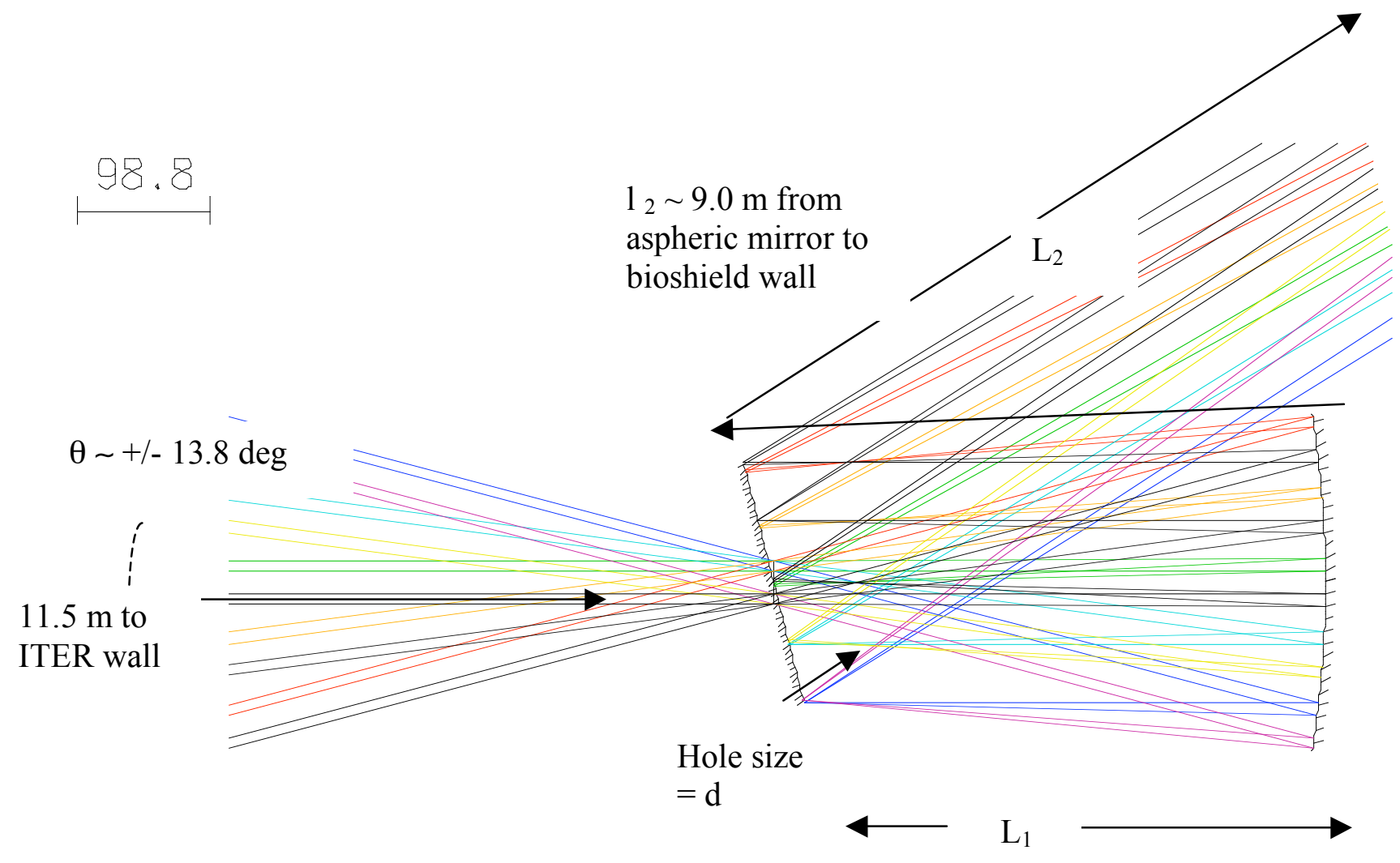

Fig. 12 Optical collection head schematic.

\section{Determination of tube size}

The following derivation shows how the tube diameter $\mathrm{D}$ is affected by the entrance hole diameter $\mathrm{d}$, the field angle $\theta$ and the distance $l_{2}$ to the first image plane of the hole.

The diameter $\mathrm{D}$ of the aspheric mirror is approximately

$$
\mathrm{D}=2 \mathrm{~L}_{1} \tan \theta+\mathrm{d}
$$

since the light beam from a point on the inspection region is very close to collimated. A tube of diameter $\mathrm{D}$ can enclose the entire space between the collecting head to the focusing telescope and the image of the hole if the image diameter is also D. Therefore, its is convenient to have the magnified image of the entrance hole

$$
\mathrm{D}=\mathrm{d} \mathrm{L} / \mathrm{l}_{1}
$$

where $\mathrm{L}_{2}$ is the distance from the focusing mirror to the image of the hole Equating the two expressions for D gives

$$
2 \mathrm{~L}_{1}^{2} \tan \theta+\mathrm{dL}_{1}-\mathrm{dL}_{2}=0
$$


and by the quadratic solution

$$
\mathrm{L}_{1}=\left[-\mathrm{d}+\operatorname{sqrt}\left(\mathrm{d}^{2}+8 \mathrm{~d} \mathrm{~L}_{2} \tan \theta\right)\right] /[4 \tan \theta]
$$

[4]

Since in general $l_{2}>>d$, we can ignore the first term under the square root, $\mathrm{d}^{2}$, so that

$$
\mathrm{L}_{1} \sim=\operatorname{sqrt}\left[\left(\mathrm{L}_{2} \mathrm{~d} / 2 \tan \theta\right)\right]-\mathrm{d} /(4 \tan \theta)
$$

and

$$
\mathrm{D} \sim=\operatorname{sqrt}\left[2 \mathrm{~L}_{2} \mathrm{~d} \tan \theta\right]+\mathrm{d} / 2
$$

where $\theta=13.8$ degrees here, and $\mathrm{L}_{2} \sim 4.5 \mathrm{~m}$.

The tube diameter $\mathrm{D}$ is set by the product of the entrance hole diameter $\mathrm{d}$, the field of view $\theta$ and the distance, $1_{2}$, to the first image of the entrance hole. For a given tube diameter and a given field size, the product of entrance hole size and the length of the relay is constant; doubling the hole size results reduces the relay distance by half. A large entrance hole means either a very large tube diameter or multiple refractive relays. These results are summarized in Table 2 .

\begin{tabular}{|l|l|l|l|l|}
\hline $\begin{array}{l}\text { Aperture hole } \\
\text { diameter d } \\
(\mathrm{mm})\end{array}$ & $\begin{array}{l}\text { Vacuum } \\
\text { tube length } \\
\text { L (mm) }\end{array}$ & $\begin{array}{l}\text { q field } \\
\text { angle }(\mathrm{deg})\end{array}$ & $\begin{array}{l}\text { Optics diameter } \\
\mathrm{D}(\mathrm{mm})\end{array}$ & $\begin{array}{l}\text { Estimated } \\
\text { resolved feature } \\
@ 5 \mu \mathrm{m}(\mathrm{mm})\end{array}$ \\
\hline 10 & 4500 & 27.6 & 149 & 11.5 \\
\hline 15 & 4500 & 27.6 & 182 & 7.7 \\
\hline 20 & 4500 & $\mathbf{2 7 . 6}$ & $\mathbf{2 1 0}$ & $\mathbf{5 . 8}$ \\
\hline
\end{tabular}

Table 2. Variation of optics diameter and resolution with aperture size. The vacuum tube diameter is slightly more than twice the optics diameter.

\section{Projected geometrical pixel size}

Figure 13 shows a more detailed description of the ITER geometry.

In this diagram, a $6.5 \mathrm{~m}$ line length in the horizontal plane is viewed with a viewing angle of 28 degrees from vertical. The center of the field is about $11.5 \mathrm{~m}$ away from the entrance hole. The law of sines can be invoked to determine each side of the triangles. 


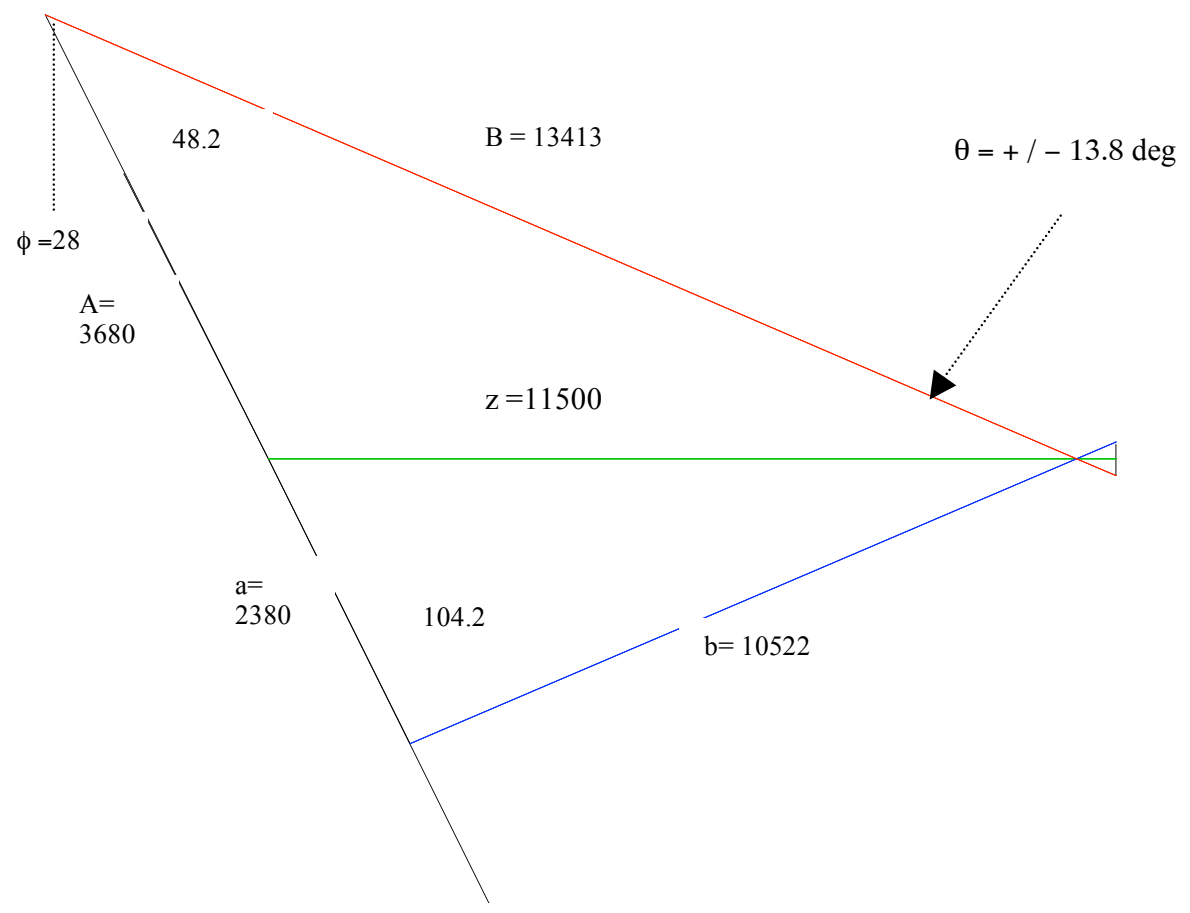

Fig 13. Detailed ITER viewing geometry.

$$
\begin{aligned}
& \left.\begin{array}{l}
11500 / \sin (90+\phi-\theta)=\mathrm{a} / \mathrm{sin}(\theta)=\mathrm{b} / \sin (90-\phi) \\
11500 / \sin (90-\phi-\theta)=\mathrm{A} / \sin (\theta)=\mathrm{B} / \sin (90+\phi)
\end{array}\right\} \quad \text { Law of sines } \\
& 11500 / \sin (96)=\mathrm{a} / \sin (22)=\mathrm{b} / \sin (62) \quad \mathrm{a}=2640, \quad \mathrm{~b}=10522 \quad \text { [8] } \\
& 11500 / \sin (40)=A / \sin (22)=B / \sin (118) \quad A=3366, \quad B=13413 \quad \text { [9] } \\
& A+a=z \sin (\theta) *[1 / \sin (90+\phi-\theta)+1 / \sin (90-\phi-\theta)]
\end{aligned}
$$

The projected pixel size can be defined as the detector pixel size projected onto the inspection region. For this example, the apparent object inspection width, perpendicular to the viewing distance, is $5.6 \mathrm{~m}$. Ignoring viewing angle effects, the average pixel size is $5.6 \mathrm{~mm}$ for a 1000 pixel width detector or $8.9 \mathrm{~mm}$ for a 640 pixel width detector. However, when viewing angle considerations are taken into effect, the pixel size at the extreme ends of the inspection region is (for a 1000 wide pixel array):

$\mathrm{a}-\mathrm{pixel}=\mathrm{b} \tan (\theta / 500) / \cos (\phi-\theta) \quad \mathrm{A}-\mathrm{pixel}=\mathrm{B} \tan (\theta / 500) / \cos (\phi+\theta)$

For the first case with a 1000 wide pixel array and a $6.5 \mathrm{~m}$ inspection region, the pixel size varies from $5.7 \mathrm{~mm}$ to $9.6 \mathrm{~mm}$. For the last case with a 640 wide pixel array and a 
$6.5 \mathrm{~m}$ inspection region, the pixel size varies from $8.9 \mathrm{~mm}$ to $15.0 \mathrm{~mm}$. Clearly, much larger pixel array sizes are required for several millimeters resolution. Results are shown in Table 3.

\begin{tabular}{|c|c|c|c|c|c|c|c|c|c|c|c|}
\hline $\begin{array}{l}1 / 2 \\
\text { field } \\
\text { angle } \\
\text { (deg) }\end{array}$ & $\begin{array}{l}\text { object } \\
\text { tilt } \\
\text { angle } \\
\text { (deg) }\end{array}$ & $\begin{array}{l}1 / 2 \text { field } \\
\text { angle } \\
\text { (rad) }\end{array}$ & $\begin{array}{l}\text { object } \\
\text { tilt } \\
\text { angle } \\
\text { (rad) }\end{array}$ & $\begin{array}{l}\text { object } \\
\text { distance } \\
(\mathrm{mm})\end{array}$ & & & & $\begin{array}{l}\# \\
\text { pixels } \\
\text { in } \\
\text { row }\end{array}$ & \multicolumn{2}{|c|}{$\begin{array}{l}\text { Resolution } \\
\text { extremes } \\
\text { along line }\end{array}$} & $\begin{array}{l}\text { object } \\
\text { height } \\
\text { normal } \\
\text { to } \\
\text { center } \\
\text { ray }\end{array}$ \\
\hline$\theta$ & $\phi$ & $\theta$ & $\phi$ & $z$ & $\mathbf{a}$ & $A$ & $a+A$ & & $\begin{array}{l}\text { a- } \\
\text { pixel }\end{array}$ & $\begin{array}{l}A- \\
\text { pixel }\end{array}$ & \\
\hline 13.8 & 28 & 0.24086 & 0.48869 & 11500 & 2830 & 3680 & 6509 & 1000 & 5.67 & 9.59 & 5649 \\
\hline 13.8 & 28 & 0.24086 & 0.48869 & 11500 & 2830 & 3680 & 6509 & 640 & 8.86 & 14.98 & 5649 \\
\hline
\end{tabular}

Table 3: Pixel resolution assumes 1000 and 640 pixel detector projected onto a line 28 degrees from the viewing direction.

\section{E. Effects of diffraction on resolution}

The diameter of the entrance hole is a more significant contributor to the resolution of the inspection region.

Due to the wave nature of light, a wavefront is diffracted by passing through an aperture. As light propagates through a circular aperture a distinct diffraction pattern of light known as an airy disc is formed (Fig. 14).
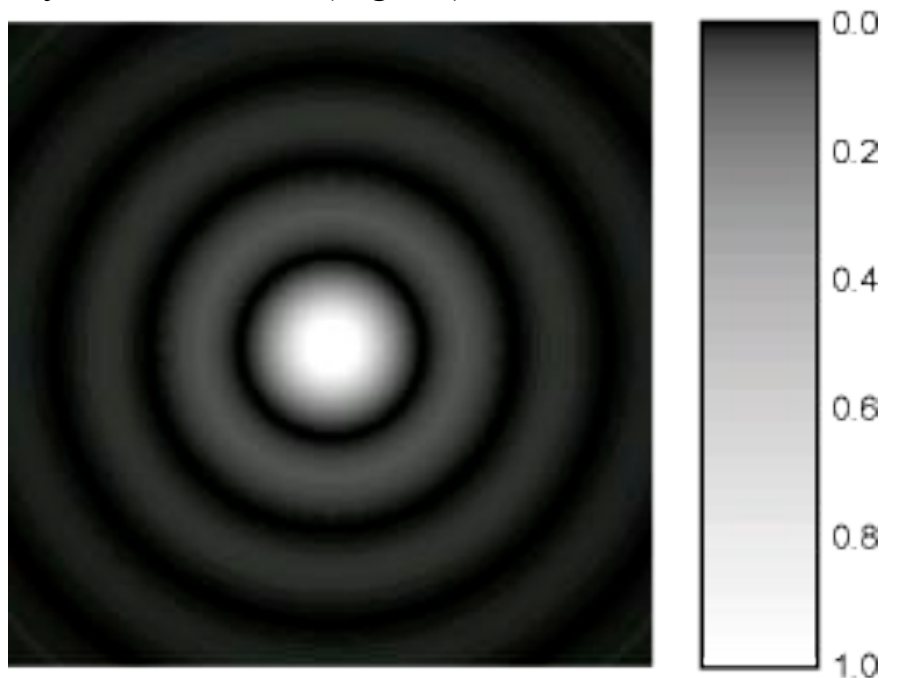

Fig. 14. Airy disc pattern ${ }^{7}$

This airy disc is a Fraunhofer diffraction pattern in the near field (within approximately the focal length of the lens). In order to resolve two objects, the central maxima of one ring must fall on the first dark ring adjacent to it (Fig. 15) where the intensity of the fringes is given by the following equation: 


$$
I(\theta)=I_{o}\left(\frac{2 J_{1}(k a \sin \theta)}{k a \sin \theta}\right)^{2}
$$

Where the distance between the central maxima of the airy disc to the first dark ring is given by the following 8 :

$$
\sin \theta=1.22 \frac{\lambda}{d}
$$

Lambda is the wavelength of the light, and $d$ is the diameter of the aperture. This is the Rayleigh criterion, the minimum distance in which two objects will be resolvable.

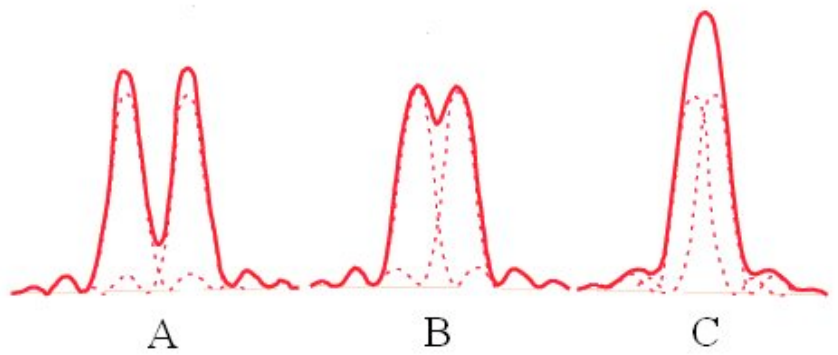

Fig. 15. A) easily resolvable B) Rayleigh criterion just resolvable C) Not resolvable.

For different aperture sizes as well as different wavelengths, the resolution was calculated. The angular and spatial resolution is shown in Table 4 for selected wavelengths and apertures. 


\begin{tabular}{|c|c|c|c|}
\hline $\begin{array}{l}\text { aperture } \\
\text { size } \\
(\mathrm{mm})\end{array}$ & $\begin{array}{l}\text { wavelength } \\
(\mathrm{nm})\end{array}$ & $\begin{array}{l}\text { resolution } \\
\text { (radians) }\end{array}$ & $\begin{array}{l}\text { spot size } \\
(\mathrm{mm})\end{array}$ \\
\hline 3 & 400 & 1.63E-04 & 2.28 \\
\hline 5 & 400 & $9.76 \mathrm{E}-05$ & 1.37 \\
\hline 7 & 400 & 6.97E-05 & 0.98 \\
\hline 10 & 400 & $4.88 E-05$ & 0.68 \\
\hline 20 & 400 & $2.44 \mathrm{E}-05$ & 0.34 \\
\hline
\end{tabular}

\begin{tabular}{lrrrrr|}
\hline $\begin{array}{l}\text { aperture } \begin{array}{l}\text { size } \\
(\mathrm{mm})\end{array} \\
\end{array}$ & $\begin{array}{l}\text { wavelength } \\
(\mathrm{nm})\end{array}$ & $\begin{array}{l}\text { resolution } \\
\text { (radians) }\end{array}$ & $\begin{array}{l}\text { spatial } \\
\text { resolution } \\
(\mathrm{mm})\end{array}$ \\
& 3 & 700 & $2.85 \mathrm{E}-04$ & 3.99 \\
& 5 & 700 & $1.71 \mathrm{E}-04$ & 2.39 \\
7 & 700 & $1.22 \mathrm{E}-04$ & 1.71 \\
& 10 & 700 & $8.54 \mathrm{E}-05$ & 1.20 \\
& 20 & 700 & $4.27 \mathrm{E}-05$ & 0.60 \\
\hline
\end{tabular}

\begin{tabular}{lrlrr|}
\hline $\begin{array}{l}\text { aperture } \begin{array}{l}\text { size } \\
(\mathrm{mm})\end{array} \\
\end{array}$ & $\begin{array}{l}\text { wavelength } \\
(\mu \mathrm{m})\end{array}$ & $\begin{array}{l}\text { resolution } \\
\text { (radians) }\end{array}$ & \multicolumn{2}{l|}{$\begin{array}{l}\text { spot size } \\
(\mathrm{mm})\end{array}$} \\
& 3 & 3 & $1.22 \mathrm{E}-03$ & 17.08 \\
& 7 & 3 & $7.32 \mathrm{E}-04$ & 10.25 \\
& 10 & 3 & $5.23 \mathrm{E}-04$ & 7.32 \\
& 20 & 3 & $3.66 \mathrm{E}-04$ & 5.12 \\
& 3 & $1.83 \mathrm{E}-04$ & 2.56 \\
\hline
\end{tabular}

\begin{tabular}{lrlrr|}
\hline $\begin{array}{l}\text { aperture } \begin{array}{l}\text { size } \\
(\mathrm{mm})\end{array} \\
3\end{array}$ & $\begin{array}{l}\text { wavelength } \\
(\mu \mathrm{m})\end{array}$ & 5 & $\begin{array}{l}\text { resolution } \\
\text { (radians) }\end{array}$ & \multicolumn{2}{l|}{$\begin{array}{l}\text { spot size } \\
(\mathrm{mm})\end{array}$} \\
& 5 & 5 & $1.03 \mathrm{E}-03$ & 28.47 \\
& 7 & 5 & $8.71 \mathrm{E}-03$ & 17.08 \\
& 10 & 5 & $6.10 \mathrm{E}-04$ & 12.20 \\
& 20 & 5 & $3.05 \mathrm{E}-04$ & 8.54 \\
\hline
\end{tabular}

\begin{tabular}{lrlrlr|}
\hline $\begin{array}{l}\text { aperture } \begin{array}{l}\text { size } \\
(\mathrm{mm})\end{array} \\
3\end{array}$ & $\begin{array}{l}\text { wavelength } \\
(\mu \mathrm{m})\end{array}$ & $\begin{array}{l}\text { resolution } \\
\text { (radians) }\end{array}$ & \multicolumn{2}{l|}{$\begin{array}{l}\text { spot size } \\
(\mathrm{mm})\end{array}$} \\
& 3 & 12 & $4.88 \mathrm{E}-03$ & 68.32 \\
& 7 & 12 & $2.93 \mathrm{E}-03$ & 40.99 \\
& 12 & 12 & $2.09 \mathrm{E}-03$ & 29.28 \\
& 12 & $1.46 \mathrm{E}-03$ & 20.50 \\
& 12 & $7.32 \mathrm{E}-04$ & 10.25 \\
\hline
\end{tabular}

Table 4. Resolution for different aperture sizes and wavelengths. A $14 \mathrm{~m}$ object distance is assumed.

Another resolution criterion is the Airy disk diameter, which is approximately twice as large. 
The initial assumption of a $5 \mathrm{~mm}$ entrance hole used for the design presented in section V.A to protect the first focusing mirror presents resolution problems. This hole is about $11.5 \mathrm{~m}$ (in the center of the field of view) from the ITER wall. The focal ratio is the distance to the inspection region, $11.5 \mathrm{~m}$ divided by the entrance hole, $5 \mathrm{~mm}$, or $\mathrm{f} / 2300$. The Airy disc diameter out to the first null ring is $2.44 \lambda \mathrm{f}_{\text {\#\# }}$. The Rayleigh depth of focus is the axial extent over which the object can be said to be in good focus and is $+/-2 \lambda f_{\#}^{2}$. Examples are shown is Table 5, showing a large depth of field for the $5 \mathrm{~mm}$ aperture.

\begin{tabular}{|r|r|r|r|r|}
\hline \multicolumn{1}{c|}{$\lambda(\mathrm{mm})$} & $z(\mathrm{~mm})$ & $D(\mathrm{~mm})$ & Airy disc $(\mathrm{mm})$ & Rayleigh Depth $(\mathrm{mm})$ \\
\hline 0.005 & 11500 & 5 & 28.1 & 52900 \\
\hline 0.003 & 11500 & 5 & 16.8 & 31740 \\
\hline 0.0007 & 11500 & 2.5 & 7.9 & 29624 \\
\hline 0.0004 & 11500 & 2.5 & 4.5 & 16928 \\
\hline
\end{tabular}

Table 5. Resolution and depth of field for small apertures.

\section{F. Object resolution}

The theoretical resolution in object space is determined by diffraction of a beam of light passing through the round entrance aperture. The Optical Transfer Function (OTF) is a measure of the contrast of the image vs. spatial frequency. The OTF decreases from unity almost linearly with frequency. The cutoff frequency, at which the contrast in the image is zero, for a circular aperture that collects a beam with a focal ratio, $\mathrm{f}_{\#}$ at a wavelength $\lambda$ is

$v_{\text {cutoff }}=1 /\left(\lambda \mathrm{f}_{\#}\right)$

The resolution requirement is that features on the order of $3 \mathrm{~mm}$ should be seen. These features should be sufficiently clear in the IR viewing system so that an estimate of the temperature differential above background can be accurately determined. A $3 \mathrm{~mm}$ feature would be at the cutoff frequency for a wavelength of $4 \mu \mathrm{m}$ and a focal ratio of $\mathrm{f} / 750$. For $33 \%$ contrast, the focal ratio would have to be about $\mathrm{f} / 500$. For a distance of $11.5 \mathrm{~m}$, this translates to an entrance hole size of $23 \mathrm{~mm}$.

The IR signal will be detected by a digital camera. The camera pixel size, projected back onto the object surface, determines whether the features can be accurately reconstructed. The projected pixel size is important because, by the Nyquist theorem, no reconstruction process can accurately recover features sizes below that spanned by two pixels. Since this infrared diagnostic will be used to try to detect features as small as 3 $\mathrm{mm}$, the projected pixel size must be no larger than $1.5 \mathrm{~mm}$. An image feature smaller than $3 \mathrm{~mm}$ can be detected, but there is no way to determine if it is a small, bright feature or a larger, less bright feature. 
Table 6 has been compiled for a number of IR designs in which a constant sized tube of about 6 inches extends from the optical collection head to beyond bioshield wall, $\sim 8.5 \mathrm{~m}$ distant. This table estimates what the resolution is and how many pixels wide the detector should be. Note that as the size of the entrance hole is increased, the relay distance 12 to the image of the hole, as calculated using equation [5], decreases. More relay lenses are required to get the image brought out beyond the bioshield wall; hole sizes of 5, 16 and $26 \mathrm{~mm}$ require zero, one and two additional refractive relays. Column 7 tabulates one-half of the cutoff spatial frequency for a beam projected back onto the object surface, given a wavelength of $4 \mu \mathrm{m}$ and a focal ratio set by the hole diameter. The feature size in column 7 is just the inverse of this frequency and estimates a reasonable size of a feature that could be resolved, provided that the camera has an adequate numbers of pixels. Since the Nyquist theorem requires that the pixel size be at least onehalf the resolution size, one can estimate the pixel array size to span the entire object length.

One concludes that, in order to achieve a $3 \mathrm{~mm}$ resolution in the IR, a detector must be about 4000 pixels wide.

Alternately, a 1000 pixel wide detector could be repositioned at one of four subfields so that each sub-field can be viewed $25 \%$ of the time. By doubling the required resolution feature from $3 \mathrm{~mm}$ to $6 \mathrm{~mm}$, the number of refractive relays can be halved and the required number of pixels can be reduced by one-half. Another possibility is to make a array of two $1000 \times 1000$ pixel detectors.

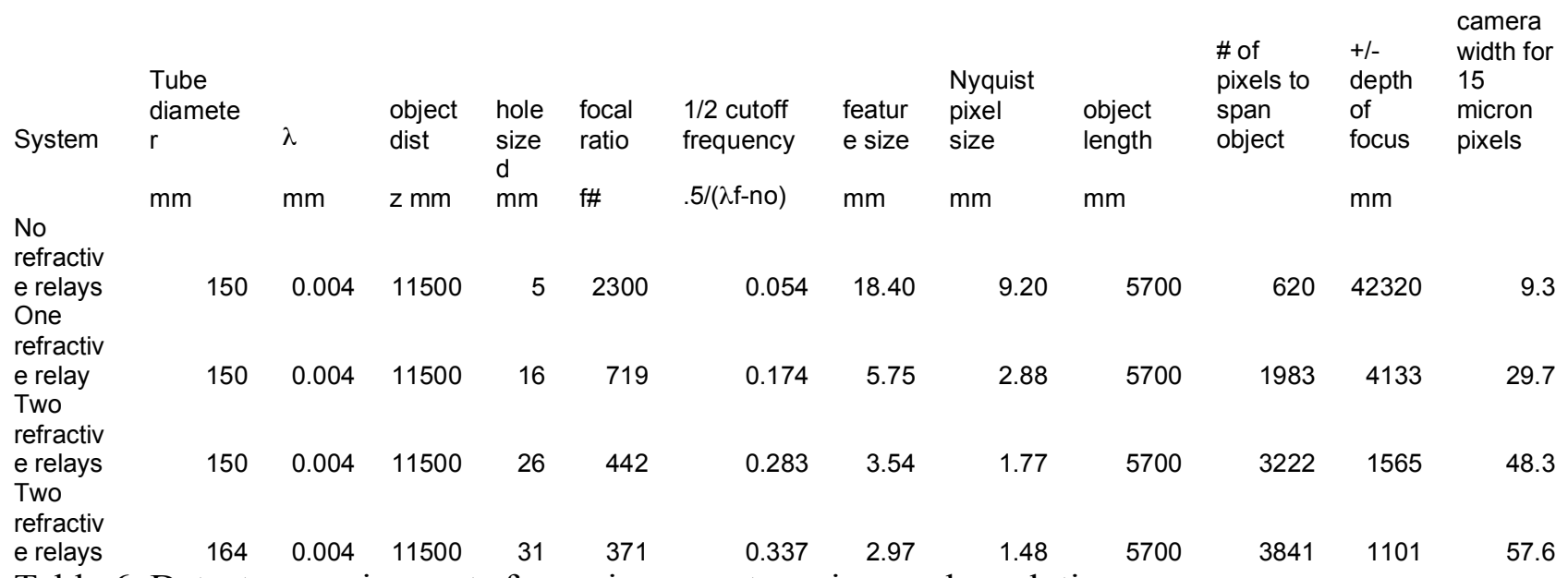

Table 6. Detector requirements for various aperture sizes and resolutions.

\section{G. Window material}

The leading candidates for window material are sapphire and zinc selenide. Sapphire has excellent harness and mechanical strength, transmits visible light well, and transmits infrared light up to approximately $4.5 \mu \mathrm{m}$ (Fig.16). ZnSe has poorer mechanical strength and a strong brown cast in visible light since it transmits very little blue. It has good infrared transmission to wavelengths longer than $10 \mu \mathrm{m}^{9}$, and much lower absorption at 3-5 $\mu \mathrm{m}$ than sapphire. The difficulty with $\mathrm{ZnSe}$ lies in forming a reliable 
vacuum seal to the material. An O-ring seal has proven to work well but likely will not be allowed for ITER because of concerns about tritium containment.

See section VII.D Transmission Losses, for comparison for absorption and reflection for sapphire and $\mathrm{ZnSe}$.

Other materials of possible interest shown in Fig. 16 are barium fluoride and calcium fluoride. In the designs discussed subsequently in this report, the window materials assumed are sapphire, and in the case of a separate window for visible light, a standard fused silica window. 

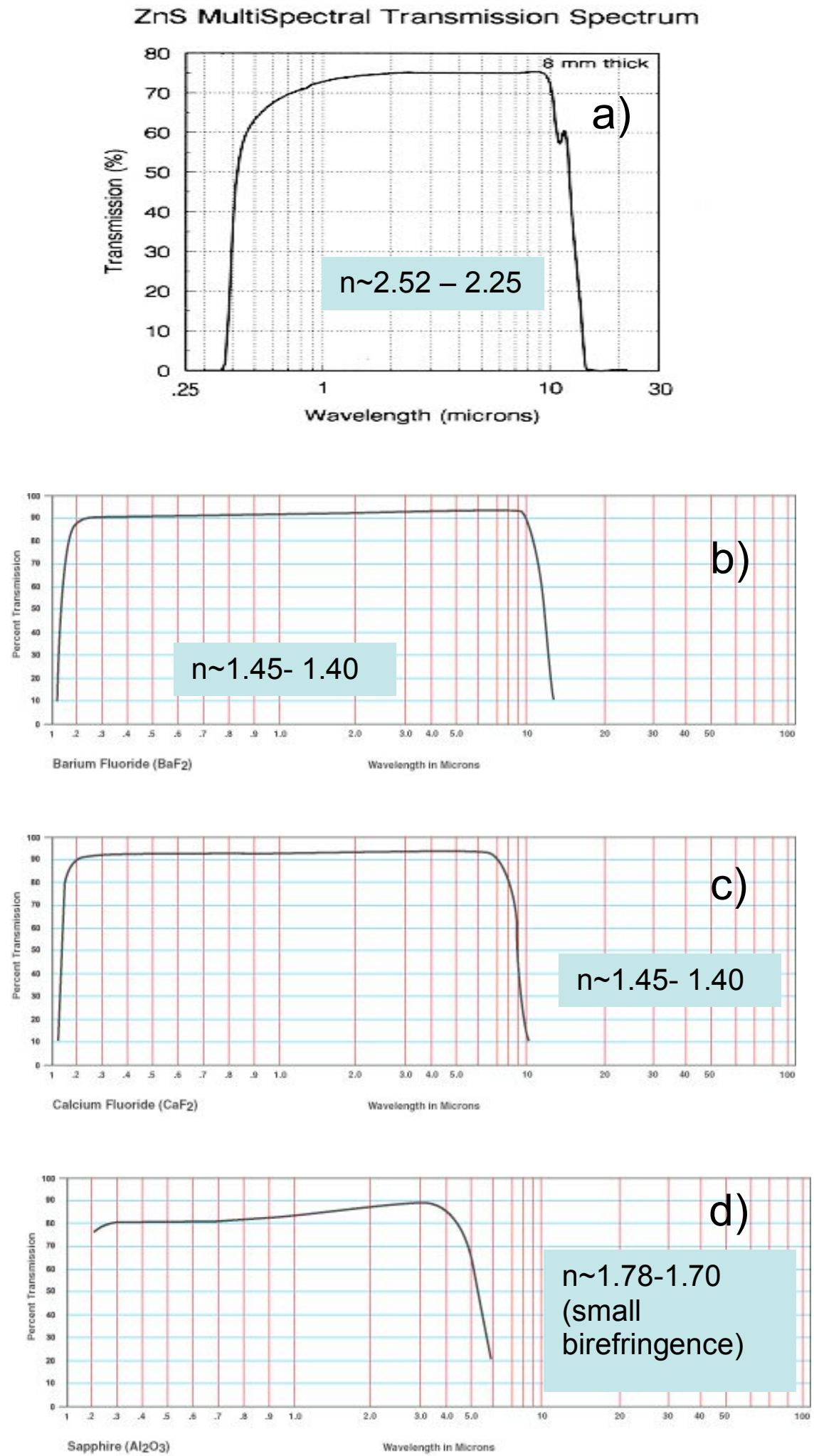

Fig. 16. Transmission spectra of some possible window materials. A) $\mathrm{ZnS}, \mathrm{B}) \mathrm{BaF}_{2}, \mathrm{C}$ ) $\mathrm{CaF}_{2}$, D) Sapphire $\left(\mathrm{Al}_{2} \mathrm{O}_{3}\right)$ 


\section{H. Birefringence of sapphire vacuum windows}

The sapphire vacuum windows operate in near-collimated beams of light in the designs presented here, nearly perpendicular to the windows. A non-collimated beam undergoes a focal shift after transmission through a flat window of

$\Delta \mathrm{f}=\mathrm{t}(\mathrm{n}-1) / \mathrm{n}$

where $\mathrm{n}=$ index of refraction and $\mathrm{t}=$ thickness of the window.

Sapphire is birefringent, so the focal shift is different for each polarization. Table 7 shows that this focal shift differential is less than $0.05 \mathrm{~mm}$ for a $25 \mathrm{~mm}$ thick window. However, in these designs this focal shift is small compared to the Rayleigh depth of focus, $+/-2 \lambda \mathrm{f}_{\#}^{2}$. For example, with an $\mathrm{f} / 12$ beam at a wavelength of $3 \mu \mathrm{m}$, the Rayleigh depth of focus is $0.85 \mathrm{~mm}$, more than 20 times the actual focal shift between polarizations. Therefore, the orientation of the window with respect to the crystal axis is unimportant, at least in terms of polarization effects on the eventual spot size.

\begin{tabular}{|r|r|r|r|r|r|r|}
\hline \multicolumn{3}{|l|}{} & \multicolumn{3}{l|}{$\begin{array}{l}\text { Focal shift due to } 25 \mathrm{~mm} \text { thick } \\
\text { window }\end{array}$} \\
\hline \multicolumn{1}{|l|}{ Sapphire } & $\mathrm{n}-\mathrm{o}$ & $\mathrm{n}-\mathrm{e}$ & \multicolumn{1}{|c|}{$\Delta \mathrm{n}$} & $\mathrm{n}$-o shift & n-e shift & $\Delta$ shift \\
\hline 5.000 & 1.624 & 1.618 & 0.006 & 7.685 & 7.642 & 0.043 \\
\hline 0.700 & 1.763 & 1.755 & 0.008 & 8.657 & 8.605 & 0.052 \\
\hline 0.400 & 1.787 & 1.778 & 0.008 & 8.805 & 8.752 & 0.053 \\
\hline
\end{tabular}

Table 7. Focal shift due to birefringence of sapphire.

\section{Radiation damage to optics}

\section{Windows and lenses}

Many optical materials suffer loss of transparency after irradiation by neutrons. Color centers form that produce a brown color cast in the material. The color grows progressively darker with more radiation exposure, absorbing more and more visible light. The damage may be partially reversed by baking the optics or bleaching with ultraviolet light. Initially the calibration of the system is affected as transmission is reduced, and later the optics become unusable. This is the main reason lenses are not used in the port plug for the designs shown here.

Numerous ITER candidate materials have been irradiated in tests by S. Yamamoto et $\mathrm{al}^{10}$. No increase in infrared absorption in sapphire was found at tested neutron doses, although visible transmission was affected. Fused silica was about 4 times better in maintaining transparency for visible light than sapphire. Sapphire showed much larger radioluminescence than fused silica in the visible wavelengths. The authors of that study recommend the use of sapphire windows for IR and fused silica or quartz for visible-light windows.

We are not aware of reports of transmission reduction through infrared optics as a result of radiation damage. We suspect that infrared photons are of a wavelength too long 
to interact efficiently with color centers formed by radiation damage. Nevertheless, all the optical materials to be used in ITER should be tested for the effects of neutron damage at the wavelengths to be used.

\section{Mirror substrates and coatings}

The CEA report ${ }^{2}$ recommends for mirrors a coating of rhodium on a substrate of GlidCop $^{11}$. Rhodium coatings are known for mechanical durability and resistance to radiation damage. GlidCop is a copper alloy with good thermal conductivity, which will facilitate cooling particularly of the first mirrors which are nearest the plasma. We find the CEA recommendation persuasive, and incorporate rhodium coatings in our calculations.

Researchers are now performing erosion and deposition tests of mirrors using ion beams and tokamak plasmas (for example, A. Litnovsky et. $\mathrm{al}^{12}$ ). It will be important to fully test exactly the substrate and coating to be used in ITER for the first mirrors. 


\section{Optical designs}

We have analyzed several optical designs with different optimizations. Each of the following sections discusses one design and how it deals with the constraints.

\section{A. 5mm aperture}

The first design is the simplest and most compact, and consequently has the lowest spatial resolution at the target. The viewing aperture diameter is $5 \mathrm{~mm}$, the same size used in the CEA design.

\section{Optical schematic}

One concern for both the reference design and the central tube design is that systems with large numbers of focusing lenses and mirrors will be difficult to install, align and maintain. A central tube layout has been designed in which no focusing elements are necessary between the input collecting head and the bioshield wall. The only requirement is that the tube between the collecting head and the bioshield wall must have about a 6 inch inner diameter. This central tube design uses only mirrors as the focusing elements.

A simplified optical layout of the central tube design is shown in Fig. 17. In order to ensure sufficient coverage of the ITER chamber, a total of six viewing ports must each inspect a length of about 6.0 to 6.5 meters. The allowed entrance viewing hole of $5 \mathrm{~mm}$ diameter is $11.5 \mathrm{~m}$ away from the inspection region. The only optical elements in the 9 meter tube that goes from the optical collection head through the bioshield wall are the flat sapphire vacuum windows. Doglegs to protect from neutron radiation, if necessary, are shown, and will slightly increase the effective distance to the bioshield wall..

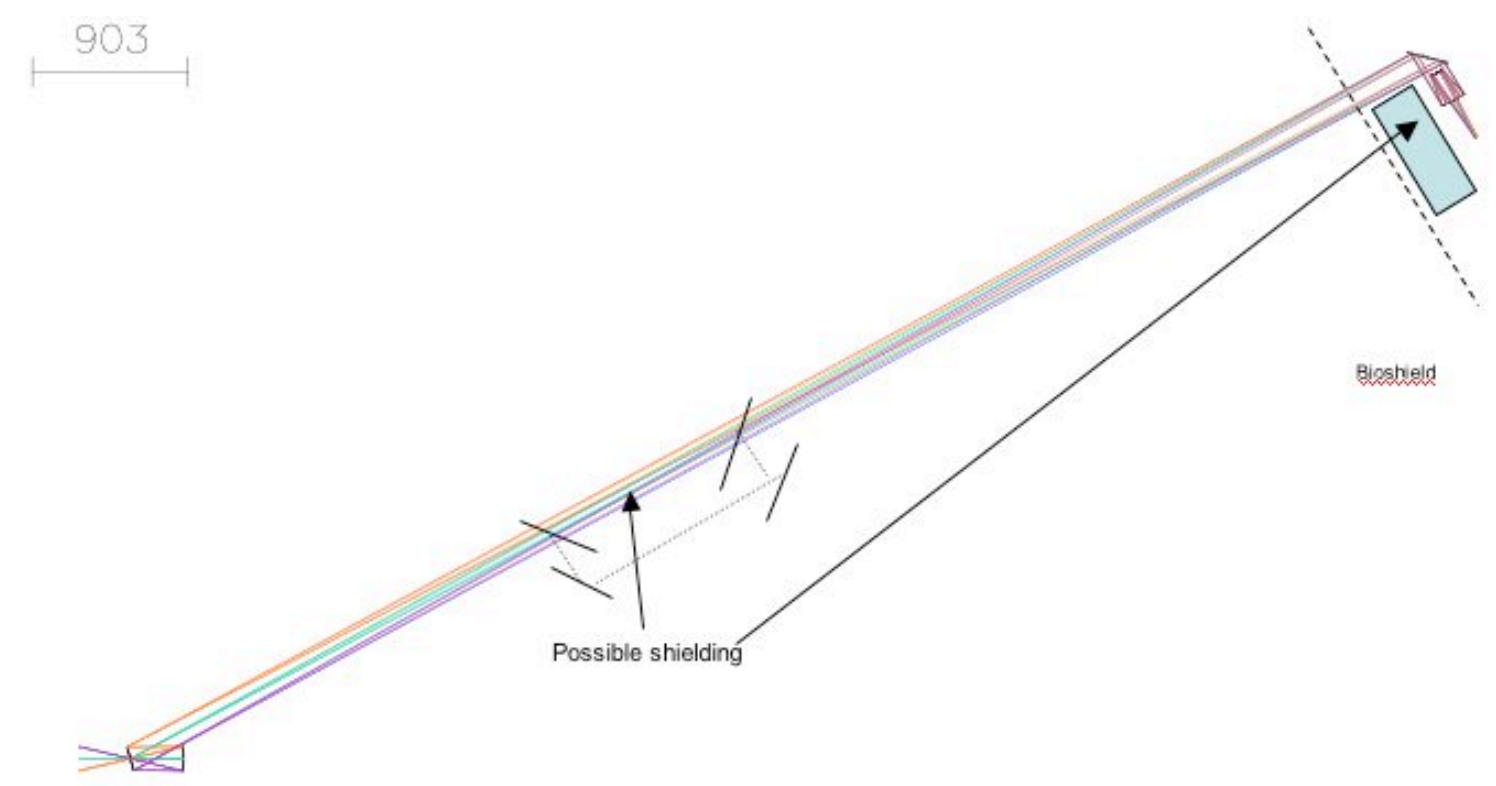

Fig. 17. Optical layout, with a possible dogleg for shielding. The camera telescope for visible light is not shown. 
The optical collection head (Fig. 18) is a single concave elliptical mirror that images the small hole of size $\mathrm{d}=5 \mathrm{~mm}$ to a point beyond the bioshield wall. At this location beyond the wall, a simple two-mirror telescope can image the inspection region onto a detector. The second flat mirror of the collection head has the $5 \mathrm{~mm}$ hole in it and simply directs the collected light away from the first focusing mirror.

$11.5 \mathrm{~m}$ to inspection region

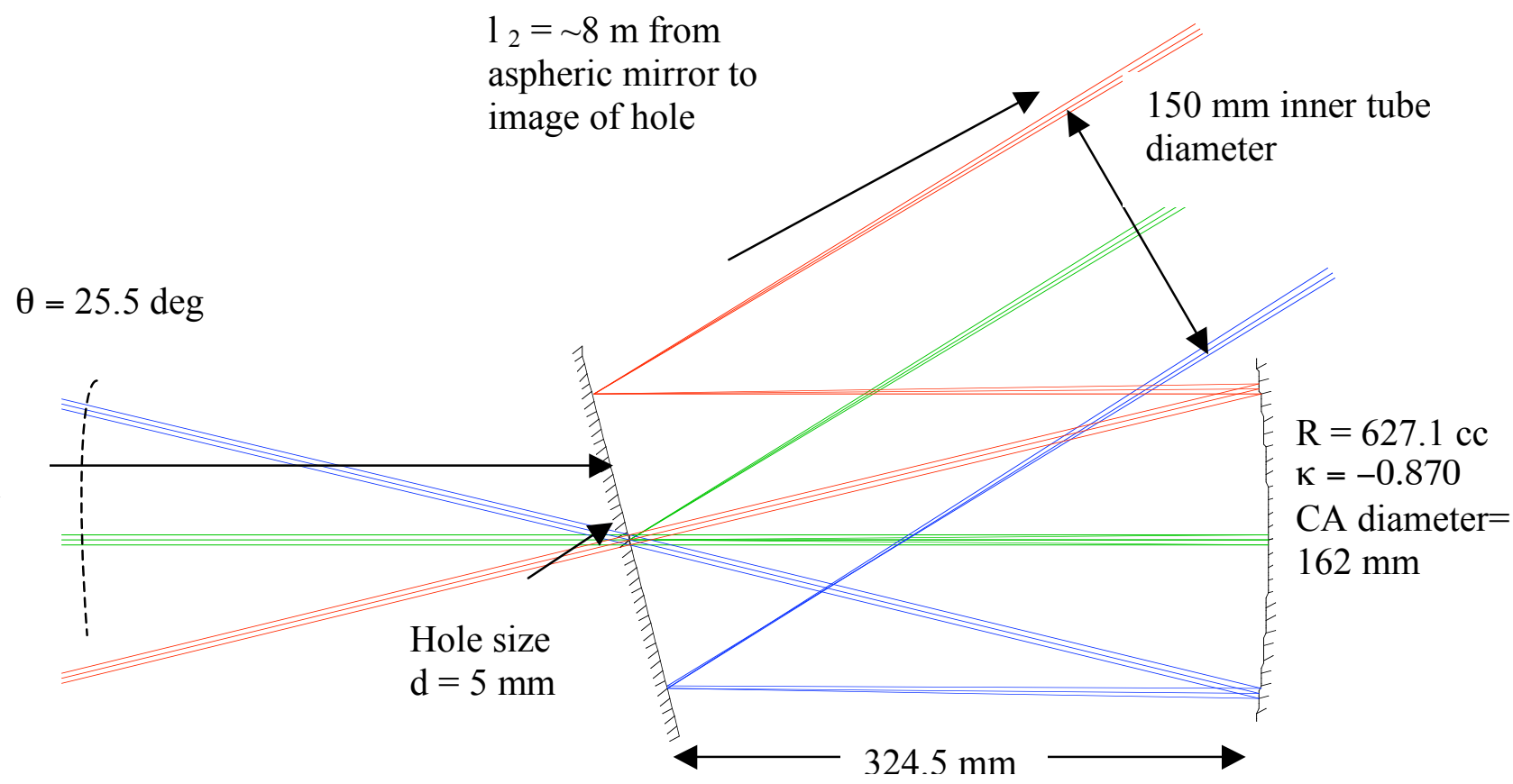

Fig. 18. Optical head design for $5 \mathrm{~mm}$ aperture.

Fig. 19 shows the telescope for the infrared light at the camera end of the optics. In front of the telescope is a turning mirror which sends light which would be obstructed by the telescope secondary mirror, to the visible light camera. This is a practice described in the CEA report ${ }^{2}$. This results in a smaller effective aperture and slower $\mathrm{f} /$ number for the visible light than for the infrared. However, since the wavelength is much shorter, the spatial resolution for the visible light is higher than for the infrared. 


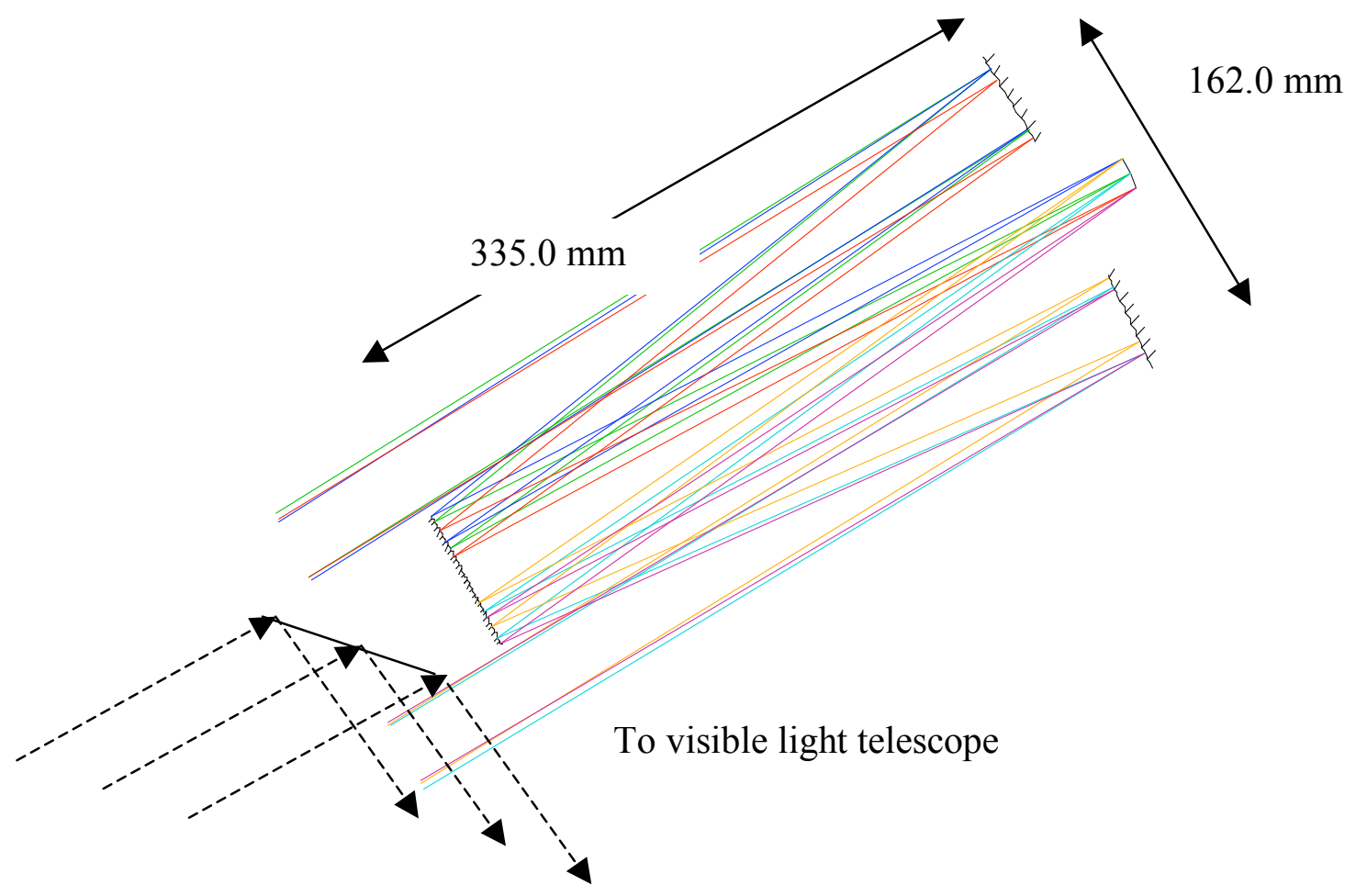

Fig. 19 Camera telescope for infrared. 


\section{Effects of diffraction on resolution}

The diameter of the entrance hole is a dominant contributor to the resolution of the inspection region. The focal ratio is the distance to the inspection region, $11.5 \mathrm{~m}$ divided by the entrance hole, $5 \mathrm{~mm}$, or $\mathrm{f} / 2300$. The Airy disc diameter out to the first null ring is $2.44 \lambda \mathrm{f}_{\mathrm{H}}$. The Rayleigh depth of focus is the extent axially over which the object can be said to be in good focus and is $+/-2 \lambda \mathrm{f}_{\#}^{2}$.

\begin{tabular}{|c|c|c|c|c|}
\hline$\lambda(\mathrm{mm})$ & $z(\mathrm{~mm})$ & $\mathrm{D}(\mathrm{mm})$ & Airy disc $(\mathrm{mm})$ & Rayleigh Depth $(\mathrm{mm})$ \\
\hline 0.005 & 11500 & 5 & 28.1 & 52900 \\
\hline 0.003 & 11500 & 5 & 16.8 & 31740 \\
\hline 0.0007 & 11500 & 2.5 & 7.9 & 29624 \\
\hline 0.0004 & 11500 & 2.5 & 4.5 & 16928 \\
\hline & & & & \\
\hline 0.005 & 13500 & 5 & 32.9 & 72900 \\
\hline 0.003 & 13500 & 5 & 19.8 & 43740 \\
\hline 0.0007 & 13500 & 2.5 & 9.2 & 40824 \\
\hline 0.0004 & 13500 & 2.5 & 5.3 & 23328 \\
\hline 0.005 & 10500 & 5 & 25.6 & 44100 \\
\hline 0.003 & 10500 & 5 & 15.4 & 26460 \\
\hline 0.0007 & 10500 & 2.5 & 7.2 & 24696 \\
\hline 0.0004 & 10500 & 2.5 & 4.1 & 14112 \\
\hline
\end{tabular}

Table 8. Diffraction-limited resolution and depth of focus for a $5 \mathrm{~mm}$ aperture.

Table 8 ignores viewing angle effects which effectively increase the spot size in one direction.

The diffracted Airy disc far exceeds the geometrical pixel resolution in the infrared region of 3 to $5 \mu \mathrm{m}$. In the visible, assuming that the collected light uses only $50 \%$ of the entrance hole diameter, the diffracted and geometrical resolution contributions are comparable. The pixel resolution and the Airy disc size combine in the best case for 400 $\mathrm{nm}$ and object closest to the optical head to be about $10 \mathrm{~mm}$. The worst case for $700 \mathrm{~nm}$ and the object farthest away yields $16 \mathrm{~mm}$. Therefore, a 1000 pixel wide camera is useful to improve resolution in the visible; otherwise a 640 pixel wide detector is probably sufficient in the infrared.

The depth of focus exceeds the range to the ITER wall even for the shortest wavelengths and the shortest distance to the entrance hole

\section{Camera telescope}

Assuming a detector pixel size of $15 \mu \mathrm{m}$ and 1000 pixels across the detector, the detector is $15 \mathrm{~mm}$ wide. Perpendicular to the optical axis, the object plane is about $5.2 \mathrm{~m}$ long for an inspection region length of $6.0 \mathrm{~m}$. The optical invariant states that the geometrical collection efficiency or etendue is a constant throughout an optical system. Therefore, given a collection focal ratio of f/2300 and an object inspection size of $5.2 \mathrm{~m}$ : 
Object length $/ \mathrm{f}_{\# \text { in }}=$ Image length $/ \mathrm{f}_{\# \text { out }}$

$\mathrm{f}_{\# \text { out }}=2300(15 \mathrm{~mm} / 5200 \mathrm{~mm})=\mathrm{f} / 6.6$

Increasing the line length to $6.6 \mathrm{~m}$ gives an output focal ratio of $\mathrm{f} / 6$ for the infrared telescope. For a telescope with a diameter of $156 \mathrm{~mm}$, the focal length is $936 \mathrm{~mm}$ and the field angle is $+/-0.5$ degrees. A two-mirror Cassegrain telescope can easily meet diffraction-limited performance.

\section{Sapphire vacuum windows}

The sapphire vacuum windows operate in near-collimated beams of light. In the above infrared optical design, the beams are $\mathrm{f} / 62.5$ at the windows and the beams are nearly perpendicular to the windows. A non-collimated beam undergoes a focal shift after transmission through a flat as shown in section IV.H.

Sapphire is birefringent, so the focal shift is different for each polarization. Table 7 shows that this focal shift differential is less than $0.05 \mathrm{~mm}$ for a $25 \mathrm{~mm}$ thick window. However, this focal shift is small compared to the Rayleigh depth of focus, $+/-2 \lambda f_{\#}^{2}$. For the $\mathrm{f} / 62.5$ beam used here, at the shortest wavelength of $400 \mathrm{~nm}$, the Rayleigh depth of focus is $3.1 \mathrm{~mm}$, more than 60 times the actual focal shift between polarizations. Therefore, the orientation of the window with respect to the crystal axis is unimportant, at least in terms of polarization effects on the eventual spot size.

\section{Optical design parameters}

The following parameters have been used to generate a central tube design that has no optical elements except for two sapphire vacuum windows between the reflecting optical collection head and the camera reflecting telescope beyond the bioshield wall:

Distance to ITER inspection region:

Viewing angle at center of region:

Inspection length:

Field angle:

Distance from entrance hole to camera telescope:

Infrared design:

Entrance hole diameter

Infrared wavelengths:

Visible design:

Entrance hole diameter

Visible wavelengths:
$11.5 \mathrm{~m}$

28.0 degrees

$6.5 \mathrm{~m}$ (5.65 m normal to central ray)

$+/-13.8$ degrees

$9.0 \mathrm{~m}$

$5.0 \mathrm{~mm}$

3 to $5 \mu \mathrm{m}$

$2.35 \mathrm{~mm}$

400 to $700 \mathrm{~nm}$ 
The first collecting mirror is an ellipsoidal mirror that exactly images a point at the center of the entrance hole to a point $9.0 \mathrm{~m}$ away. The mirror magnification is $28.7 \mathrm{x}$ which yields a conic constant of $\kappa=-0.867$.

The camera telescope primary mirror can be constrained to be a paraboloid, $\kappa=-1.00$ and still get diffraction-limited performance for all visible and infrared wavelengths over the entire inspection region.

Figs. 20 and 21 show the optical performance at $3 \mathrm{~m}$, and Figs. 22 and 23 show the visible-light performance. Visible performance was evaluated at a wavelength of $550 \mathrm{~nm}$ using $47 \%$ of the entrance hole diameter.

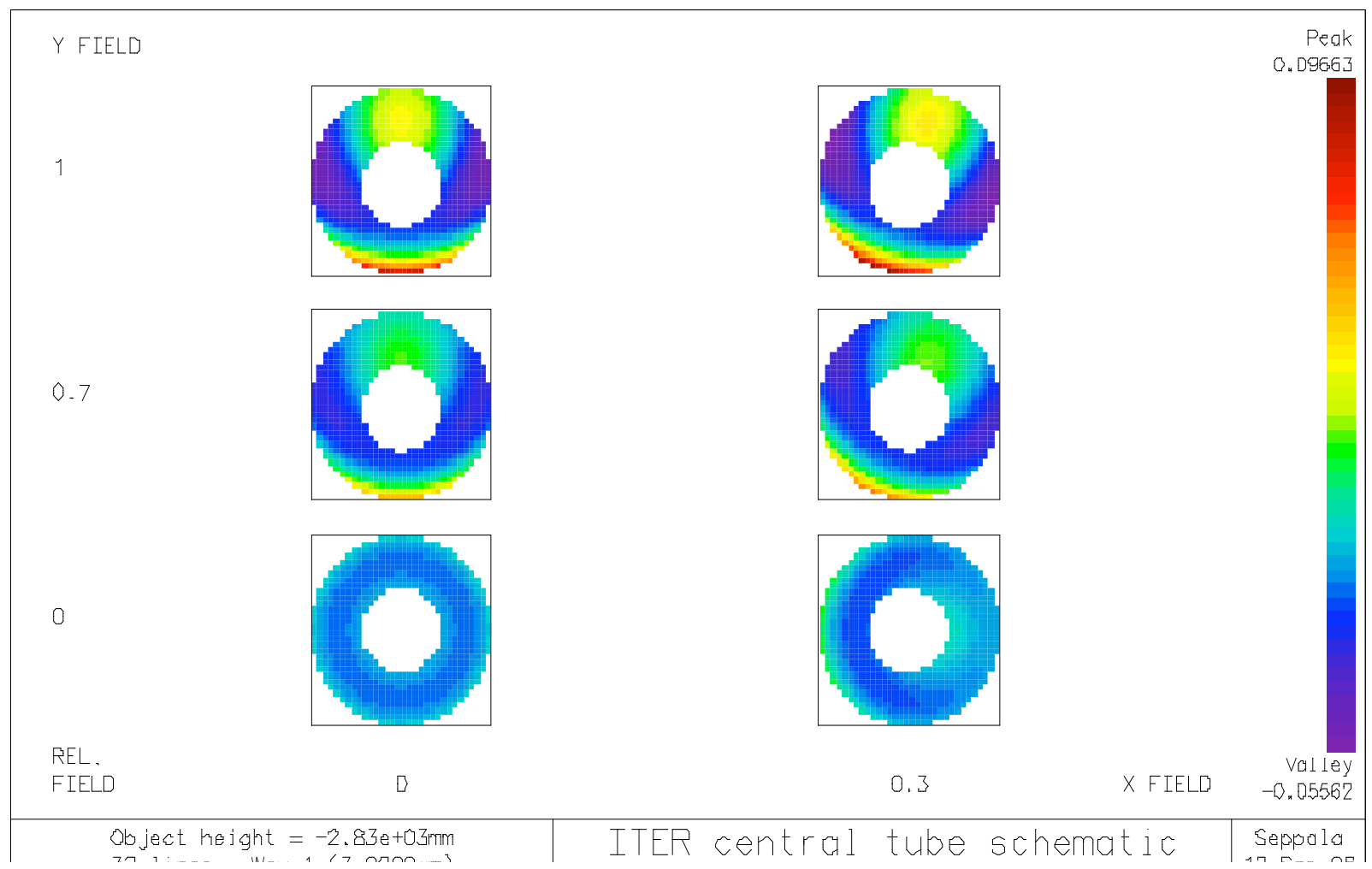

Fig. 20. Peak to valley wavefront error is less than 0.15 waves @ $3 \mu \mathrm{m}$ anywhere in a $6.6 \mathrm{~m} \times 2.0 \mathrm{~m}$ region 


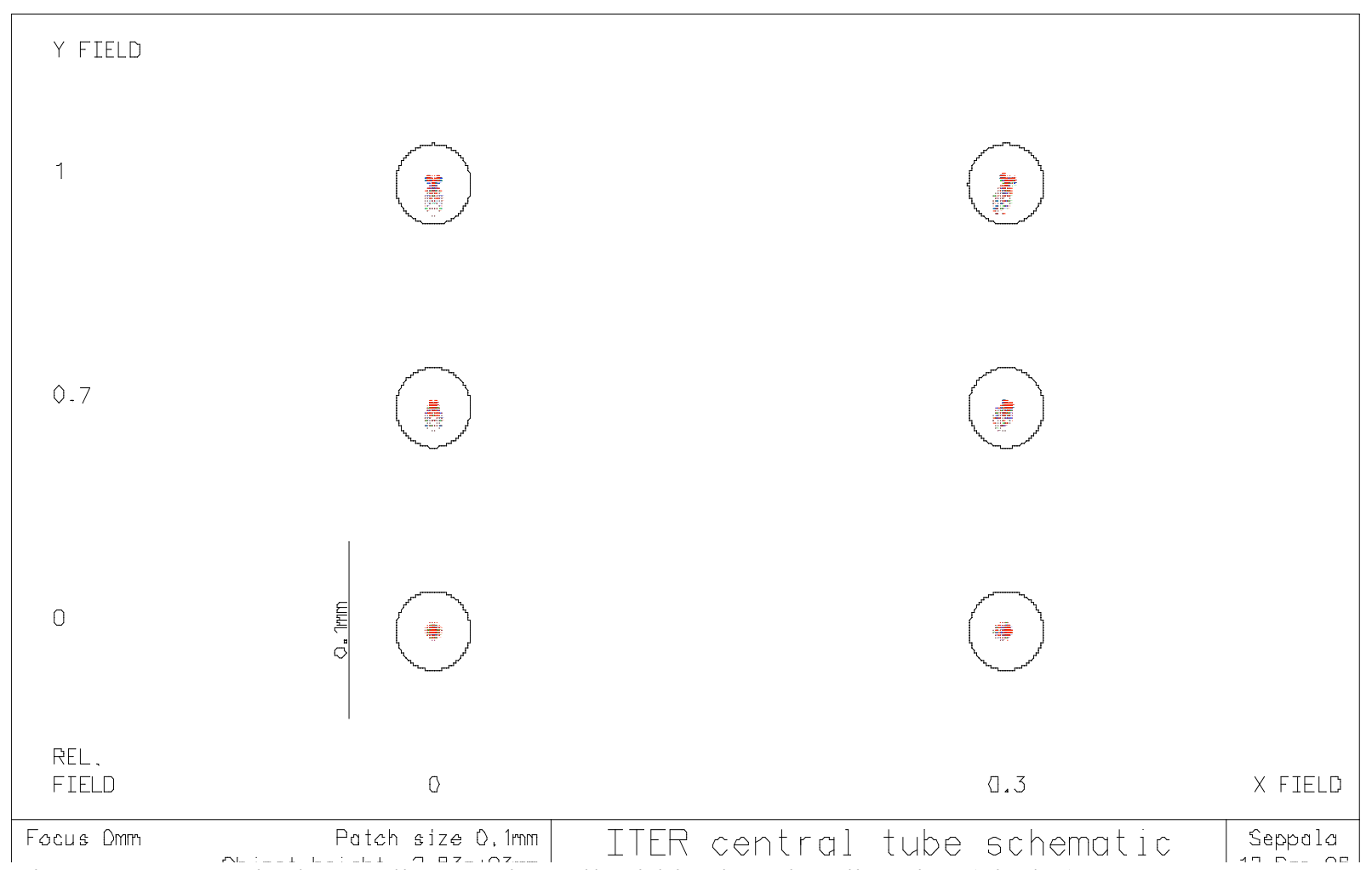

Fig. 21. Geometrical spot diagram is well within the Airy disc size (circles) at $3 \mu \mathrm{m}$ anywhere in a $6.6 \mathrm{~m} \times 2.0 \mathrm{~m}$ region

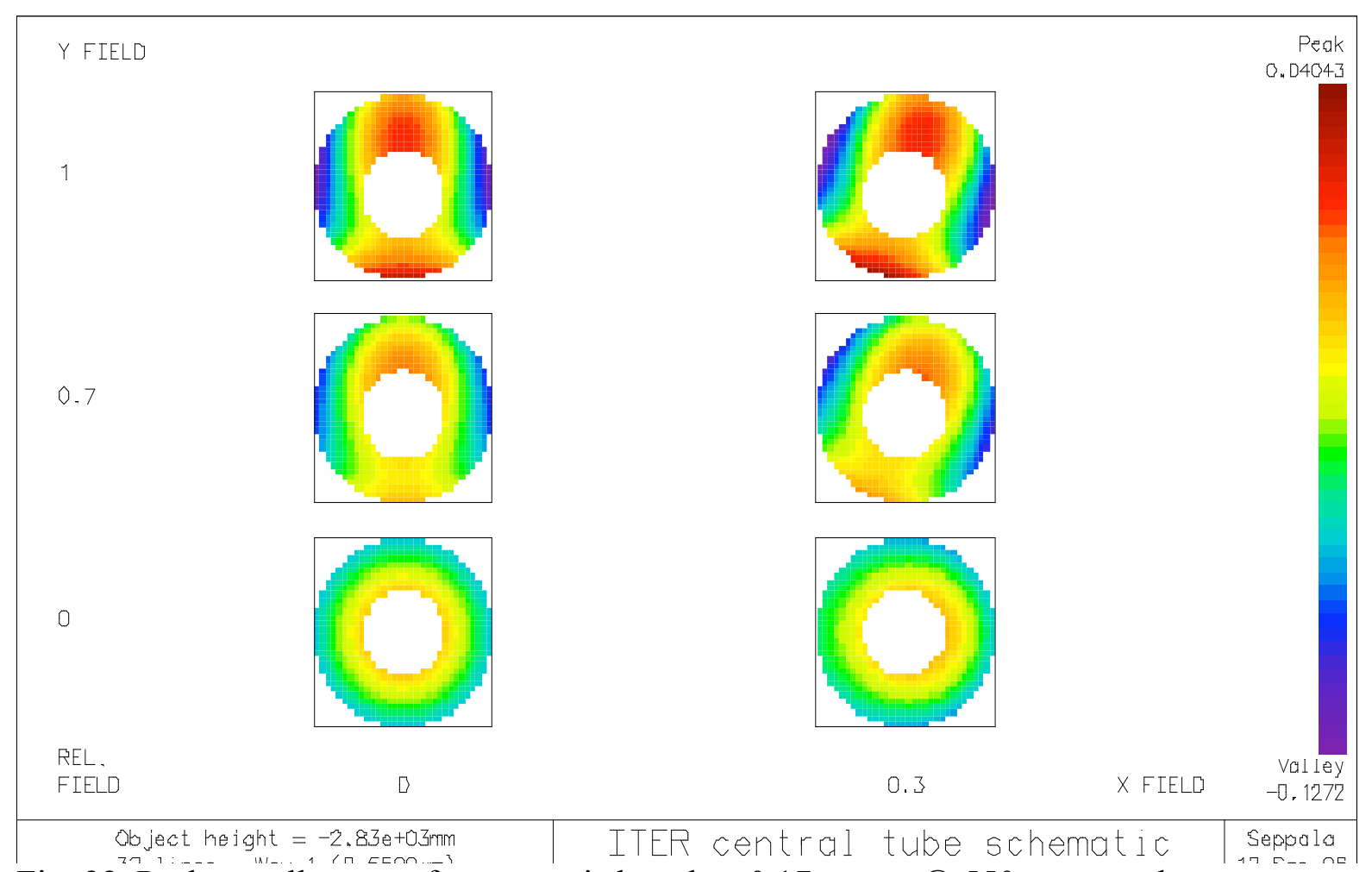

Fig. 22. Peak to valley wavefront error is less than 0.17 waves @ 550 nm anywhere in a $6.6 \mathrm{~m} \times 2.0 \mathrm{~m}$ region 


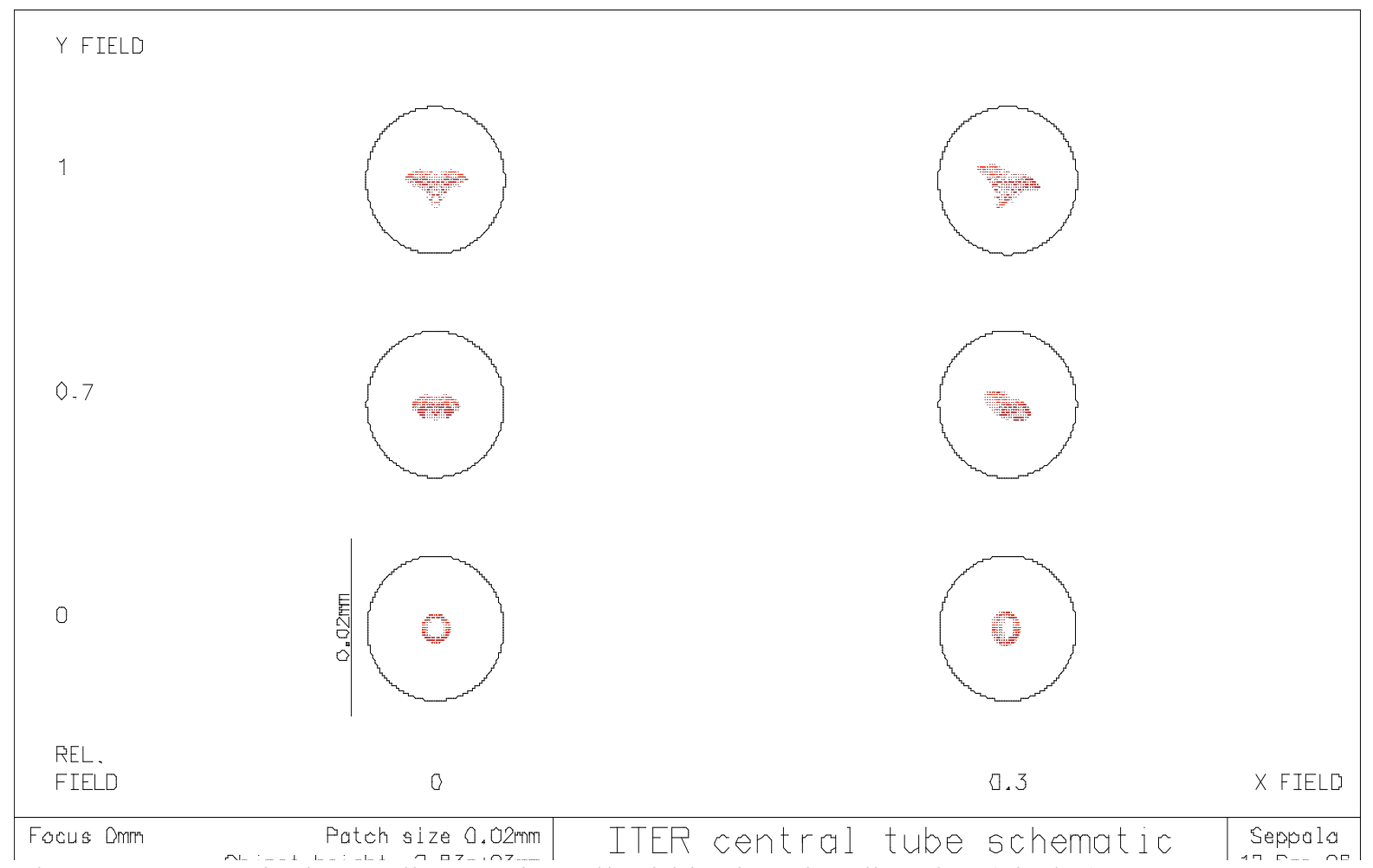

Fig. 23. Geometrical spot diagram is well within the Airy disc size (circles) at 550 nanometers anywhere in a $6.6 \mathrm{~m} \times 2.0 \mathrm{~m}$ region.

There is a visible light camera telescope that has the exact same optical prescription except that both of the mirrors are $\sim 50 \%$ of the diameter of the infrared telescope mirrors. 


\section{B. $20 \mathrm{~mm}$ aperture}

A design with a $20 \mathrm{~mm}$ aperture gives improved resolution compared to the $5 \mathrm{~mm}$ aperture. The large size of the optics is not easily compatible with the central tube concept.

\section{Optical layout}

An optical layout of the design is shown in Fig. 24. In order to ensure sufficient coverage of the ITER chamber, a total of six viewing ports must each inspect a length of 6.5 meters. The entrance viewing hole is $11.5 \mathrm{~m}$ away from the inspection region. The visible and infrared beams are split just inside the vacuum windows, and the IR beam passes through a Cassegrain telescope just outside the vacuum. Lens relays are used to carry the beams to the cameras.

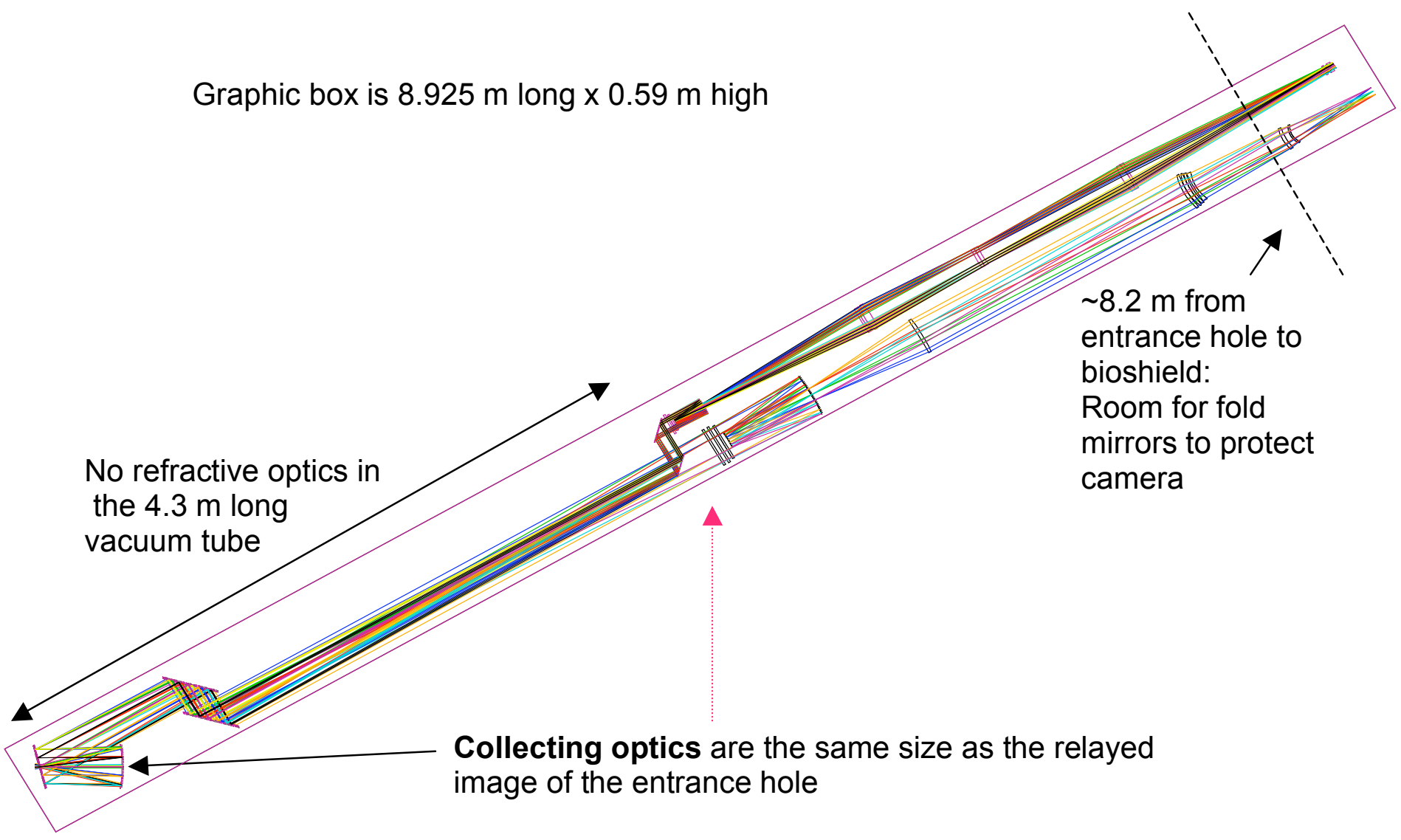

Fig. 24. Visible (top) and IR (bottom) relay optical designs 


\section{Optical collection head}

The optical collection head (Fig. 25) is a single concave elliptical mirror that images the small entrance hole further up toward the bioshield wall. For sufficiently small entrance holes and large tube sizes, this image point can lie beyond the bioshield wall. At this location beyond the wall, a simple two-mirror telescope can image the ITER wall onto a detector. The second flat mirror of the collection head has the $20 \mathrm{~mm}$ hole in it and simply directs the collected light away from the first focusing mirror.

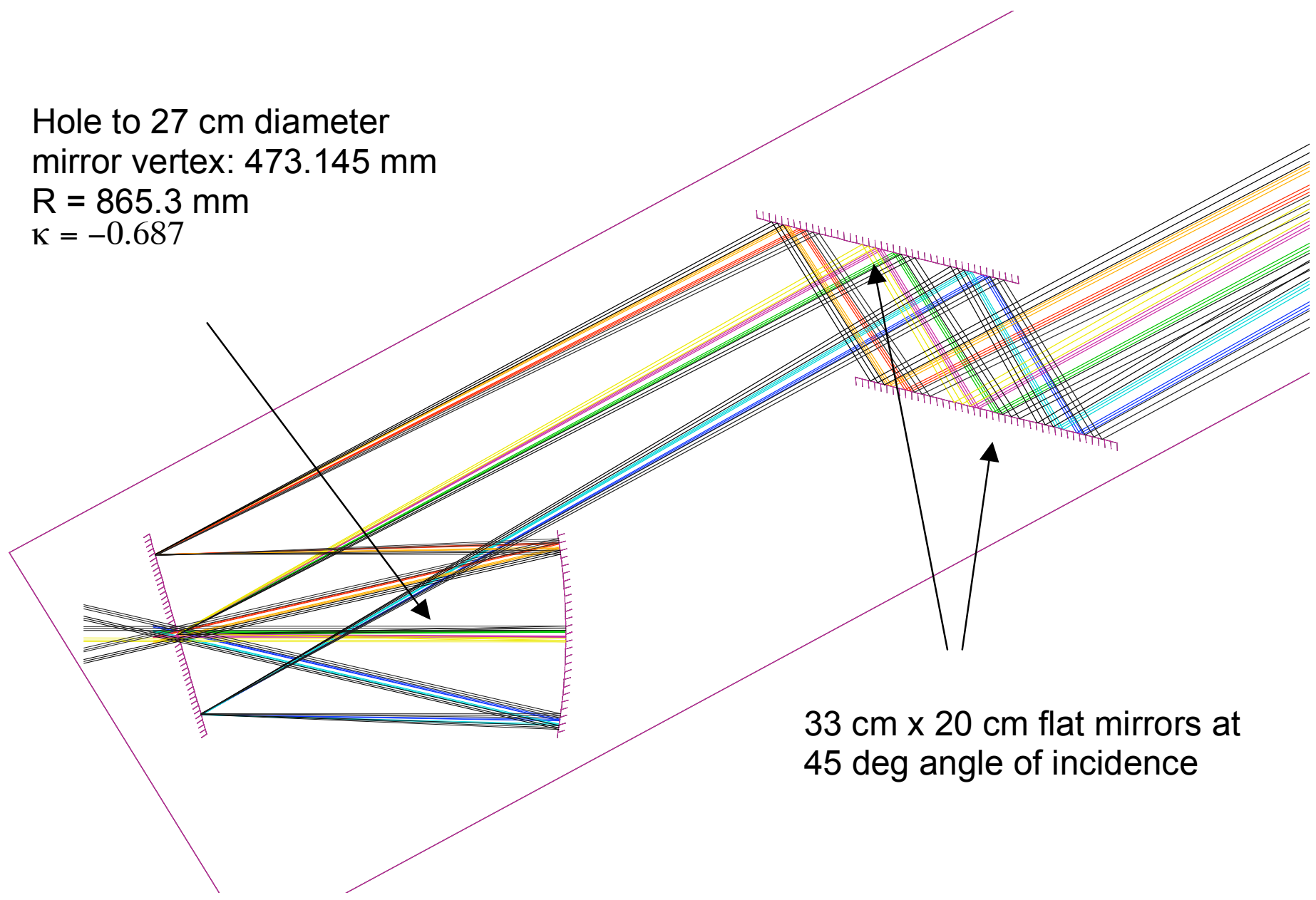

Fig. 25. Collector head: $20 \mathrm{~mm}$ entrance hole Field of view $5.65 \mathrm{~m}$ at distance of $11.5 \mathrm{~m}$ ( $\sim 6.5 \mathrm{~m}$ at $28^{0}$ viewing angle) 


\section{Effects of diffraction on resolution}

The diameter of the entrance hole is the dominant contributor to the resolution of the inspection region. This hole is about $11.5 \mathrm{~m}$ from the ITER wall at the center of the field of view. The focal ratio is the distance to the inspection region, $11.5 \mathrm{~m}$ divided by the entrance hole, $20 \mathrm{~mm}$, or $\mathrm{f} / 575$. The Airy disc diameter out to the first null ring is $2.44 \lambda$ $\mathrm{f}_{\text {H. }}$. The Rayleigh depth of focus is the extent axially over which the object can be said to be in good focus and is $+/-2 \lambda \mathrm{f}_{\#}^{2}$. Results for spatial resolution and depth of focus for the $20 \mathrm{~mm}$ aperture are shown in Table 9.

\begin{tabular}{|c|c|c|c|c|c|}
\hline $\begin{array}{c}\text { Distance to } \\
\text { divertor }\end{array}$ & $\begin{array}{c}\text { Viewing } \\
\text { aperture } \\
\text { size }\end{array}$ & $\boldsymbol{\lambda}$ & $\begin{array}{c}\text { Object feature at } \\
\text { which the MTF } \\
\text { goes to zero } \\
\text { contrast }\left(\boldsymbol{\lambda} \mathbf{f}_{\#}\right)\end{array}$ & $\begin{array}{c}\text { Estimate of } \\
\text { resolved feature } \\
(\mathbf{2} \boldsymbol{\lambda} \mathbf{f})\end{array}$ & $\begin{array}{c}\text { +/- Depth of } \\
\text { focus }\end{array}$ \\
\hline$(\mathrm{mm})$ & $(\mathrm{mm})$ & $(\mu)$ & $(\mathrm{mm})$ & $(\mathrm{mm})$ & $(\mathrm{m})$ \\
\hline 11500 & 20 & 5 & 2.88 & 5.75 & 3.31 \\
\hline 11500 & 20 & 3 & 1.73 & 3.45 & 1.98 \\
\hline 11500 & 8.3 & 0.7 & 0.97 & 1.94 & 2.69 \\
\hline 11500 & 8.3 & 0.4 & 0.55 & 1.11 & 1.54 \\
\hline
\end{tabular}

Table 9. Aperture size of $20 \mathrm{~mm}$ nearly gives required resolution of $\sim 3 \mathrm{~mm}$ in the IR at the $3 \mu$ wavelength but not at $5 \mu$. This table ignores viewing angle effects that effectively increase the spot size in one direction.

The diffracted Airy disc does not meet the required resolution in the infrared region of 3 to $5 \mu \mathrm{m}$. In the visible, assuming that the collected light uses only $50 \%$ of the entrance hole diameter, the diffracted and geometrical resolution contributions are comparable. Good resolution in the visible is possible assuming a sufficient number of pixels.

The depth of focus exceeds the range to the ITER wall even for the shortest wavelengths and the shortest distance to the entrance hole.

\section{Optical design parameters}

The following parameters have been used to generate a design that uses two refractive relays between the reflecting optical collection head and the camera reflecting telescope beyond the bioshield wall:

Distance to ITER inspection region:

Inspection length:

Viewing angle of wall at center of field:

Field angle:

Distance from entrance hole to camera telescope:
$11.5 \mathrm{~m}$

$6.5 \mathrm{~m}$ (5.65 m normal to central ray)

28 degrees

$+/-13.8$ degrees

$\sim 8.6 \mathrm{~m}$ 
Infrared design:

Entrance hole diameter

$20.0 \mathrm{~mm}$

Infrared wavelengths:

Visible design:

Entrance hole diameter

3 to $5 \mu \mathrm{m}$

Visible wavelengths:

$8.3 \mathrm{~mm}$

425 to $700 \mathrm{~nm}$

\section{Detailed schematics of the optical train}

A schematic of the visible/IR split in the optical train is shown in Fig. 26, with a detailed view of the split in Fig. 27. We note in Fig. 26, locations where images are formed in the system. A closer view of the region near the vacuum windows is shown in Fig. 28. An overall view of the lens relays is shown in Fig. 29, and we note the materials of the lenses. The optics to focus to light onto camera detectors are shown in Fig. 30. In Fig. 30 we see the location of a cold stop for the IR camera. 


\section{$19 \mathrm{~cm}$ diameter fused silica/ \\ CaFI doublet}

$13 \mathrm{~cm}$ fused silica windows: $1.1 \mathrm{~cm}$ thick

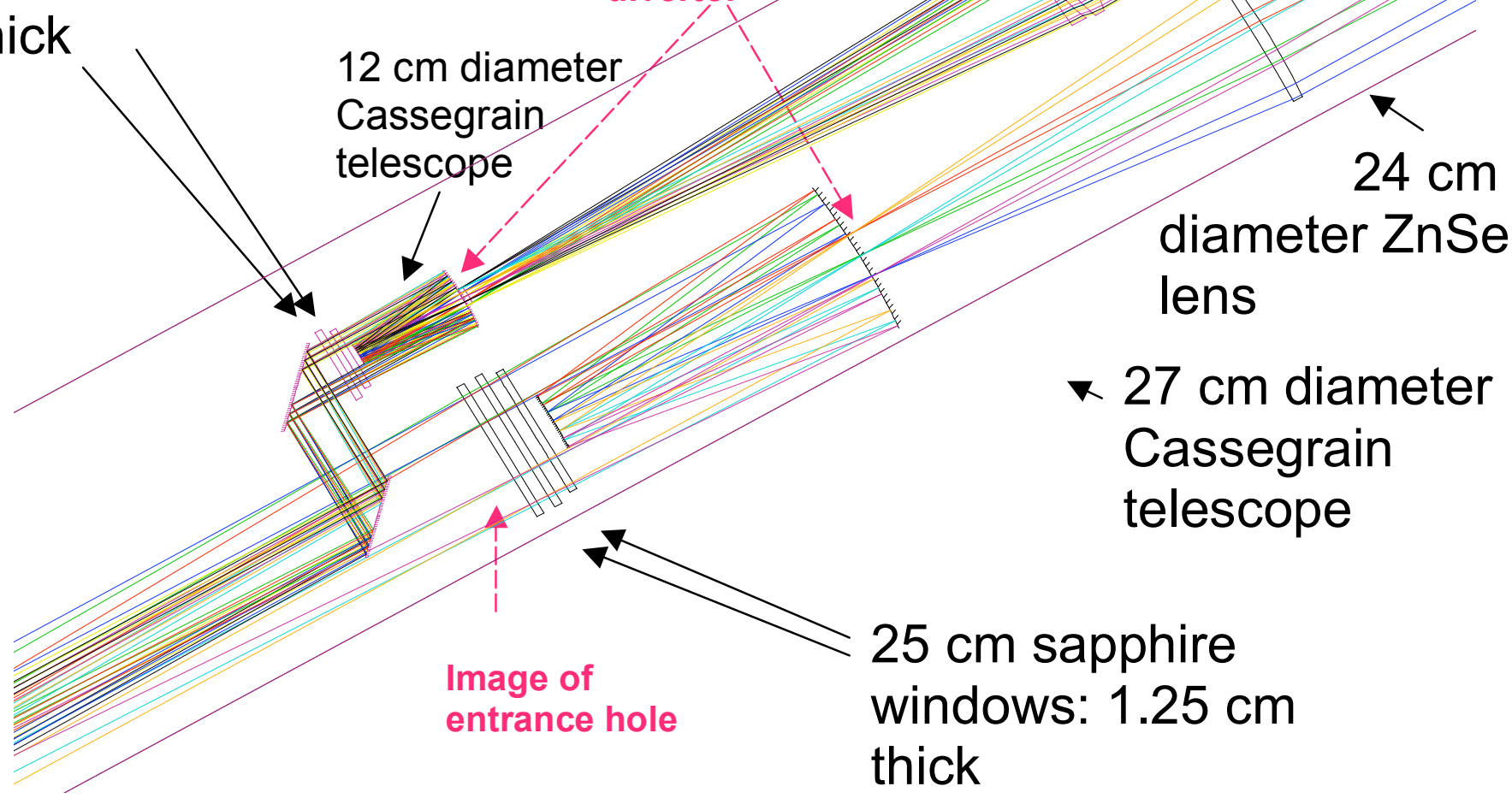

Fig. 26. Visible (top) and IR (bottom) designs 


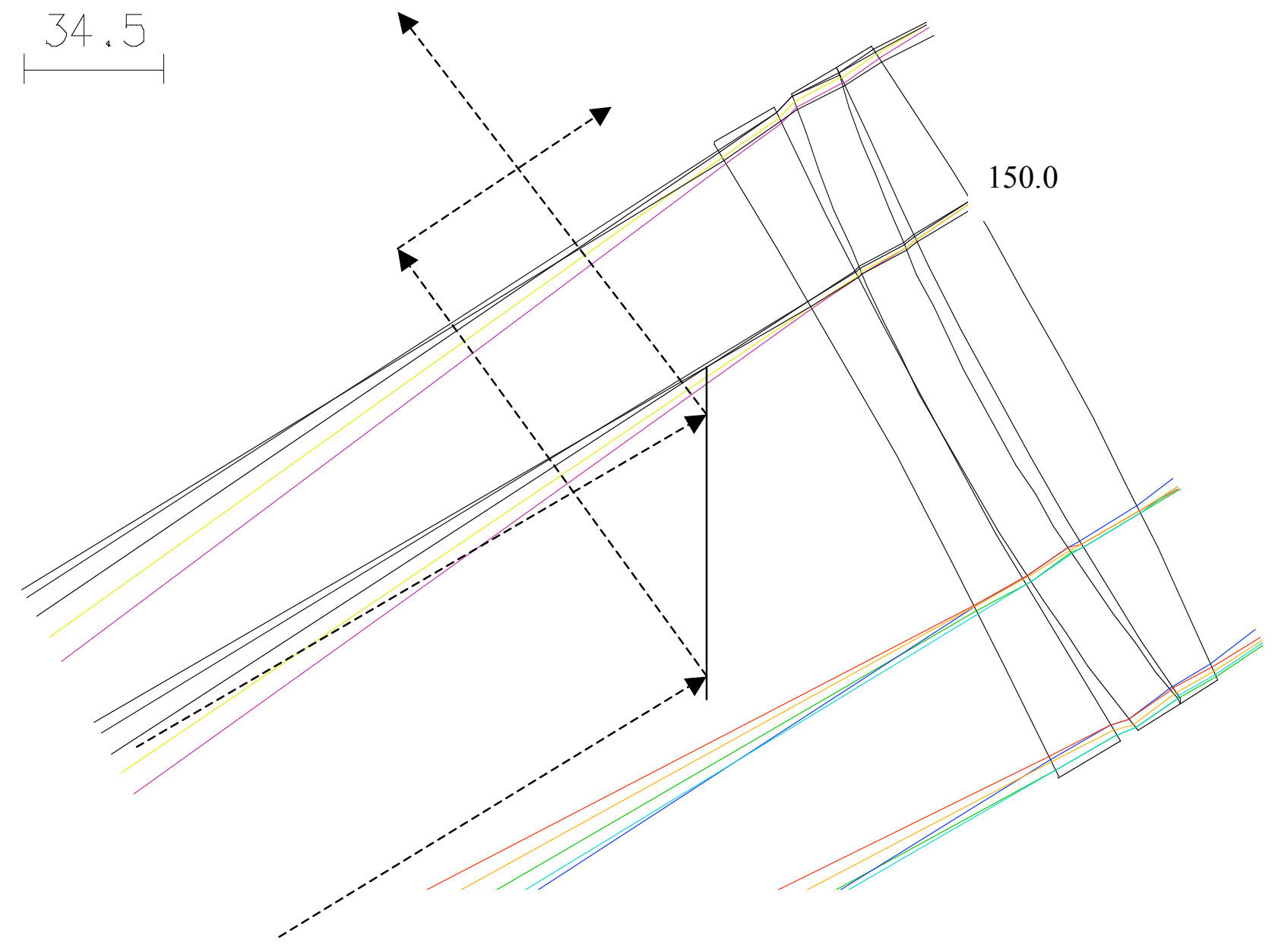

Fig. 27. schematic of IR/visible separation 


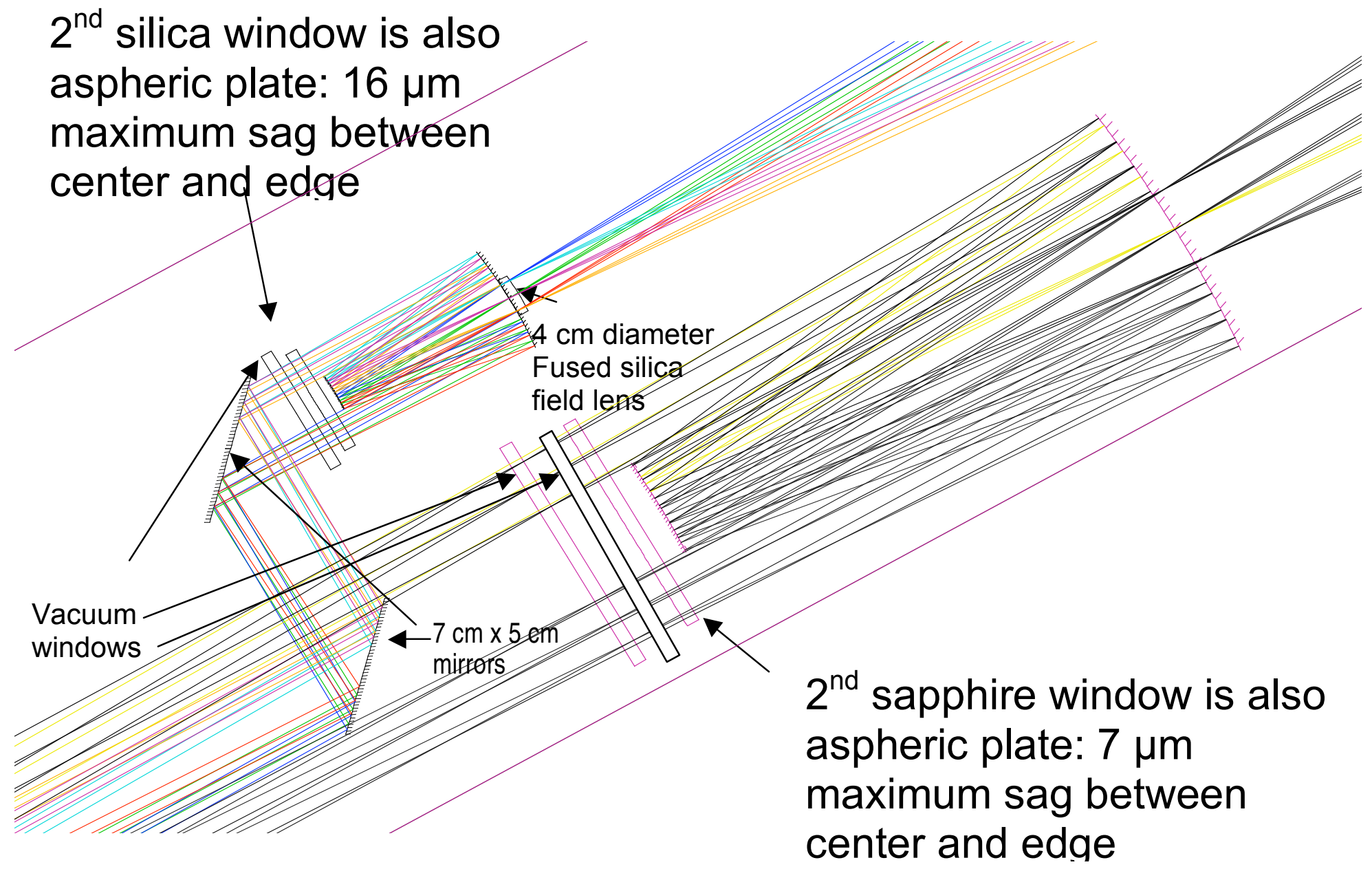

Fig. 28. Visible (top) and IR (bottom) designs 


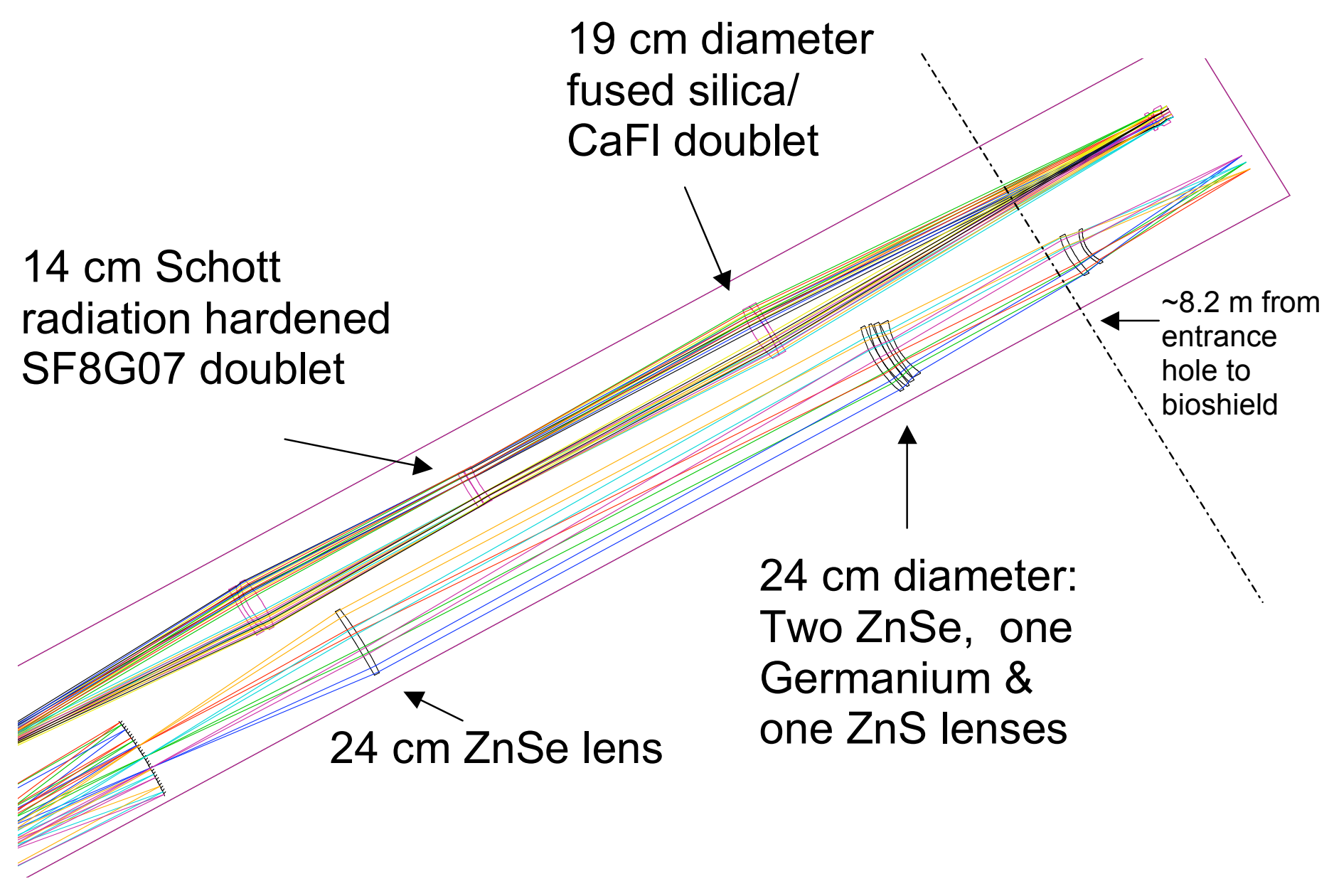

Fig. 29. Visible (top) and IR (bottom) designs 


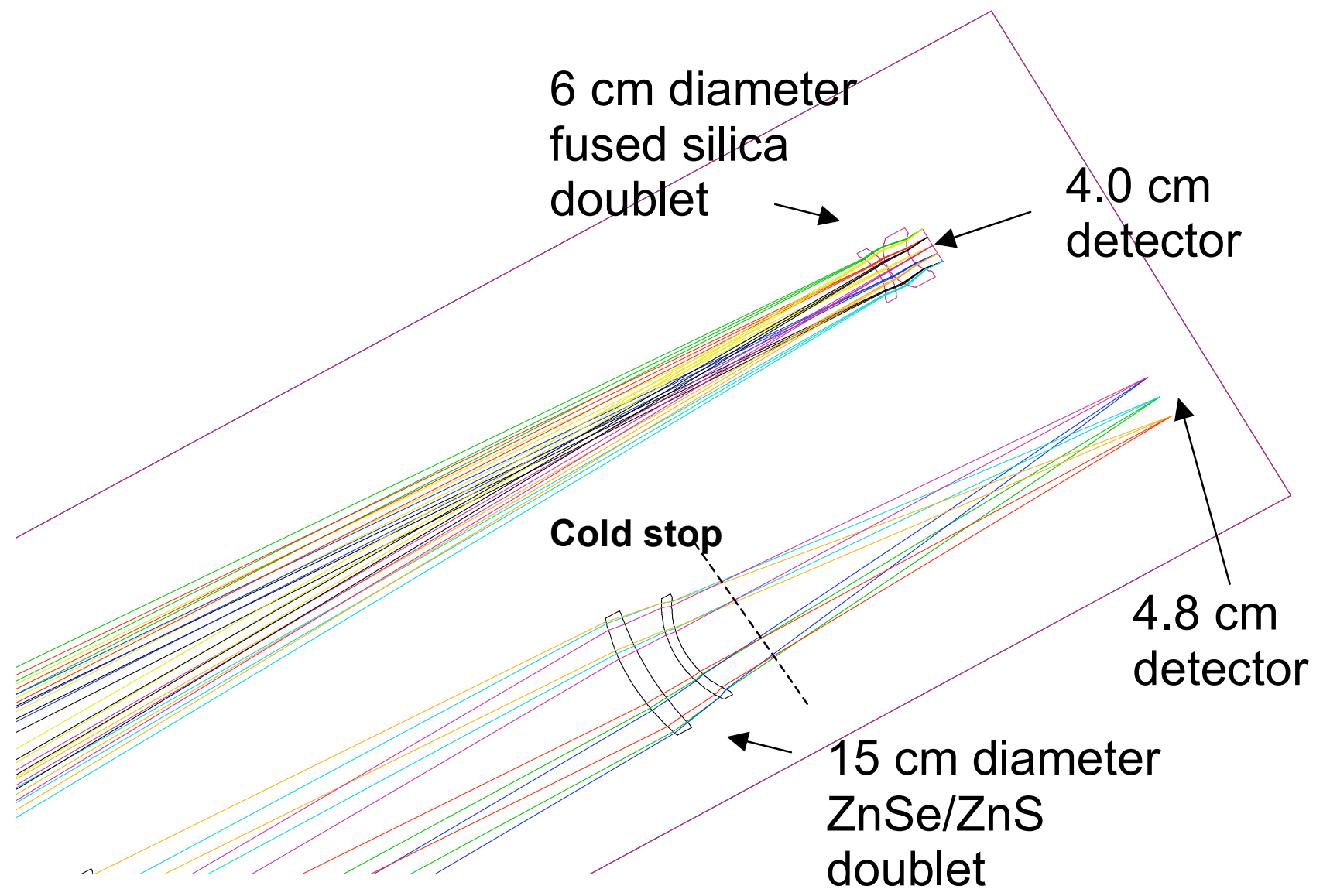

Fig. 30. Visible (top) and IR (bottom) designs 


\section{Sapphire vacuum windows}

The sapphire vacuum windows operate in near-collimated beams of light. In the above infrared optical design, the beams are $\mathrm{f} / 12$ at the windows and the beams are nearly perpendicular to the windows. A non-collimated beam undergoes a focal shift after transmission through a flat as discussed in section IV.H.

Sapphire is birefringent, so the focal shift is different for each polarization. Table 7 shows that this focal shift differential is less than $0.05 \mathrm{~mm}$ for a $25 \mathrm{~mm}$ thick window. However, this focal shift is small compared to the Rayleigh depth of focus, $+/-2 \lambda \mathrm{f}_{\#}^{2}$. For an $\mathrm{f} / 12$ beam at an wavelength of $3 \mu \mathrm{m}$, the Rayleigh depth of focus is $0.85 \mathrm{~mm}$, more than 20 times the actual focal shift between polarizations. Therefore, the orientation of the window with respect to the crystal axis is unimportant, at least in terms of polarization effects on the eventual spot size.

The visible beam can use a fused silica window which is not birefringent. However, the visible beam through the window is about $\mathrm{f} / 24$. Even at $400 \mathrm{~nm}$ the depth of focus is 0.46 , about 9 times the focal shift for a $25 \mathrm{~mm}$ thick sapphire window.

\section{Optical performance}

The modulation transmission function of the system is plotted for the infrared wavelengths in Fig. 31. In Fig. 32 is shown the corresponding plot for visible wavelengths. Fig. 33 shows analysis of aberrations for the IR, and in Fig. 34 are calculations of aberrations for the visible light. As seen in these figures, aberrations are small in this design, and do not affect the image quality.

Fig. 35 shows longitudinal focal shift vs. wavelength is small. The system is highly wavelength-corrected (apochromatic). 


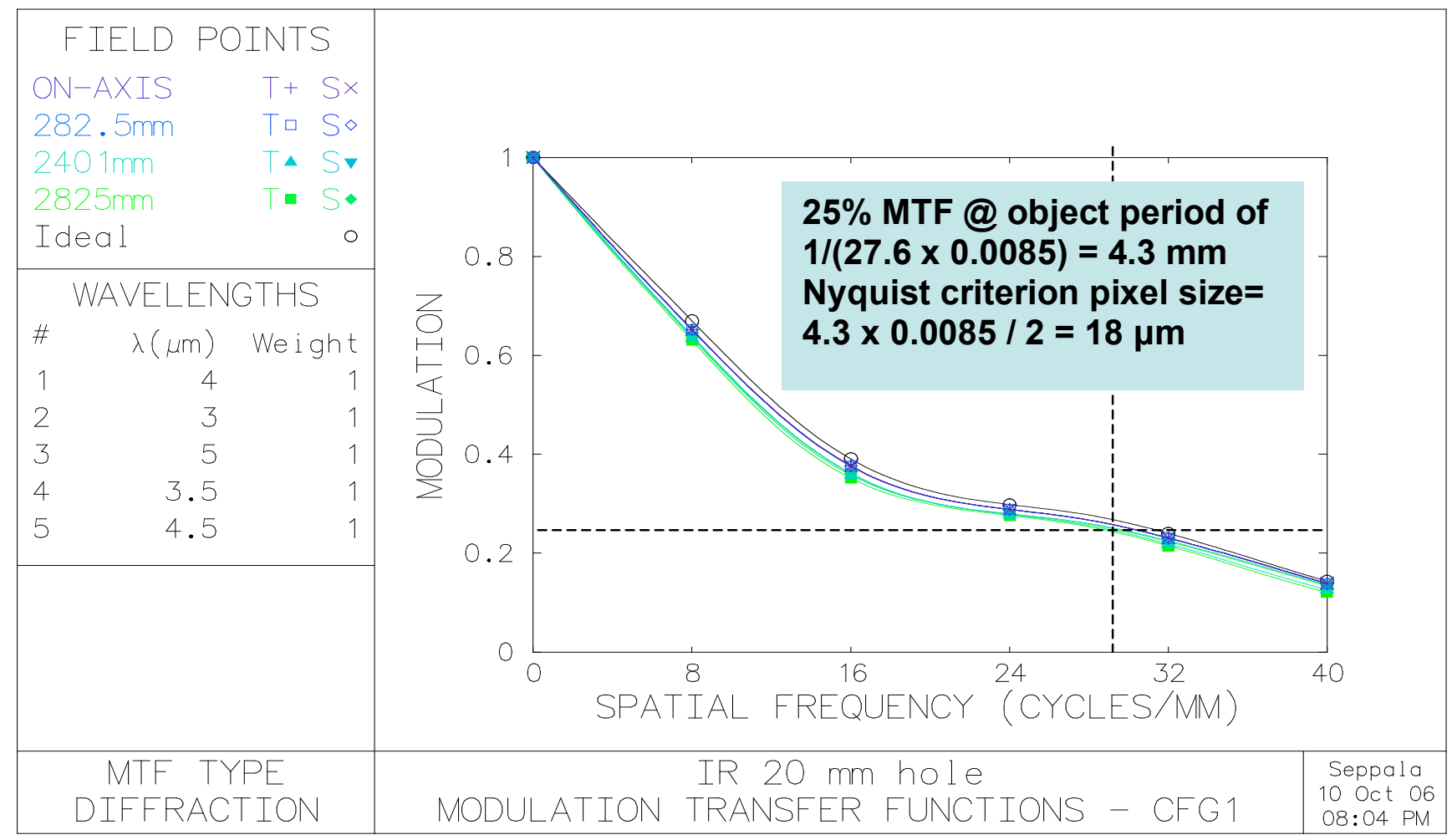

Fig. 31. IR performance: detector $48 \mathrm{~mm}$ long, magnification $=0.00850, \mathrm{f} / 4.89$ image requires 2600 pixels

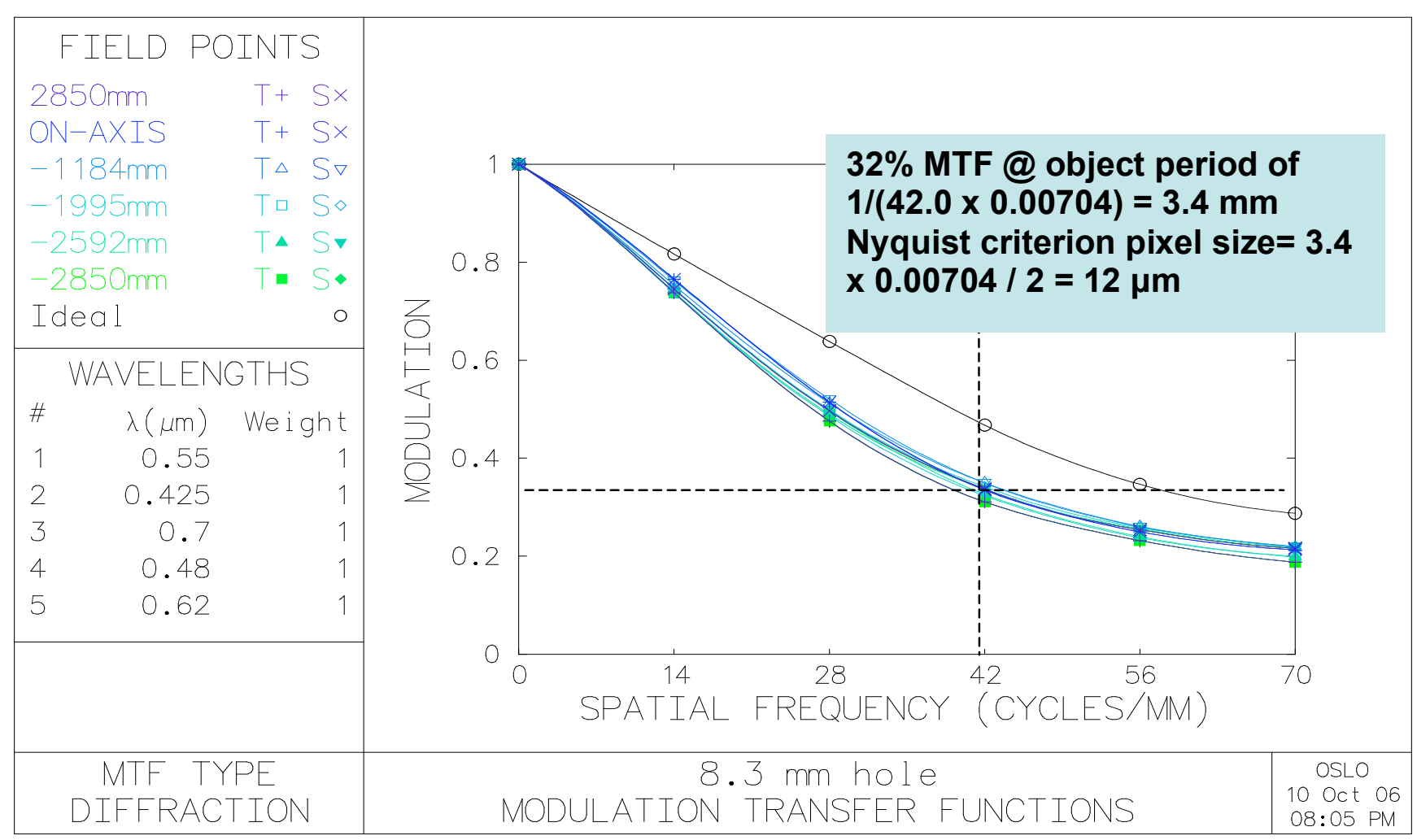

Fig. 32 Visible performance: detector $40 \mathrm{~mm}$ long, magnification $=0.00704, \mathrm{f} / 9.76$ requires 3300 pixels 


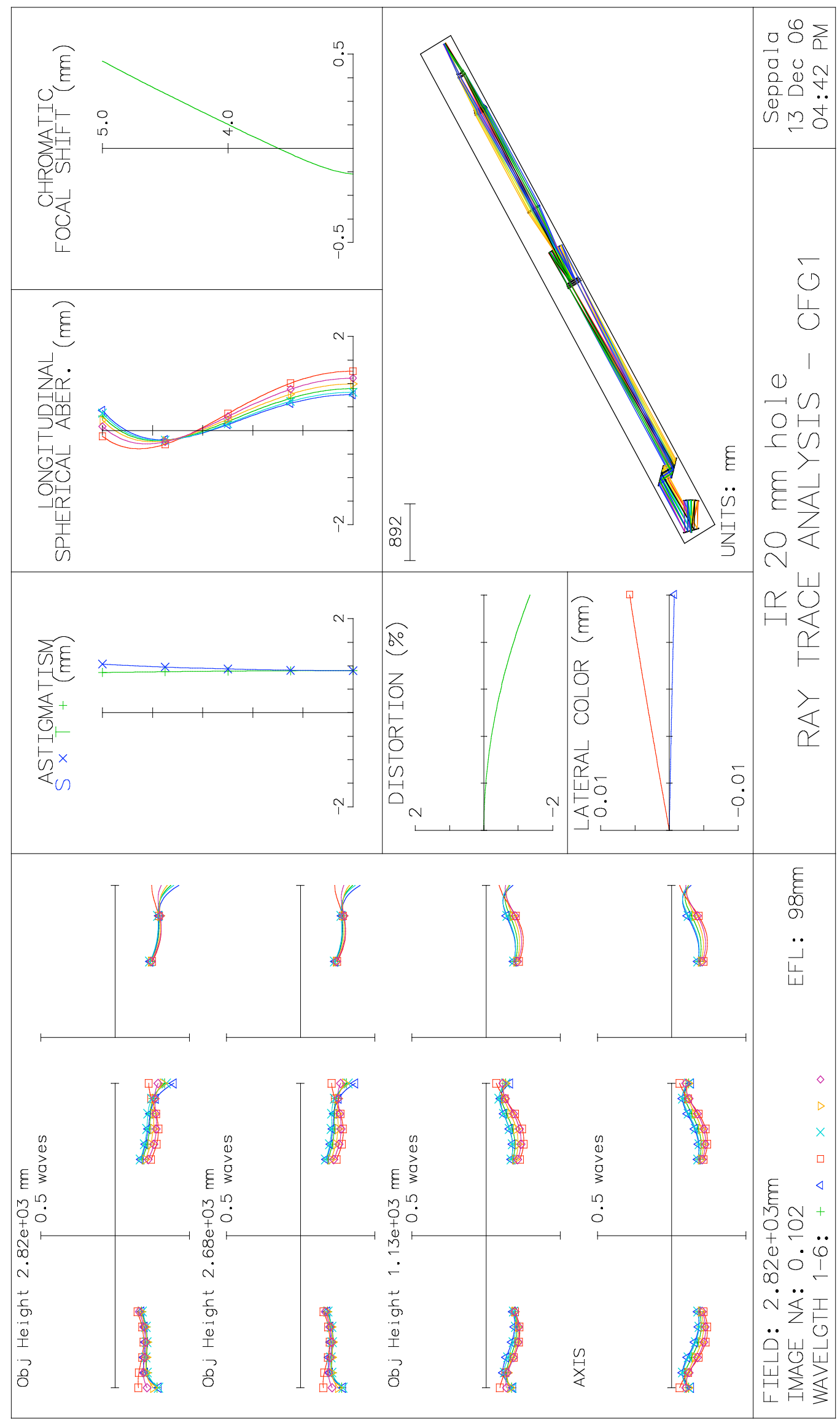

Fig. 33. IR system analysis plots 


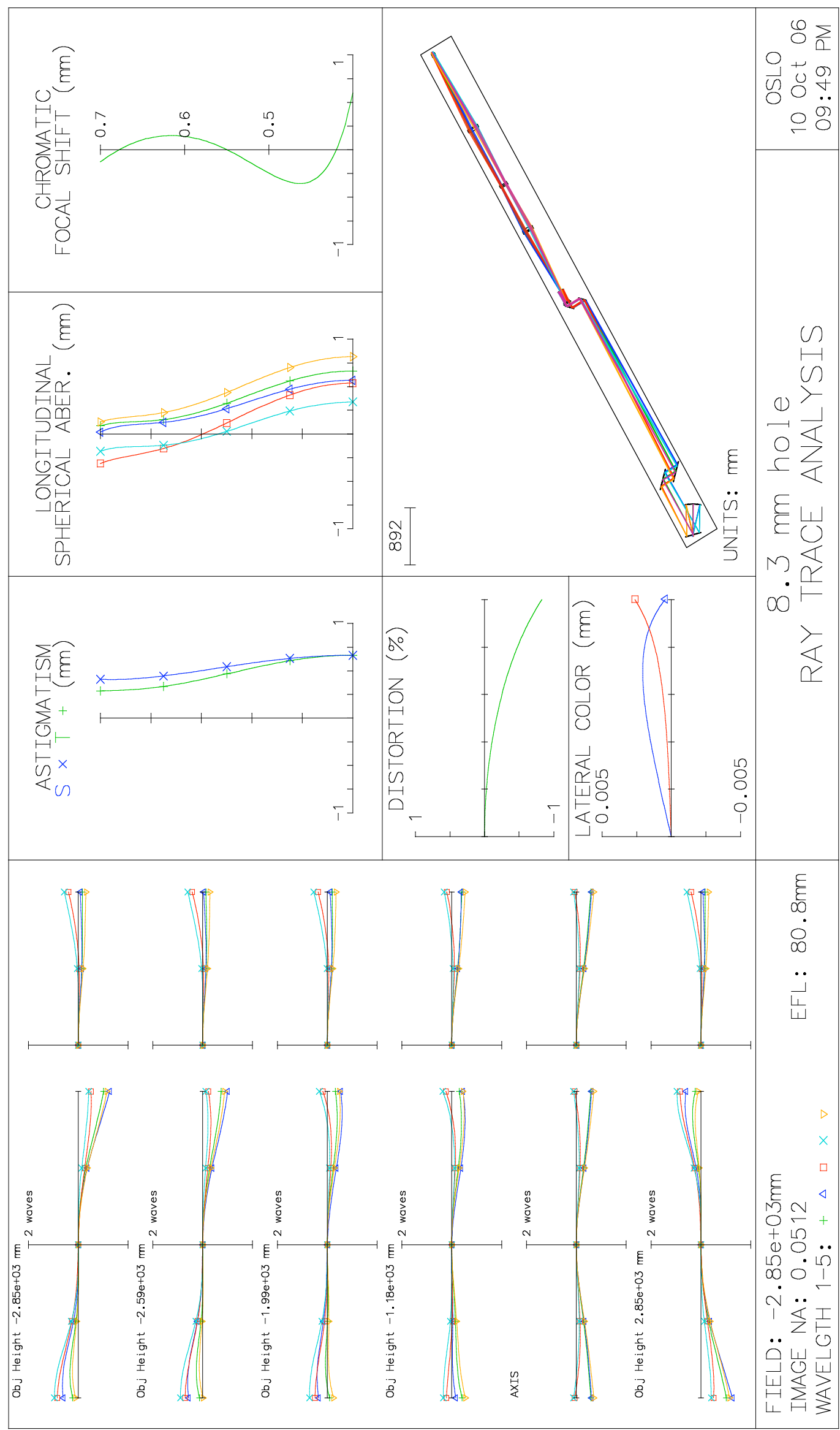

Fig. 34. Visible system analysis plots 


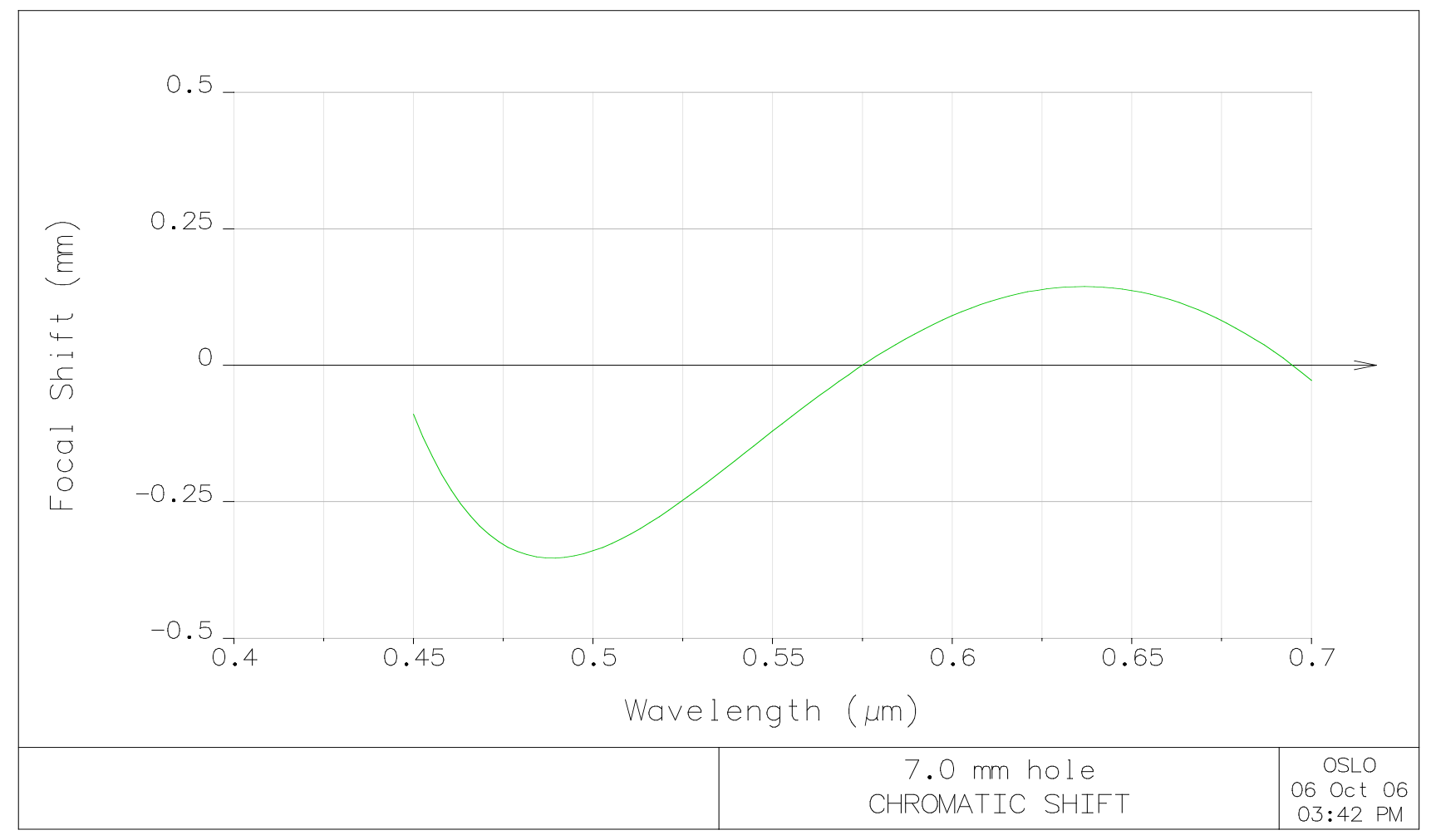

Fig. 35. Longitudinal focal shift vs. wavelength shows system is highly corrected (apochromatic). 


\section{Drawings of the system}

Simplified mechanical drawings of this design have been made and are shown here. Fig. 36 shows an overall view of the system for orientation. Figs. 37 and 38 show views of the optics in the port plug. In Fig. 39 are shown IR and visible beams coming out of the port plug after splitting. Fig. 40 is a view along the axis of the port plug, as seen from the plasma side. Fig. 41 shows a view from above the port plug. Fig. 42 is a close-up of the first mirror group, including two dogleg (rectangular) mirrors. Fig. 43 is a close-up of the vacuum window area. Fig. 44 shows an overview of the optics. A rectangular tube enclosing the optics shown would fill the port.

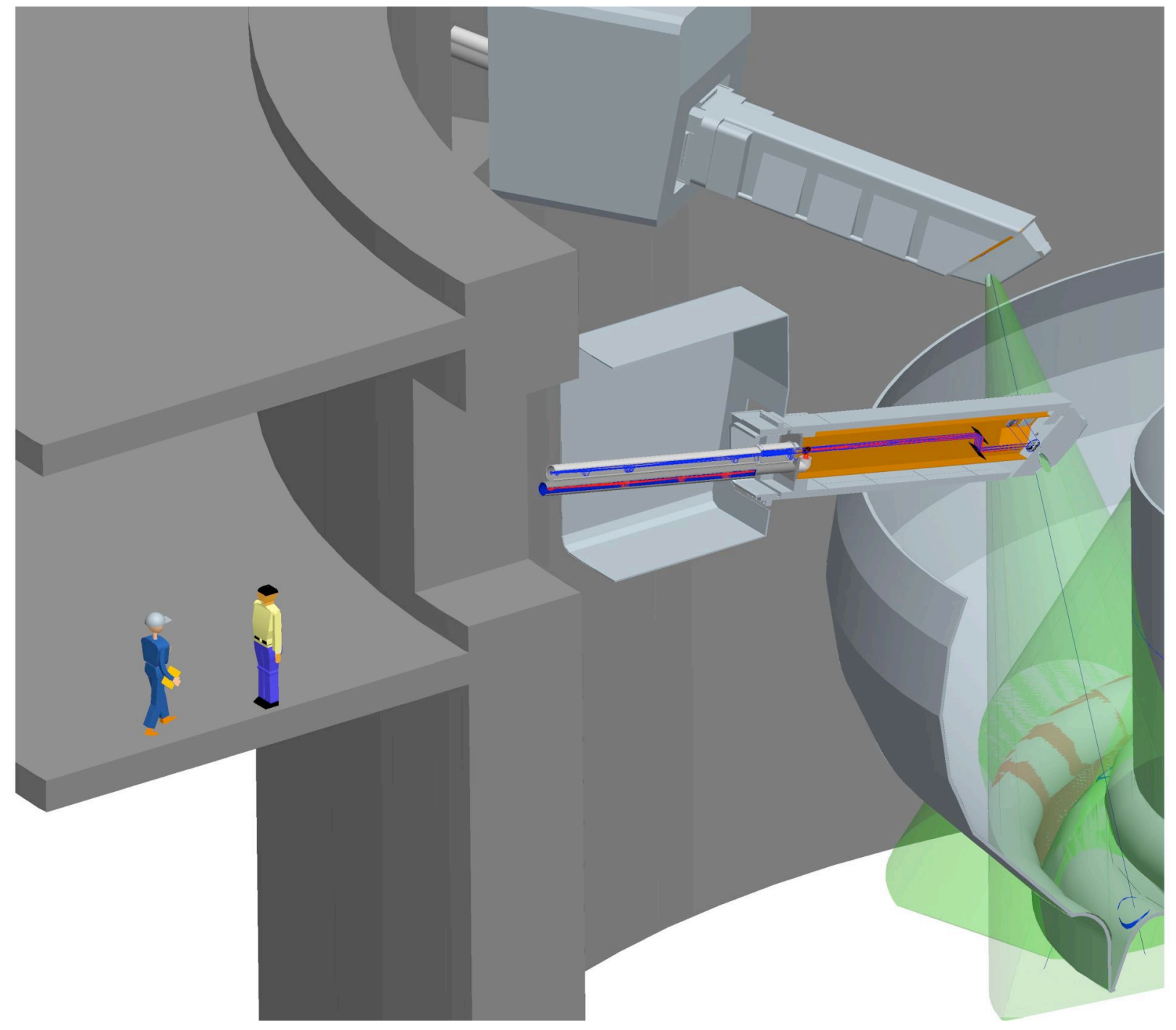

Fig. 36. View of the system showing the tokamak, two port plugs, and the bioshield. 


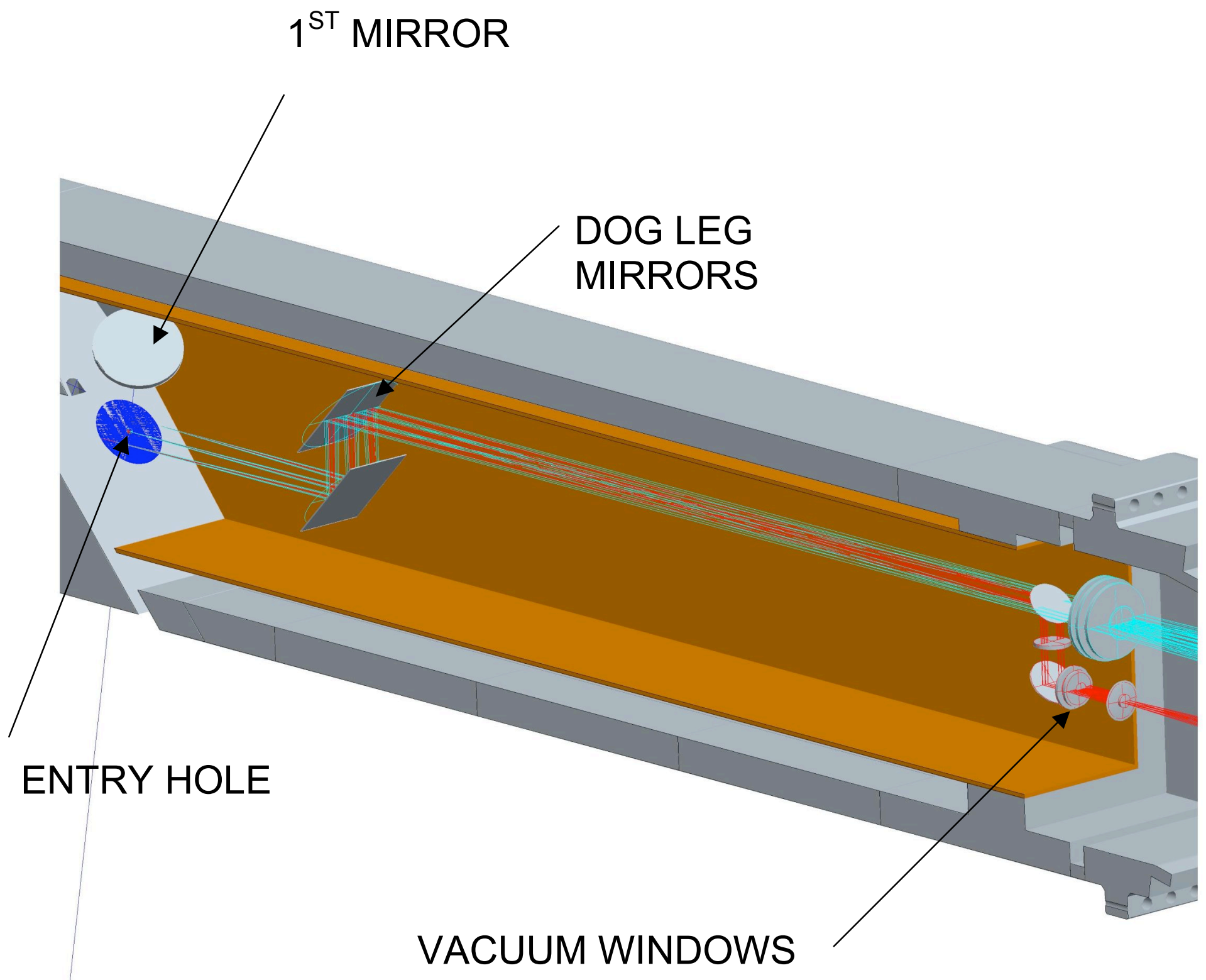

Fig. 37. The optics in the port plug. 


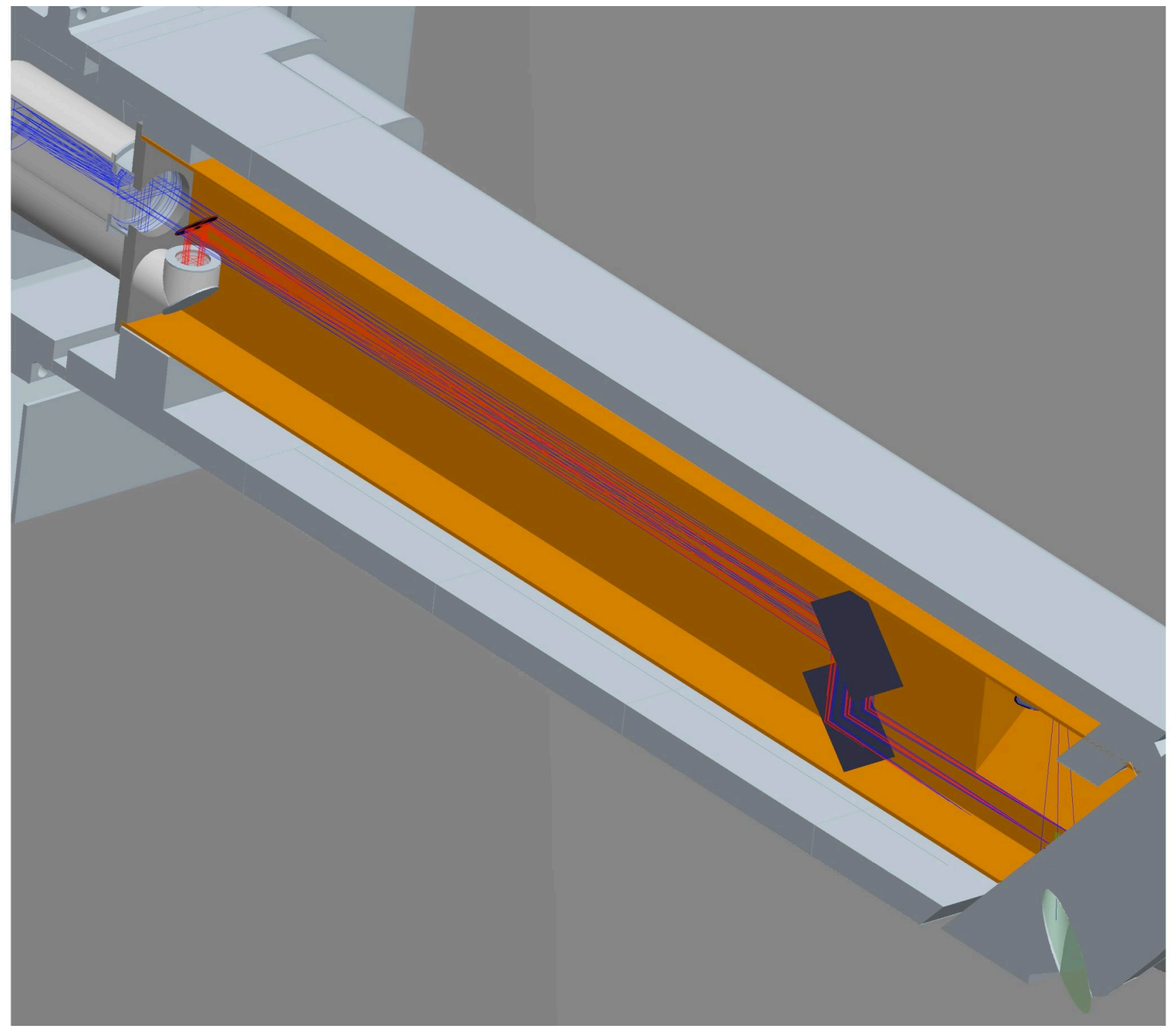

Fig. 38. Another view of the port plug. 


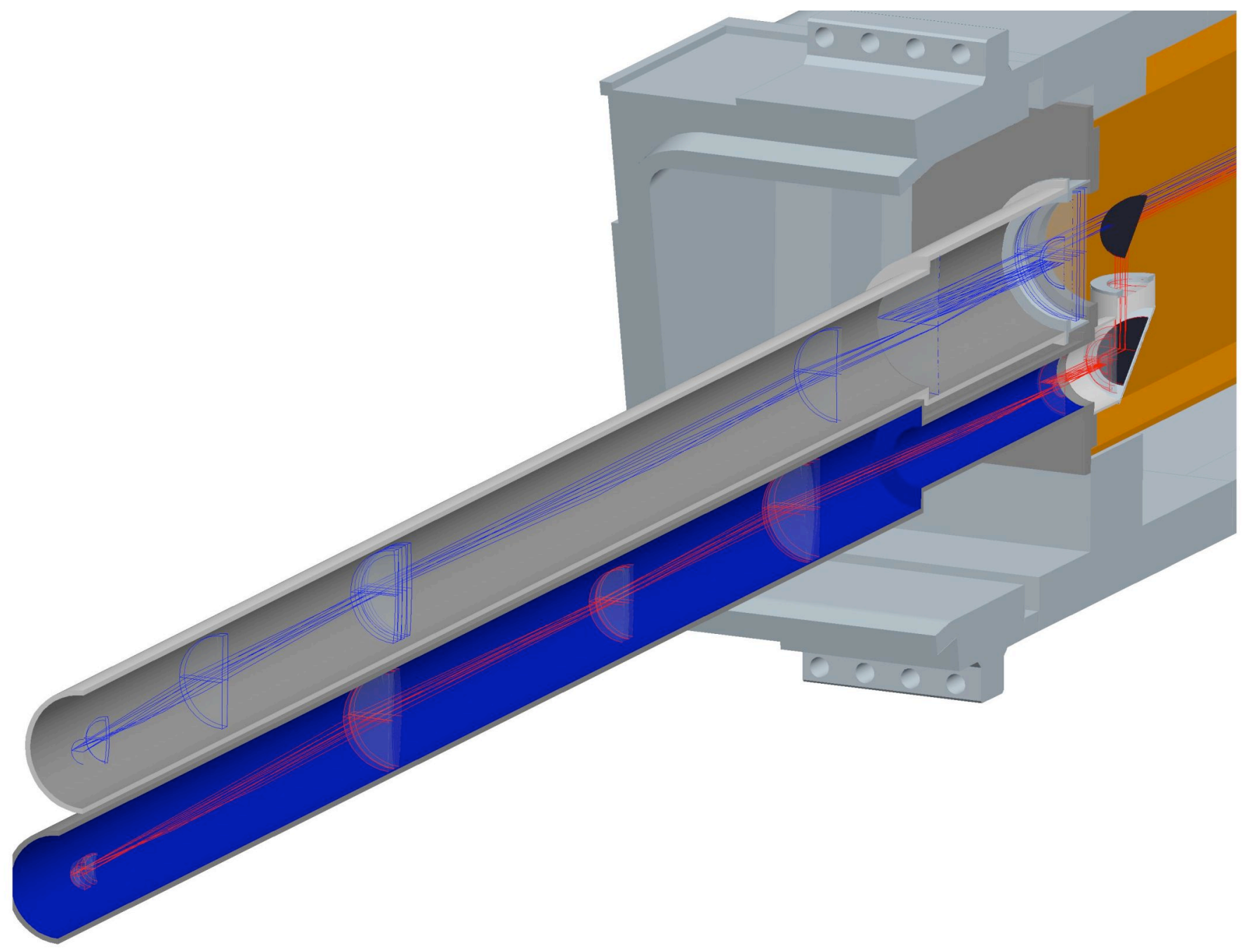

Fig. 39 The IR and visible beams coming out of the port plug after splitting. 


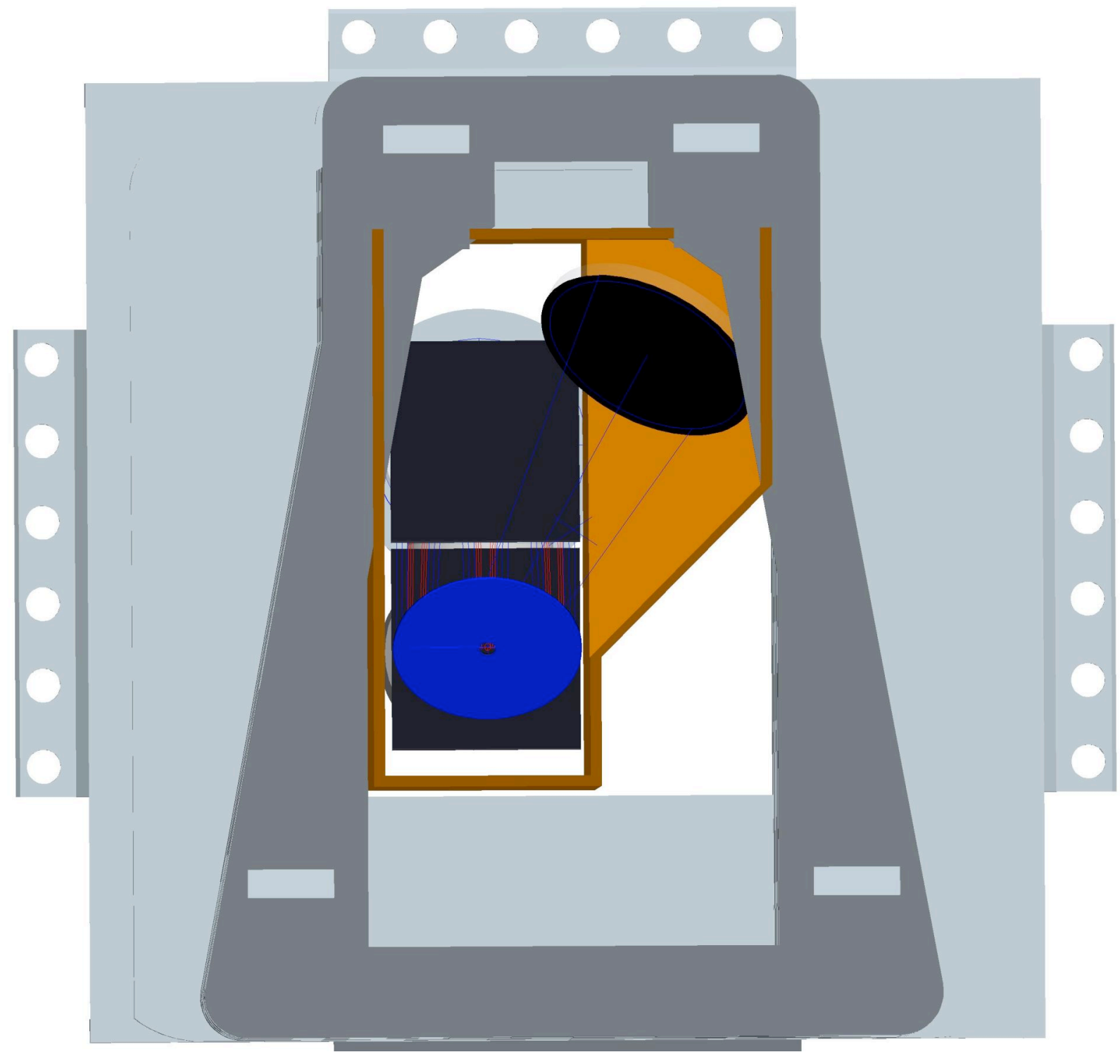

Fig. 40. View along the axis of the port plug, as seen from the from the plasma side. 


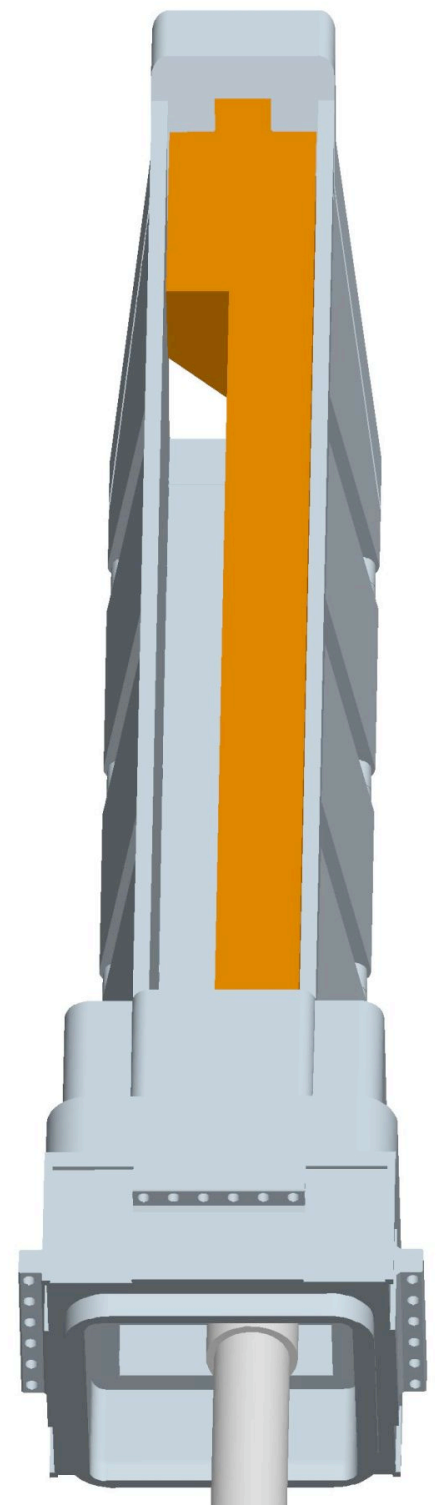

Fig. 41 A view from above the port plug. 


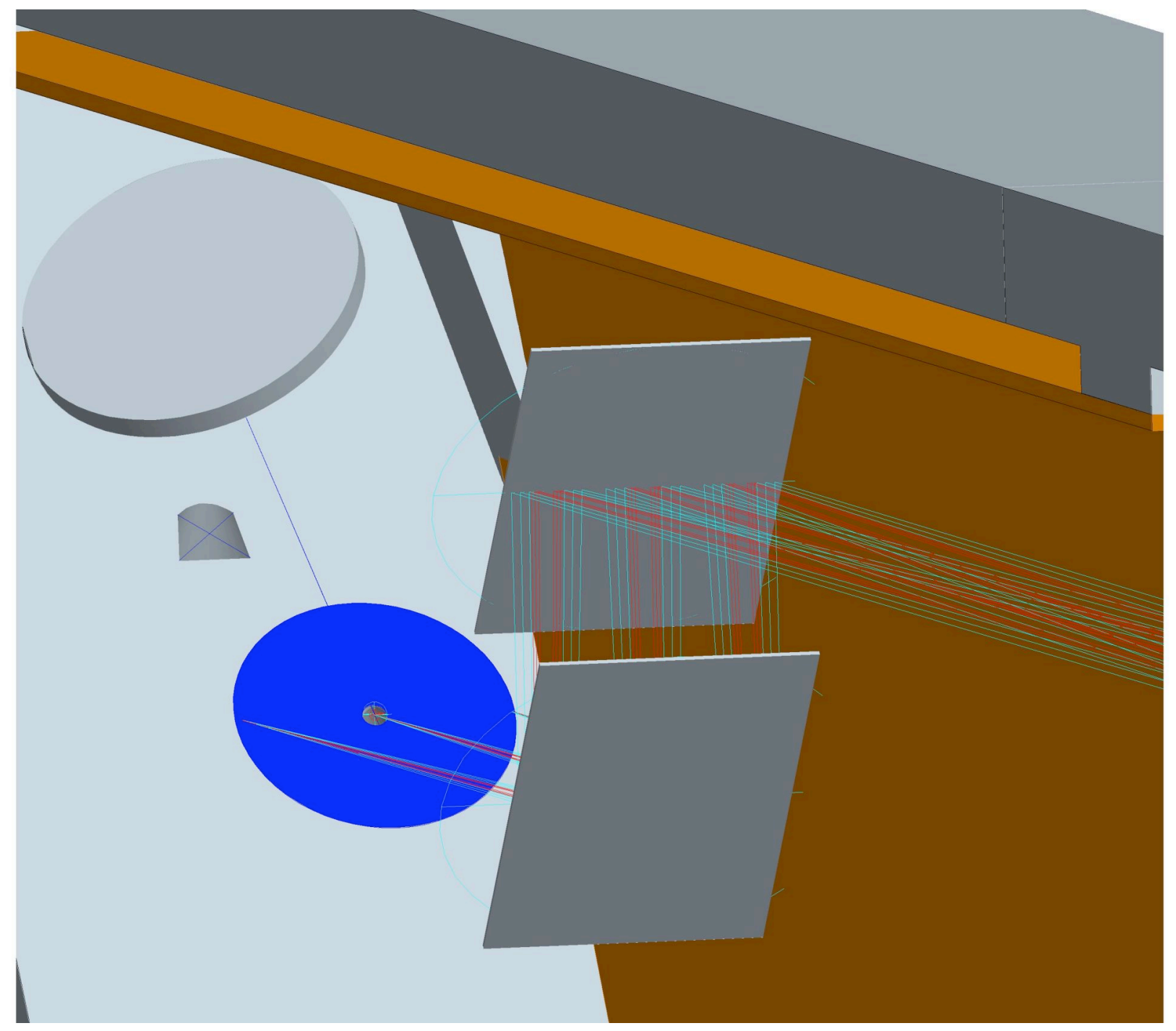

Fig. 42. A close-up of the first mirror group. The two rectangular parts are dogleg mirrors to allow radiation shielding. The upper disk is the aspheric primary mirror, and the lower disk is the flat secondary mirror with the entrance aperture in the center. 


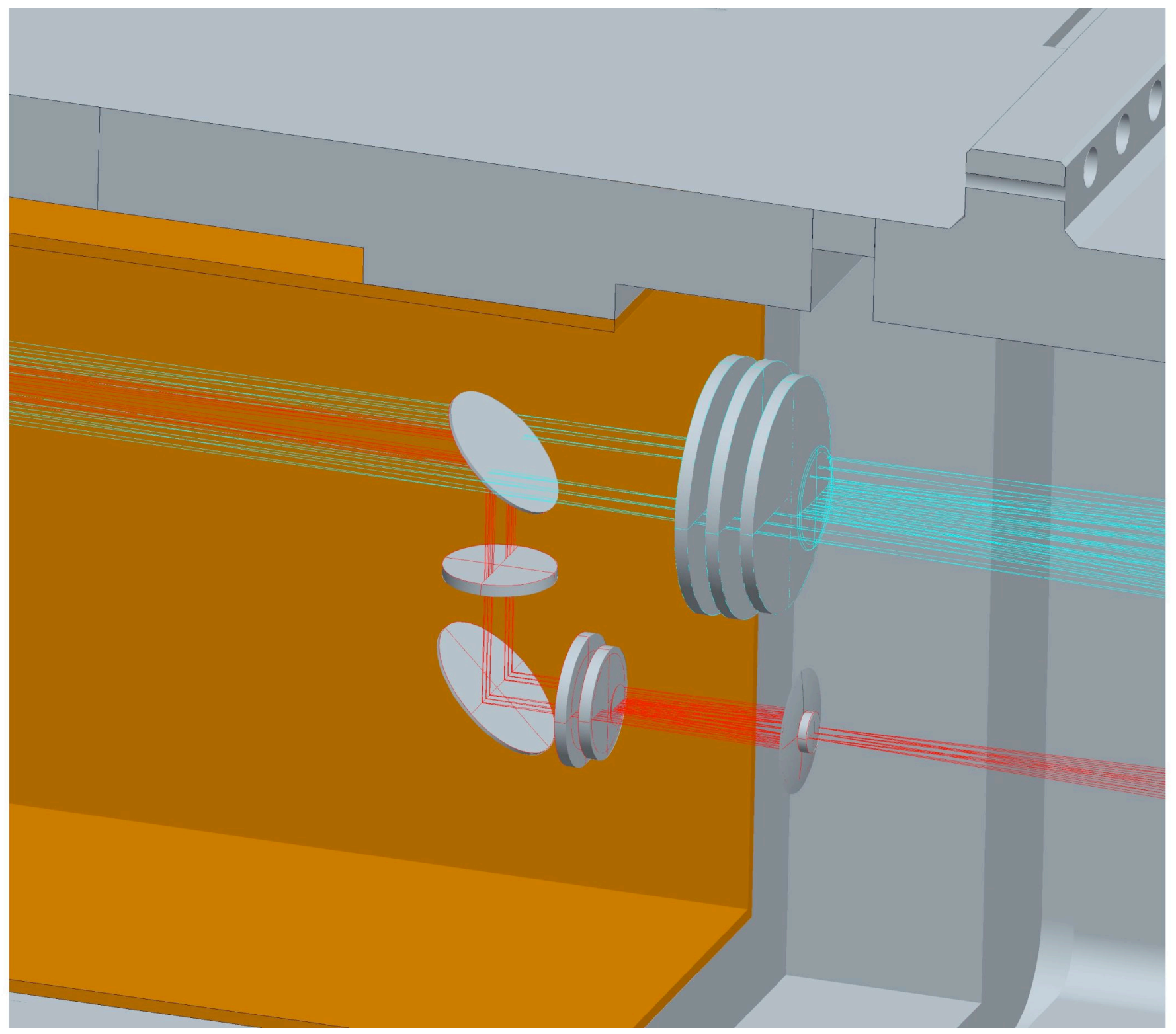

Fig. 43. A close-up of the vacuum window area. 


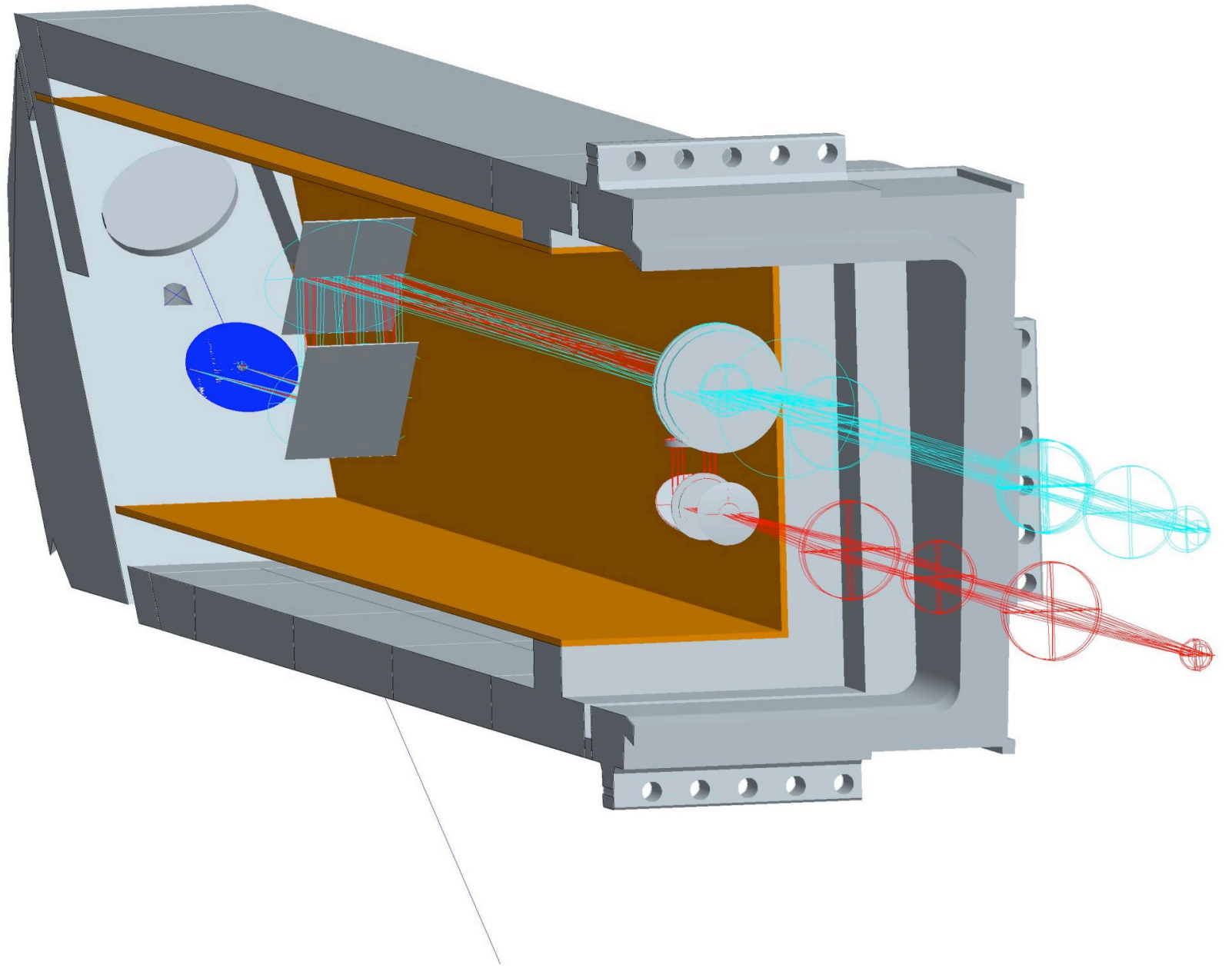

Fig. 44. An overview of the optics. 


\section{C. $10 \mathrm{~mm}$ aperture in $360 \mathrm{~mm}$ tube}

This design is constrained to fit inside a tube with an inside diameter of $360 \mathrm{~mm}$, which allows a double-walled tube with space between inner and outer walls for cooling water flow. The associated entrance aperture is $10 \mathrm{~mm}$.

\section{Optical schematic}

This design has the same required field of view as the $5 \mathrm{~mm}$ and $20 \mathrm{~mm}$ aperture designs, The general approach is the same, with a similar layout to the $20 \mathrm{~mm}$ design. Fig. 45 shows the overview.

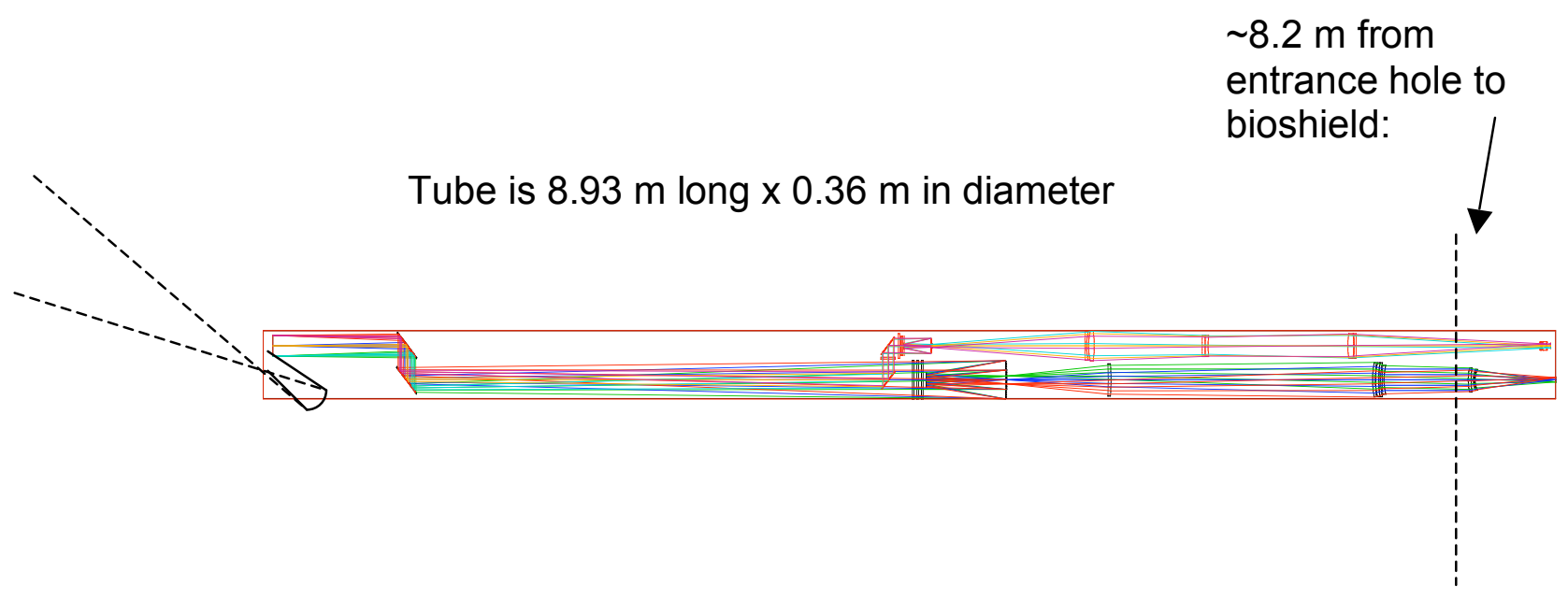

Fig. 45. Optical schematic of the $10 \mathrm{~mm}$ aperture design.

\section{Optical resolution}

Compared to the $20 \mathrm{~mm}$ aperture design, the spatial resolution is correspondingly reduced. Table 10 shows the visible and IR resolution as well as the depth of focus. 


\begin{tabular}{|c|c|c|c|c|c|}
\hline $\begin{array}{c}\text { Distance } \\
\text { to } \\
\text { divertor } \\
\text { aperture } \\
\text { size }\end{array}$ & $\begin{array}{c}\text { Viewing } \\
\boldsymbol{A}\end{array}$ & $\begin{array}{c}\text { Object feature } \\
\text { at which the } \\
\text { MTF goes to } \\
\text { zero contrast } \\
\left(\mathbf{l ~ f} \mathbf{f}_{\#}\right)\end{array}$ & $\begin{array}{c}\text { Estimate of } \\
\text { resolved feature } \\
(\mathbf{1 . 5} \boldsymbol{\lambda} \text { f\#) }\end{array}$ & $\begin{array}{c}\text { +/- Depth of } \\
\text { focus }\end{array}$ \\
\hline$(\mathrm{m})$ & $(\mathrm{mm})$ & $(\mu \mathrm{m})$ & $(\mathrm{mm})$ & $(\mathrm{mm})$ & $(\mathrm{m})$ \\
\hline 11.5 & 10 & 5.0 & $\mathbf{5 . 8}$ & 8.6 & 13 \\
\hline 11.5 & 10 & 3.0 & $\mathbf{3 . 5}$ & 5.2 & 11 \\
\hline 11.5 & 4.15 & 0.7 & $\mathbf{1 . 9}$ & 2.9 & 6 \\
\hline 11.5 & 4.15 & 0.4 & $\mathbf{1 . 1}$ & 1.7 & 8 \\
\hline
\end{tabular}

Table. 10. Resolution and depth of focus for the $10 \mathrm{~mm}$ aperture design.

\section{Optical performance}

In Fig. 46 is shown the MTF curve for the infrared wavelengths from 3 to $5 \mu$. The system shows no chromatic aberration for the IR. The vertical dotted lines show the spatial frequencies corresponding to $9 \mathrm{~mm}$ and $6 \mathrm{~mm}$ object sizes, respectively. The 9 $\mathrm{mm}$ object size shows an MTF of $25 \%$, which is barely resolvable but not sufficient for accurate thermography. To reach an MTF of $80 \%$, a feature size of approximately $35 \mathrm{~mm}$ is needed, which is far from the specified $3 \mathrm{~mm}$ spatial resolution.

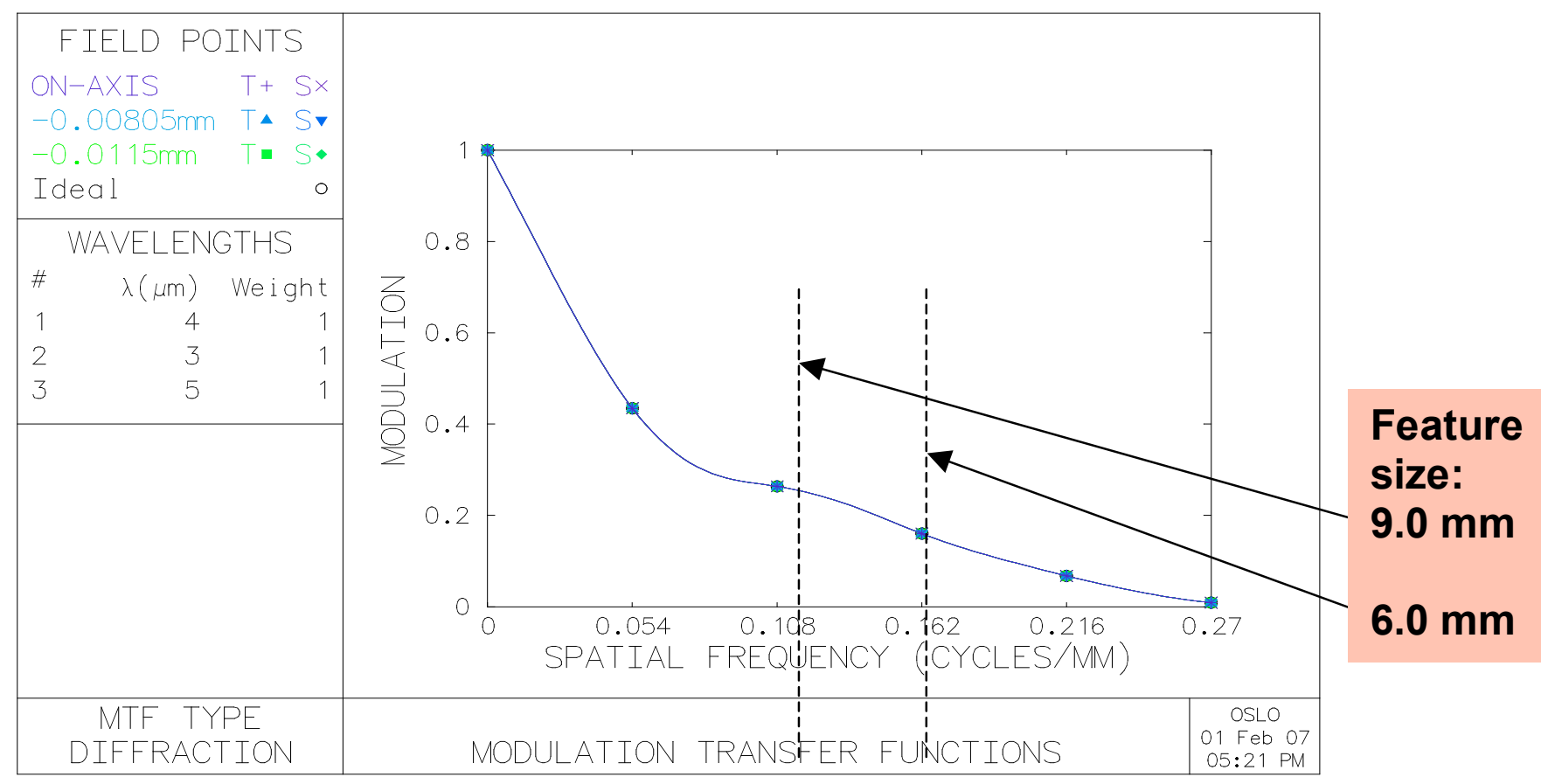

Fig. 46. Modulation transmission function for the $10 \mathrm{~mm}$ aperture design. The MTF for a $9 \mathrm{~mm}$ object is approximately $25 \%$. 


\section{Optical design details}

In this case the primary mirror is elliptical, and once again a flat mirror with an aperture is used to redirect the light down the tube (Fig. 47).

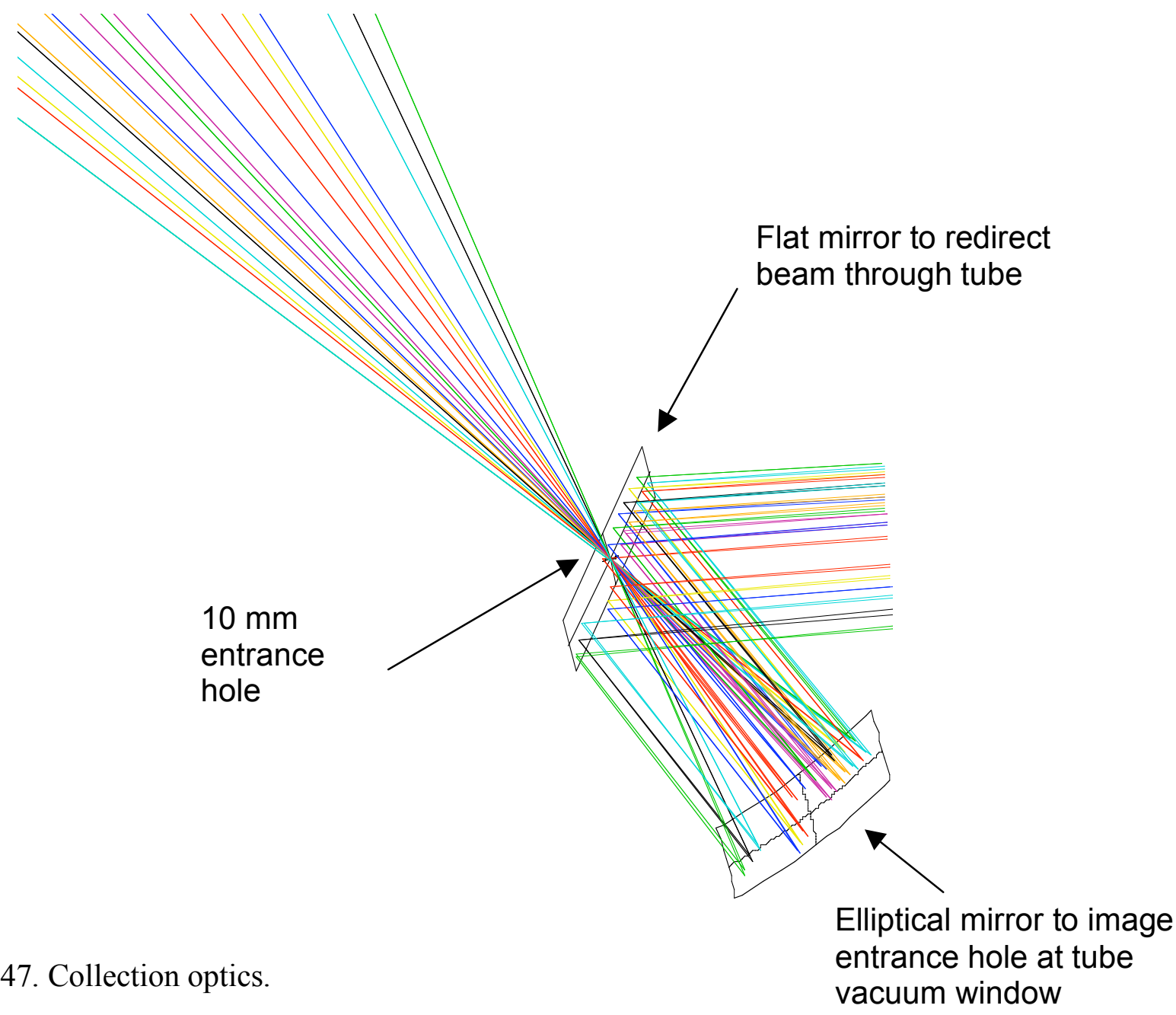

The hole in the flat mirror produces a blind spot, which has been positioned away from the outer target plate. The IR Cassegrain is $20 \mathrm{~cm}$ diameter, as are the sapphire windows, and the visible Cassegrain is $8 \mathrm{~cm}$ in diameter (compare with Fig. 26 for the 20 $\mathrm{mm}$ aperture design). The fused silica visible light windows are $10 \mathrm{~cm}$ in diameter.

The details of the relay optics are shown in Fig. 48. In Fig. 49 is shown an expanded view of the final relay and camera optics. The visible camera requires a detector $2.7 \times 1.3 \mathrm{~cm}$, with $6.7 \mu \mathrm{m}$ numbering 4000 pixels across the long dimension of the detector. The IR detector is $3.1 \times 1.5 \mathrm{~cm}$, with $20 \mu \mathrm{m}$ pixel size, and 1550 pixels across the long dimension. 


\section{$16 \mathrm{~cm}$ diameter $\quad 11 \mathrm{~cm}$ radiation fused silica/ CaFI hardened Schott doublet
$4.5 \mathrm{~cm}$ $13 \mathrm{~cm}$ diameter fused silica/ CaFI doublet
diameter
fused
silica SF8G07 doublet}

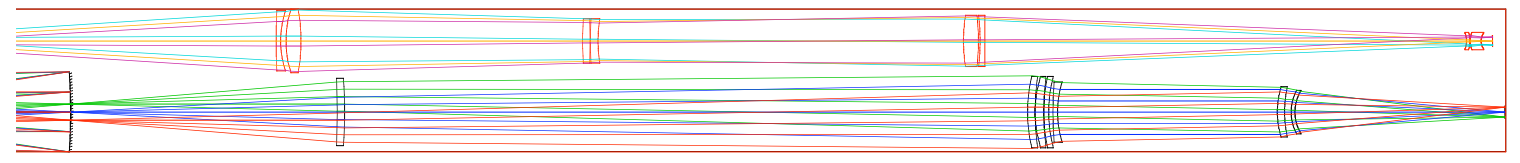

$17 \mathrm{~cm} \mathrm{ZnSe} \mathrm{lens}$

$18 \mathrm{~cm}$ diameter: Two

ZnSe, one Germanium

$\&$ one $\mathrm{ZnS}$ lenses
$13 \mathrm{~cm}$ diameter $\mathrm{ZnSe} / \mathrm{ZnS}$ doublet

Fig. 48. Relay optics.

$13 \mathrm{~cm}$ diameter fused silica/ CaFI $4.5 \mathrm{~cm}$ diameter doublet fused silica doublet

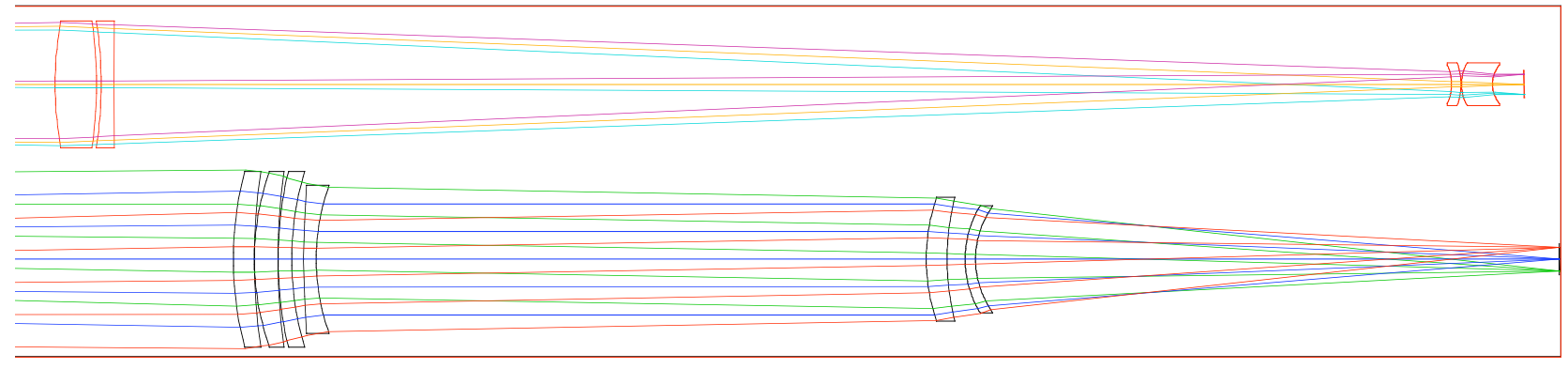

$18 \mathrm{~cm}$ diameter: Two ZnSe, one Germanium \& one $\mathrm{ZnS}$ lenses

$\begin{array}{ll}13 \mathrm{~cm} & 7 \mathrm{~cm} \\ \text { diameter } & \text { diameter } \\ \text { ZnSe/ZnS } & \text { cold stop } \\ \text { doublet } & \end{array}$

Fig. 49. Detail of final relay and camera optics. 


\section{Physical layout}

A physical view of the port is shown in Fig. 49. A jog is incorporated in the beam path for neutron blocking. The visible-IR split takes place inside the vacuum. Figure 50 shows a view of the collection optics, with the light path displayed.

Fig. 51 shows the locations of the vacuum windows. In Fig. 52 is the light path through the port plug, with visible light in blue and infrared represented in green.

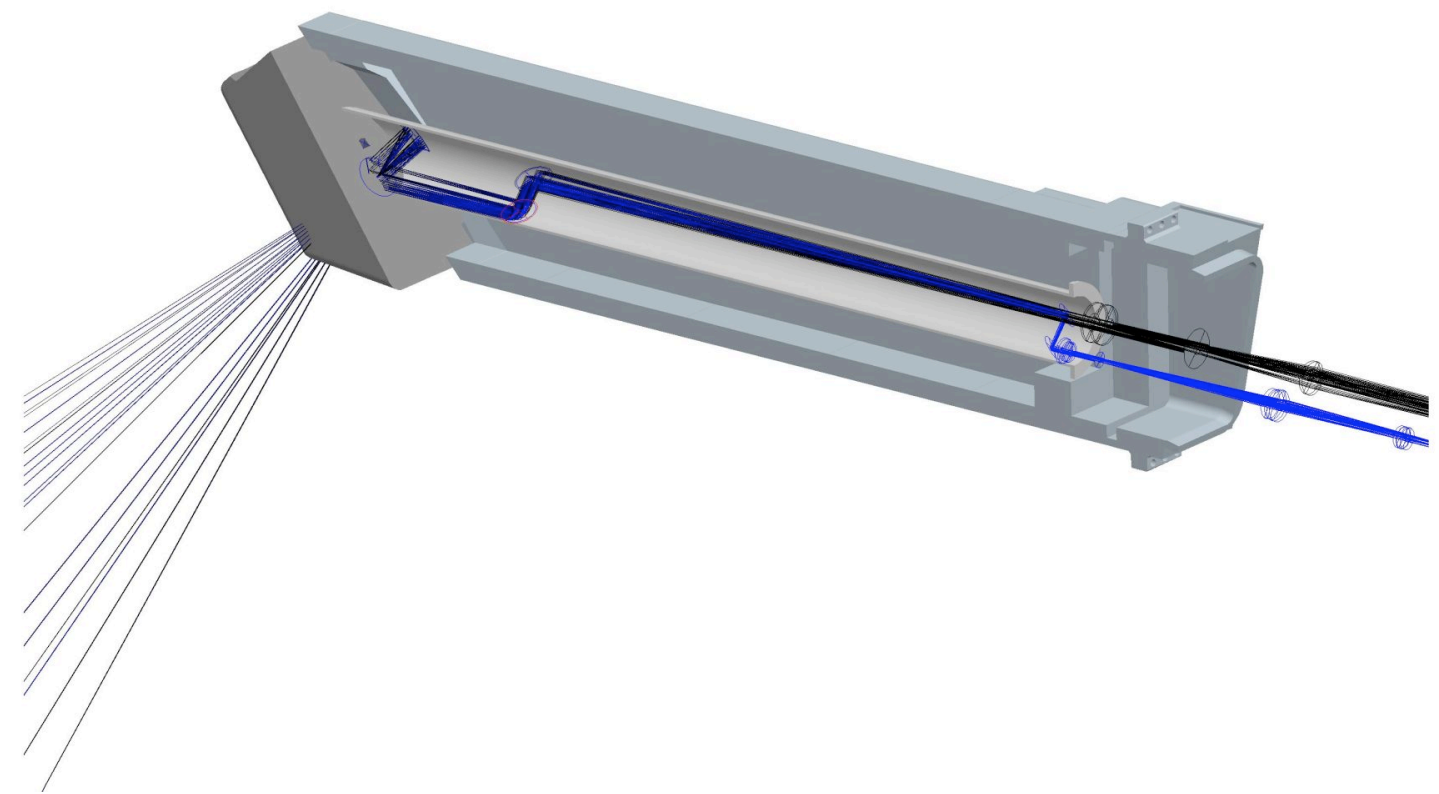

Fig. 49. A view of an upper port showing a $36 \mathrm{~cm}$ tube, containing optics for the $10 \mathrm{~mm}$ aperture design. 


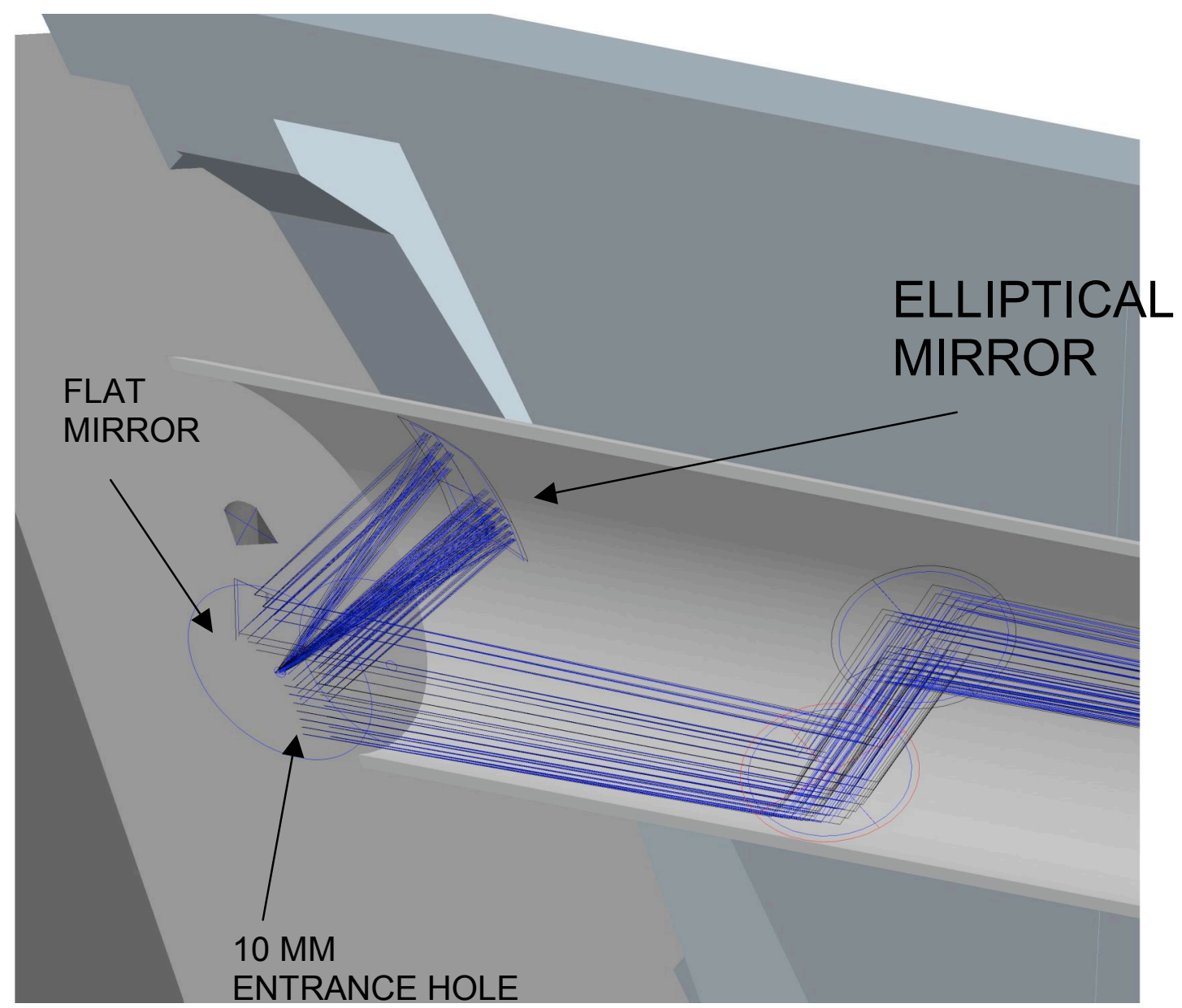

Fig. 50. Physical view of the collection optics. 


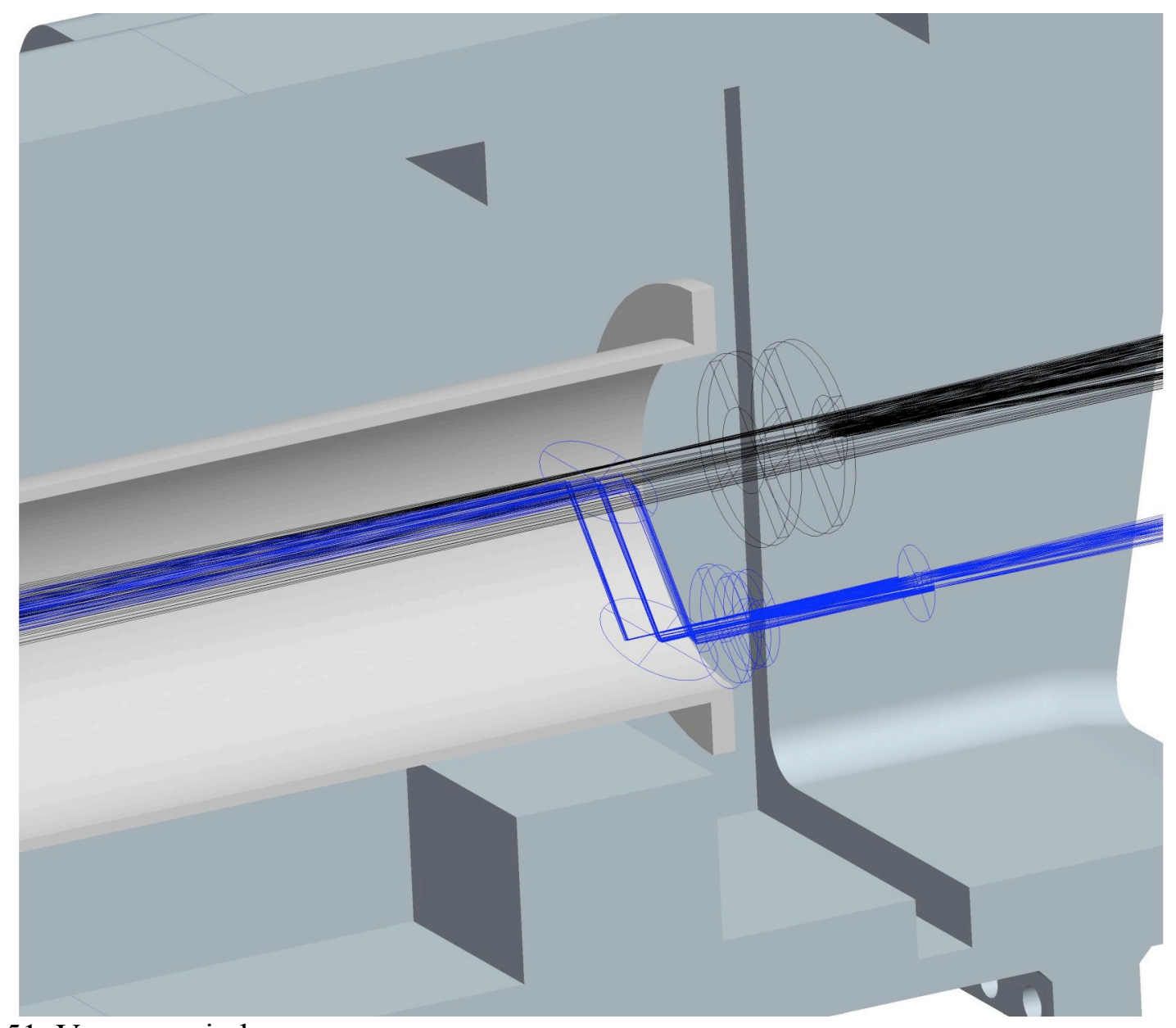

Fig. 51. Vacuum windows. 


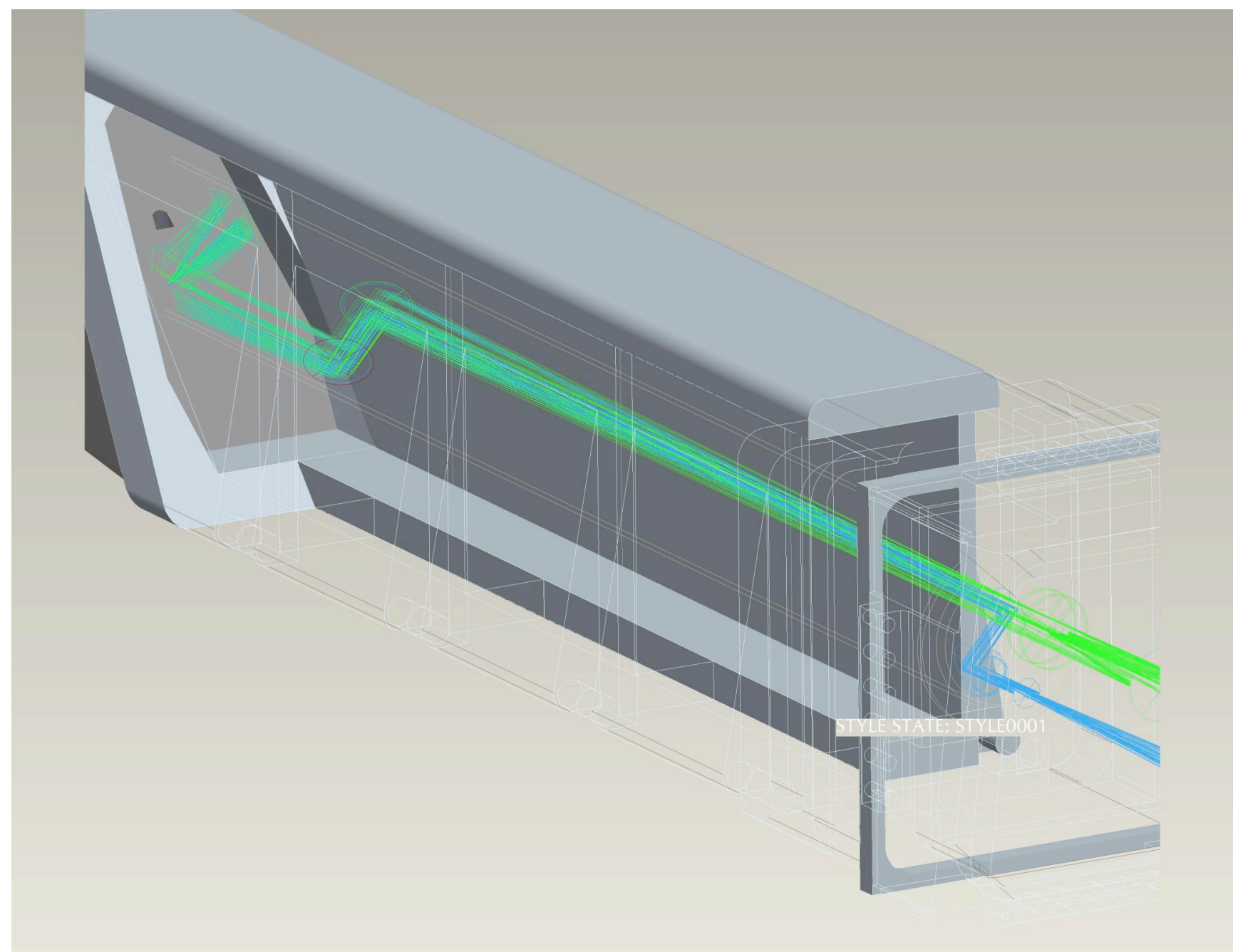

Fig. 52. Light path through the port plug. Visible light is shown in blue and infrared is represented in green. 


\section{Consultation with European experts}

One of the authors (Lasnier) traveled to JET to consult with some of the Europeans who are or may be involved in the design of the visible/IR systems for the ITER midplane ports. We discussed a preliminary design quite similar to the $20-\mathrm{mm}$ aperture design presented in section V.B of this report, and the ITER-like wide-angle IRTV system recently installed on JET. Among the physicists contacted were Drs. Eric Gauthier (CEA), Yann Corre (CEA), Philip Andrew (JET), and Guy Matthews (JET). These conversations are summarized below.

Dr. Eric Gauthier: We talked for approximately two hours about the ITER visible/IR optics design. Dr. Gauthier pointed out that commercial camera have a cold filter/window which is smaller than the detector. Our present design has converging rays at an angle which would cause some vignetting of the image for such a window. In his opinion the specification of $3 \mathrm{~mm}$ resolution over the whole divertor is unrealistic. He favors a high-resolution view of a limited area. He pointed out that to get a thermographic measurement with an error bar of $10 \%$, the MTF for a particular feature size should be $80 \%$ or greater. This is seen by looking at radiative intensity versus slit size. We have used a lower threshold for MTF, which is appropriate for discerning an image by eye but less so for quantitative calculations. He believes the uncertainty will be too large at an MTF of $40 \%$. He expected that it will be difficult to get a good braze seal of a large zinc selenide window, in part due to differential thermal expansion. He raised the issue of possible neutron damage to sapphire windows. The size of the detector chip we are recommending caused him some concern as he does not expect such a chip to be commercially available any time soon. He expects difficulty in the event of relying on any limited-production (custom) chip, e.g. difficulty in getting spares, and possibly reliability problems. He is worried that the optical design would have to be changed to use a different camera.

We also discussed the ITER-like wide-angle IR system he built for JET. In that system the head mirrors are mounted on a structure machined from a solid block of metal to preserve relative alignment. The length of the endoscope is allowed to change with thermal expansion, without degrading the image. The camera was customized by CEDIP to use a casing that provides magnetic shielding, the ability to accept an external command to take data from the JET system, and a remote-controlled filter wheel. The camera covers 3.8-4.6 $\mu \mathrm{m}$. Filters include 4-4.2 $\mu \mathrm{m}$ and a narrow-band 40nm filter, 3.97$4.01 \mu \mathrm{m}$ for high-temperature measurements. They have a block of neutron absorber between the camera and the tokamak. Dr. Gauthier believes it is important to provide an image at room temperature for focusing and alignment. The wide-angle system does that quite well.

Dr. Gauthier explained that the camera data is captured in RAM on a PC, and is then written to files on a server and on a disk accessible by a PC in the control room. The data is up to $1 \mathrm{~GB}$ per shot. One saw was $750 \mathrm{MB}$. The data acquisition software was written by the company that supplied the camera.

Dr. Yann Corre: Dr. Corre is an author of the CEA report ${ }^{2}$ on the ITER visible/IR design and is still involved with that task. We spoke for about 1.5 hours. He said he received copies of the emails sent to Dr. Dominique Guilhem, who is now in charge of a 
different project. They spent about 2.5 years on their design, although the contract was for one man-year. Although their report is very large, he said big chunks of the content were available from other sources, e.g., from Tore Supra. He pointed out that their design includes a shutter with heater and thermocouple to measure changes in transmission of the optics, as a result of erosion, deposition, and neutron damage. He expects that the head mirrors will become damaged and should be replaceable as a unit, as easily as possible. They are planning to do ray-tracing study of reflections in the divertor, and offered to look at our view as well. The company doing the ray-tracing does commercial work examining reflections in windshields for car manufacturers.

He is concerned about reflectivity of the divertor material, and believes a twocolor system will be necessary to account for unknown emissivity of the divertor, particularly if the surface is tungsten. They also have included an active system in their design, which heats the surface with a laser to measure the emissivity. This will provide only local information. There is concern about change in emissivity with time, as the divertor surface is altered by the plasma. One of the concerns with the ultimate design is dealing with heat flux onto the mirrors.

Dr. Philip Andrew: Dr. Andrew was the JET contact for installation of the wideangle system, and is the JET staff person for IRTV. We talked with for about 1.5 hours about the ITER-like wide-angle system, and a bit about the JET divertor IR system. He said the total cost of the wide-angle system was around 1 million Euros. His opinion is that the optics are extremely good, but he has some complaints about the reliability of the camera. Occasionally it will hang up, and he has to walk from the control room to the lab to restart the camera and the associated PC. There is Windows analysis software provided by the company that is quite flexible but does not quite fit the JET data model of storing the data on a server and being able to analyze it from anywhere.

Dr. Guys Mathews: The wide-angle IR view is very popular and much-requested in many experiments. 


\section{Estimates of system signal-to-noise ratios and limiting frame rates}

\section{A. Estimating radiated power from a target reaching a detector pixel}

Assume a radiating object and radiation focused onto a detector with pixel size $b$, and assume square pixels. Let the object area viewed by this pixel be of size $\mathrm{O}$ and assume the object area is $\mathrm{O}^{2}$. Assume the focusing is by a thin lens of focal length $\mathrm{L}$ and aperture diameter A (Fig. 53).

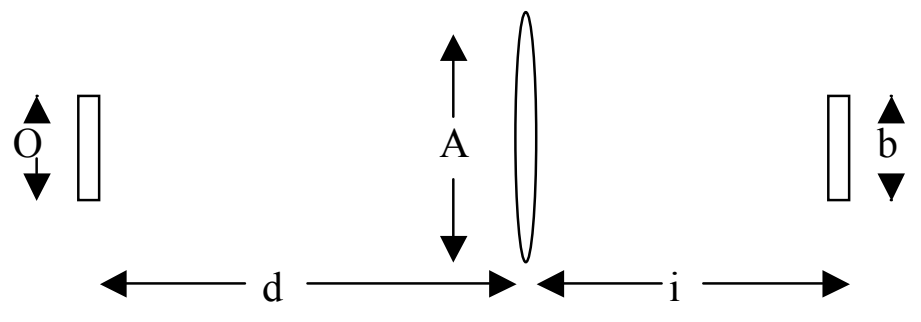

Fig, 53. Idealized thin lens geometry.

The solid angle subtended by the lens as seen from the object is

$\sigma \approx \frac{\pi(A / 2)^{2}}{4 \pi d^{2}} 4 \pi=\frac{\pi A^{2}}{4 d^{2}}$

The image size is $\mathrm{b}=\mathrm{O} * \mathrm{M}$ where $\mathrm{M}$ is the magnification

$M=-i / d$.

From the thin lens equation

$\frac{1}{L}=\frac{1}{i}+\frac{1}{d}$.

so that

$i=\frac{L d}{d-L}$

and

$M=\frac{L d}{L-d} \frac{1}{d}=\frac{L}{L-d}$. 
Therefore

$O=\frac{b(L-d)}{L}$.

Power per unit wavelength entering the lens from the object element is

$$
\begin{aligned}
P & =u(\lambda) O^{2} \sigma \\
& =\frac{\pi}{f^{2}} \frac{b^{2}}{4}\left(\frac{L}{d}-1\right)^{2} u(\lambda)
\end{aligned}
$$

which can be rewritten in a more standard form,

$\mathrm{P}=\frac{u(\lambda) \pi}{f^{2}} \frac{b^{2}}{4} \frac{1}{(1-M)^{2}}$

where $u(\lambda)$ is the power radiated by the target per unit area per unit solid angle per unit wavelength, and $f$ is the focal ratio $L / A$. This is also the power captured by the detector pixel assuming no losses in the lens.

\section{B. Estimating radiated blackbody power on an IR camera pixel}

The measurement of surface temperature of the tungsten parts of the ITER divertor using IR thermography poses certain difficulties. The surface emissivities of metals are low (they are good reflectors) so that the IR emission from the surface is reduced compared to a blackbody at the same temperature. The relatively high reflectivity means that nearby hot carbon surfaces may reflect more IR from the tungsten than the tungsten emits itself, even though the carbon may be at a lower temperature. The emissivity of tungsten at 3-5 $\mu \mathrm{m}$ is reported as $.05-0.5$ by various authors, probably depending on surface conditions ${ }^{13,14}$.

It is worthwhile to consider surface treatments for the tungsten that increase surface roughness, which will decrease the reflectivity. Such a surface may not retain is texture for long under plasma bombardment, so it may be desirable to test such surfaces in an existing machine. The micro-cracking and texture which are seen to develop in plasma simulators may be an advantage for the IR measurement.

If we assume an emissivity of 0.5 for the tungsten divertor plates and 0.9 for carbon, we can estimate the fractions of emitted and reflected IR from the tungsten. We assume an IR camera is integrating the IR emission from 3 to $5 \mu \mathrm{m}$.

$$
\begin{aligned}
& \text { Starting with Planck' } \\
& I(v, T)=\frac{2 h v^{3}}{c^{2}} \frac{1}{e^{\frac{h v}{k T}}-1}
\end{aligned}
$$


where $I(v, T)$ is radiated power per unit area per unit frequency per unit solid angle. If we integrated over the detected wavelengths we obtain the power per unit surface area per unit solid angle emitted within that wavelength range. The power received at the camera detector $P$ will be this integral multiplied by a factor $g$ which depends on the geometry and transmission of the optics and windows.

$$
P(T)=g \int_{v_{a}}^{v_{b}} I(v, T) d v
$$

where $\lambda_{a}=3 \mu \mathrm{m}$ and $\lambda_{b}=5 \mu \mathrm{m}$, so that $v_{1}=\mathrm{c} / \lambda_{\mathrm{a}}$ and $v_{2}=\mathrm{c} / \lambda_{\mathrm{b}}$. The integration must be done numerically.

$$
\int_{v_{a}}^{v_{b}} I(v, T) d v=\frac{2 h}{c^{2}} \int_{v_{a}}^{v_{b}} v^{3}\left[\frac{1}{e^{h v / k T}-1}\right] d v
$$

with a change of variables $x=h v / k T, d v=(k T / h) d x$, this becomes

$$
P(T)=\frac{2 g(k T)^{4}}{c^{2} h^{3}} \int_{x_{1}}^{x_{2}} x^{3}\left[\frac{1}{e^{x}-1}\right] d x
$$

where $x_{1}=h c / \lambda_{1} k T$ and $x_{2}=h c / \lambda_{2} k T$.

From equation [25] we have

$$
g=\frac{\pi}{f^{2}} \frac{b^{2}}{4} \frac{1}{(1-M)^{2}}
$$

We have

$$
\begin{aligned}
& h=6.626 \times 10^{-34} \mathrm{~J}-\mathrm{s} \\
& k=1.36054 \times 10^{-23} \mathrm{~J} / \mathrm{K} \\
& c=2.9979 \times 10^{8} \mathrm{~m} / \mathrm{s}
\end{aligned}
$$

and for

$$
\begin{aligned}
& \lambda_{1}=5 \times 10^{-6} \mathrm{~m} \\
& \lambda_{2}=3 \times 10^{-6} \mathrm{~m}
\end{aligned}
$$

we have

$$
\begin{aligned}
& x_{1}=\frac{2877.8 K}{T} \\
& x_{2}=\frac{4796.4 K}{T} .
\end{aligned}
$$


For two wavelengths of interest, the values of $\mathrm{x}$ are shown in Table 10 for two representative object temperatures.

\begin{tabular}{ccc}
$\lambda(\mathrm{m})$ & $\mathrm{T}(\mathrm{K})$ & $\mathrm{X}$ \\
\hline $5 \times 10^{-6}$ & 298 & 9.66 \\
$5 \times 10^{-6}$ & 1473 & 1.95 \\
& & \\
$3 \times 10^{-6}$ & 298 & 16.1 \\
$3 \times 10^{-6}$ & 1473 & 3.26
\end{tabular}

Table 10. values of $x=h c / \lambda k T$

From equation (6) of W.K Widger and W.P. Woodhall ${ }^{17}$

$$
\begin{aligned}
\int_{x}^{\infty} \frac{x^{3}}{e^{x}-1} d x= & \\
& \sum_{n=1}^{\infty} e^{-n x}\left[x^{3} n^{-1}+3 x^{2} n^{-2}+6 x n^{-3}+6 n^{-4}\right]
\end{aligned}
$$

According to Ref. 13, for the values of $\mathrm{x}$ we need for IRTV, keeping the first 10 terms of

\begin{tabular}{|c|c|c|}
\hline$f$ & 4.89 & 4.89 \\
\hline$b, m$ & $3.00 \mathrm{E}-05$ & $1.80 \mathrm{E}-05$ \\
\hline M & 0.0085 & 0.0085 \\
\hline$\lambda, \mathrm{m}$ & $\begin{array}{l}\text { 3-4.5E-6 } \\
P \text { (Watts) }\end{array}$ & $\begin{array}{l}\text { 3-4.5E-6 } \\
P \text { (Watts) }\end{array}$ \\
\hline $\mathrm{T}(\mathrm{K})$ & & \\
\hline 298 & $1.969 \mathrm{E}-11$ & 7.088E-12 \\
\hline 473 & $1.919 \mathrm{E}-09$ & $6.909 \mathrm{E}-10$ \\
\hline 1273 & $3.618 \mathrm{E}-07$ & $1.303 \mathrm{E}-07$ \\
\hline 1773 & $9.502 \mathrm{E}-07$ & $3.421 \mathrm{E}-07$ \\
\hline 2773 & $2.555 \mathrm{E}-06$ & $9.199 \mathrm{E}-07$ \\
\hline 303 & $2.405 \mathrm{E}-11$ & $8.657 \mathrm{E}-12$ \\
\hline 303.085 & $2.413 \mathrm{E}-11$ & $8.686 \mathrm{E}-12$ \\
\hline
\end{tabular}
the sum should provide 10 significant figures or more of accuracy.

Table 11. IR power onto a detector pixel 
Table 11 gives results of this calculation for $\mathrm{f} / 4.89$ optics, 30 or $18 \mu \mathrm{m}$ pixels, and five different temperatures.

\section{Signal-to-noise ratios for IR}

IR camera signal-to-noise levels may be characterized by the noise equivalent temperature difference, $N E \Delta T$, which is the change in scene temperature required to change the camera signal by an amount equal to the noise $(\mathrm{S} / \mathrm{N}=1)$ for a particular $f / \#$ and measurement bandwidth $B$.

To calculate signal-to-noise ratio, we scale the tested $N E \Delta T$ from an existing detector by using the appropriate bandwidth and $\mathrm{f} / \#$.

From Equation (2) of Ref. 18, we have ${ }^{18}$

$$
N E \Delta T=\frac{\sqrt{A B}}{D_{B}^{*}\left(d P_{B} / d T\right) \sin ^{2}(\theta / 2)}
$$

where $N E \Delta T$ is the change in scene temperature required to change the camera signal by an amount equal to the noise $(\mathrm{S} / \mathrm{N}=1)$ for a particular $f / \#$ and measurement bandwidth $B$. $D_{B}^{*}$ is the normalized blackbody detectivity, $P_{B}$ is the integrated blackbody power, and $T$ is the temperature, and $\mathrm{A}$ is the detector area.

From Ref.18, the field-of-view angle $\theta$ is related to the $f / \#$ by

$$
\sin ^{2}(\theta / 2)=\left(4 f^{2}-1\right)^{-1}
$$

We see from equation [35] that $N E \Delta T$ should scale with $\sqrt{B}$ as well as $1 /\left(4 f^{2}-1\right)$ for fixed scene temperature. This is reasonable, since longer integration times will reduce shot noise and thermal noise (but not readout noise).

For instance, from Table 11, for the $18 \mu \mathrm{m}$ detector pixel and target at $303 \mathrm{~K}$, the received power in a $3-4.5 \mu \mathrm{m}$ band at $\mathrm{f} / 4.89$ is $8.66 \mathrm{E}-12$ watts. A detector which had $N E \Delta T$ of $85 \mathrm{mK}$ at $f / 4.89$, has a noise equivalent power of $8.686 \mathrm{E}-12 \mathrm{~W}-8.657 \mathrm{E}-12 \mathrm{~W}=$ $2.9 \mathrm{E}-14 \mathrm{~W}$ for a the signal to noise ratio $S / N=299$. This is similar to the performance of the detector characterized in Ref. 14, running at $10 \mathrm{~Hz}$, and $N E \Delta T$ of $23 \mathrm{mK}$ at $f / 2.5$, which scales to $85 \mathrm{mK}$ at $f / 4.89$. However, if the frame rate is increased to $10 \mathrm{kHz}$, then $S / N=299 \cdot \sqrt{10 / 10000}=9.5$ (poor but detectable). At the ITER-spec 10ms time resolution $\mathrm{B}=0.5 / .01 \mathrm{~s}=50 \mathrm{~Hz}$, so $S / N=134(N E D T=0.19 \mathrm{~K})$.

For performance at a more reasonable scene temperature of $473 \mathrm{~K}$ (the minimum $200{ }^{\circ} \mathrm{C}$ temperature in the ITER spec), we will assume that the noise equivalent power calculated above is a characteristic of the camera and is independent of the scene temperature. This ignores statistical photon noise, which becomes proportionally less important with the 
higher photon flux at higher target temperatures. Here the power on the detector pixel is $6.9 \mathrm{E}-10 \mathrm{~W}$, for $S / N=23800$ at $10 \mathrm{~Hz}, S / N=10600$ at $50 \mathrm{~Hz}$, and $S / N=750$ at a $10 \mathrm{kHz}$ frame rate. The $S / N=256$ ( 8 bits) at $86 \mathrm{kHz}$. At higher temperatures the signal is even larger.

These calculations have assumed the entire 3-4.5 $\mu \mathrm{m}$ band is integrated by the detector. If we elect to use a narrower band, the signal power and thus the $S / N$ is reduced. In the event of additional noise from external sources, $S / N$ will be reduced accordingly. It is difficult to completely eliminate external noise when operating near a tokamak.

\section{Transmission losses}

This calculation so far has not taken into account transmission losses in the optics, or thermal emission by the optics, which will add noise. Reflectivity of rhodium mirror coatings from 3-5 $\mu \mathrm{m}$ has been measured ${ }^{19}$ at $\sim 92 \%$. A bounce off each of the two head mirrors if both are rhodium-coated, passes $85 \%$ of the light. The mirrors are assumed to be at a temperature of $200{ }^{\circ} \mathrm{C}$ and will radiate infrared with an emissivity of $8 \%$ each. Of the light emitted by the first mirror and striking the second mirror, $8 \%$ is absorbed by the second mirror and the rest is passed on through the optical chain.

The emitted light from the first two mirrors passed on through the optics is approximately $0.08 * 0.92 * \mathrm{P}_{\mathrm{BB}, 200}$ from the first mirror and $0.08 * \mathrm{P}_{\mathrm{BB}, 200}$ from the second mirror, where $\mathrm{P}_{\mathrm{BB}, 200}$ is the radiated power which would be captured from a blackbody at $200{ }^{\circ} \mathrm{C}$. The total is equivalent to viewing a single body of the same temperature, with an emissivity of $15.4 \%$. Therefore by passing through the first two mirrors we lose $15 \%$ of the signal and gain $15.4 \%$ of the light emitted by a $200 \mathrm{C}$ target as background light. The background light decreases the contrast in the image and therefore reduces the signal-tonoise ratio. However it is not as simple as adding the background power to the noise equivalent power. Because the background light adds to both the bright and dark areas of the image, the effective dynamic range of the instrument is reduced. In the extreme case of large background light and small signal, the image becomes "washed out." Due to the shape of a typical IR camera calibration curve, the background light influences the measurement of low-temperature targets most strongly. In addition, background light adds statistical photon noise.

The IR light absorbed in the two windows depends on the material (assumed to be sapphire) and the thickness. Some light will also be reflected. The reflection coefficient is $^{20}$

$$
R=\left(\frac{1-n}{1+n}\right)^{2}
$$

and the transmission coefficient in the absence of absorption is ${ }^{20}$

$$
T=\frac{4 n}{(1+n)^{2}}
$$


where $\mathrm{n}$ is the index of refraction and the surrounding medium is assumed to have $\mathrm{n}=1$. From the Melles Griot catalog ${ }^{21}$, we can calculate the index of refraction. The result are summarized in Table 12, in which we also include visible wavelengths.

$\begin{array}{ccccccc}\lambda(\mu \mathrm{m}) & \begin{array}{c}\mathrm{n} \\ \text { (ordinary) }\end{array} & \begin{array}{c}\mathrm{n} \\ \text { (extraordinary) }\end{array} & \mathrm{R}(\mathrm{o}) & \mathrm{R}(\mathrm{e}) & \mathrm{T}(\mathrm{o}) & \mathrm{T}(\mathrm{e}) \\ 0.4 & 1.7865 & 1.7258 & 0.0797 & 0.0709 & 0.9203 & 0.9291 \\ 0.7 & 1.7632 & 1.7276 & 0.0763 & 0.0712 & 0.9237 & 0.9288 \\ 3.0 & 1.7122 & 1.7313 & 0.0690 & 0.0717 & 0.9310 & 0.9283 \\ 4.0 & 1.6752 & 1.7337 & 0.0637 & 0.0720 & 0.9363 & 0.9280 \\ 5.00 & 1.6240 & 1.7368 & 0.0566 & 0.0725 & 0.9434 & 0.9275\end{array}$

Table 12. Index of refraction of sapphire

Assuming the incident light to be unpolarized, the reflection coefficient is the average of the ordinary and extraordinary coefficients (Table 13). Also shown are the transmission coefficients for unpolarized light.

$\begin{array}{ccc}\lambda(\mu \mathrm{m}) & \mathrm{R}_{\mathrm{u}}=\left(\mathrm{R}_{\mathrm{e}}+\mathrm{R}_{\mathrm{o}}\right) / 2 & 1-\mathrm{R}_{\mathrm{u}} \\ 0.4 & 0.0753 & 0.9247 \\ 0.7 & 0.0737 & 0.9263 \\ 3.0 & 0.0703 & 0.9297 \\ 4.0 & 0.0679 & 0.9321 \\ 5.0 & 0.0645 & 0.9355\end{array}$

Table 13. Reflection and transmission coefficients for sapphire for unpolarized light.

According to a Saint-Gobain Sapphire material data sheet ${ }^{22}[10]$, the absorption coefficient of sapphire at 3,4 and $5 \mu \mathrm{m}$ is approximately $0.15,0.2$, and $1.3 \mathrm{~cm}^{-1}$ respectively, at $200{ }^{\circ} \mathrm{C}$. The transmission fraction (without reflections) is given in Table 14.

$\begin{array}{cccc}\begin{array}{c}\text { absorption } \\ \text { coeff St.- } \\ \text { Gobain } \\ \lambda(\mu \mathrm{m})\end{array} & \begin{array}{c}\text { T } 20 \mathrm{~mm} \text { (no } \\ \text { reflections)(St.- reflections)(St.- } \\ \left.\text { G } \mathrm{mm}^{-1}\right)\end{array} & \begin{array}{c}\text { Gobain) } \\ \text { Gobain) }\end{array} \\ 3.0 & 0.015 & 0.7408 & 0.5488 \\ 4.0 & 0.02 & 0.6703 & 0.4493 \\ 4.5 & 0.03 & 0.5488 & 0.3012 \\ 4.7 & 0.05 & 0.3679 & 0.1353 \\ 4.8 & 0.075 & 0.2231 & 0.0498 \\ 5.0 & 0.13 & 0.0743 & 0.0055\end{array}$

Table 14. Transmission fraction for sapphire. 
The transmission at $5 \mu \mathrm{m}$ through 20 or $40 \mathrm{~mm}$ of sapphire is quite low. The upper limiting wavelength for useful transmission for these thick windows is approximately 4.7 $\mu \mathrm{m}$. By comparison, the absorption coefficient for $\mathrm{ZnSe}$ is $5 \mathrm{e}-5$, virtually flat from 2-10 $\mu \mathrm{m}$. The absorption is negligible but reflection drops the transmission to $72 \%$ for each window, unless AR coatings are used. Anti-reflection coatings are available for 3-5 or 3$12 \mu \mathrm{m}$.

\section{E. Self-emitted light}

\section{IR}

Each element in the optical chain emits its own infrared radiation, which contributes background signal. The background signal reduces contrast in the infrared image. The background infrared power $P_{k}$ contributed by the $k t h$ element in the optics chain is

$$
P_{k}=a_{k} P_{k, B B} \prod_{i=k}^{n} Y_{i},
$$

where the power $P_{k, B B}$ is that collected from a blackbody of the same temperature as the optical element and captured by the succeeding optics, and is given by equation (8), using the Planck function for $u(\lambda)$. The emissivity of the $k t h$ optical element is $a_{k}$. Each of the $k$ elements may be at a different temperature.

The total background infrared power is obtained by summing over all the $n$ optical elements.

$$
\begin{aligned}
P_{\text {background }} & =\sum_{i=1}^{n} P_{k} \\
= & \sum_{k=1}^{n}\left[a_{k} P_{k, B B} \prod_{i=k}^{n} Y_{i}\right]
\end{aligned}
$$

This assumes none of the components is wavelength dependent. In reality each transmittance or reflectance can be a function of wavelength, and the products should be integrals over the products of the wavelength-dependent functions. The power emitted is a function of wavelength, so the Planck function should be inside the integral. However, the spectral regions where the transmittance or reflectance drops sharply will not contribute much to the power integral, so we will approximate the reflectances and transmittances as constants over a smaller wavelength band where the variation is small.

The background power calculated here is not uniformly distributed over the detector. Power radiated from a point on an optical element near an image plane will map to a point on the detector. Radiation from a point on an optic not near an image plane will map to a disk on the detector. 


\section{Visible}

In ITER, radiation levels can be high enough to produce significant fluorescent emission in the visible from windows and lenses. This is yet another reason not to have lenses in the port plug. Copious UV light will be emitted by the plasma, but not reflected well by the collection head mirrors, which will reduce the UV radiation at the windows. Any florescence will contribute background light to the measurements, adding photon statistical noise. If background light is unanticipated in the design, it can badly affect the dynamic rage of the system by raising the noise floor close to the system saturation.

\section{F. Visible system signal-to-noise estimates}

We have calculations of line-integrated photon radiation rates provided by A.S. Kukushkin from his modeling of ITER discharges for $\mathrm{D}_{\alpha}$, and carbon lines at 514.7 , 229.8 , and $580.6 \mathrm{~nm}^{23}$ using the $\mathrm{B} 2.5$-Irene code. The radiation rate for the carbon line at $465 \mathrm{~nm}$ was obtained using the $229.8 \mathrm{~nm}$ model result along with the branching ratios from the NIST atomic spectra database ${ }^{24}$.

The photon emission was integrated along two chords (Chords $1 \& 2$ in Table 15). The endpoints of the two chords are shown in Fig. 54. Chord 1 ended at the private flux baffle, and chord 2 at the bottom of the outer target plate.

The predicted photon rate at each pixel may be used to calculate a signal-to-noise ratio for a chosen camera. The signal-to noise ratio (SNR) is given $b^{25}$ :

$$
S N R=P Q_{e} t /\left[P Q_{e} t+D t+N_{R}^{2}\right]^{1 / 2}
$$

where $P$ is the incident photon rate on a pixel in photons/second/pixel, $Q_{e}$ is the quantum efficiency, $t$ is the integration time, $D$ is the dark current in electrons/second/pixel, and $N_{R}$ is the read noise in electrons/pixel. We use the target viewing area of a single pixel in the $20 \mathrm{~mm}$ aperture design, which is $1.7 \mathrm{~mm}$ wide and tall. The effective aperture of the system is $8.3 \mathrm{~mm}$, and the object distance in the center of the view is $11.5 \mathrm{~m}$.

We use estimates of read noise of 30 electrons/pixel ${ }^{26}$ and dark current of 30 electrons/pixel/second ${ }^{27}$, and the quantum efficiencies for a CIDTEK CID3710D camera $^{28}$. The calculated SNR is given in Table 15 .

For the integration time we have used $0.02 \mathrm{~s}$ for the standard European video rate. We see that the CIV line is barely detectable, while other lines have acceptable SNR. At higher frame rates the SNR is correspondingly reduced. Table 16 shows SNR for chord 2 for various integration times. Frame rates up to 20,000 may be used while viewing the CIII line, with lower rates for other lines. The SNR and allowable frame rates will increase with higher quantum efficiency of the camera, and drop for smaller system entrance aperture.

In Table 17 is shown the same table for the $5 \mathrm{~mm}$ entrance aperture design. We see that now CIII at $465 \mathrm{~nm}$ could be measured at a maximum frame rate near 2000 frames per second, and all SNR is correspondingly reduced. Measurement of CIV at $580.6 \mathrm{~nm}$ becomes impractical. The effective aperture for the visible system in this design is 2.35 $\mathrm{mm}$. 


\begin{tabular}{|c|c|c|c|c|c|c|c|c|}
\hline \multirow[b]{2}{*}{ Chord } & \multirow[t]{2}{*}{$\begin{array}{l}\text { wavelength } \\
\text { (m) }\end{array}$} & \multicolumn{2}{|c|}{ 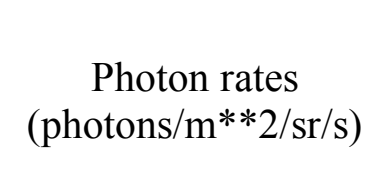 } & \multirow{2}{*}{\multicolumn{2}{|c|}{ photon rate on a pixel }} & \multirow[t]{2}{*}{$\begin{array}{c}\text { Quantum } \\
\text { efficiency } \\
\mathrm{Q}_{\mathrm{e}}\end{array}$} & \multicolumn{2}{|c|}{$\begin{array}{l}\text { Calculated } \\
\text { SNR }\end{array}$} \\
\hline & & 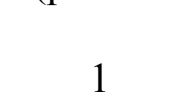 & ( & & 2 & & $\begin{array}{c}\text { Chord } \\
1\end{array}$ & $\begin{array}{c}\text { Chord } \\
2\end{array}$ \\
\hline $\mathrm{D}_{\alpha}$ & $6.56 \mathrm{E}-07$ & $1.39 \mathrm{E}+20$ & $1.22 \mathrm{E}+21$ & $1.31 \mathrm{E}+07$ & $1.15 \mathrm{E}+08$ & 0.23 & 243 & 726 \\
\hline $\begin{array}{l}\text { CII } \\
514.7\end{array}$ & $5.15 \mathrm{E}-07$ & $6.76 \mathrm{E}+17$ & $4.06 \mathrm{E}+19$ & $6.36 \mathrm{E}+04$ & $3.82 \mathrm{E}+06$ & 0.25 & 9 & 135 \\
\hline $\begin{array}{l}\text { CIII } \\
229.8\end{array}$ & $2.30 \mathrm{E}-07$ & $2.06 \mathrm{E}+19$ & $2.43 \mathrm{E}+21$ & $1.94 \mathrm{E}+06$ & $2.29 \mathrm{E}+08$ & 0.13 & 65 & 770 \\
\hline $\begin{array}{l}\text { CIV } \\
580.6\end{array}$ & $5.81 \mathrm{E}-07$ & $4.38 \mathrm{E}+16$ & $3.45 \mathrm{E}+17$ & $4.12 \mathrm{E}+03$ & $3.25 \mathrm{E}+04$ & 0.27 & 1 & 5 \\
\hline $\begin{array}{l}\text { CIII } \\
465.0\end{array}$ & 4.65E-07 & $3.85 \mathrm{E}+19$ & $\begin{array}{r}4.54 \mathrm{E}+21 \\
\text { 4. }\end{array}$ & $3.62 \mathrm{E}+06$ & 4.27E+08 & 0.22 & 123 & 1371 \\
\hline
\end{tabular}

Calculated SNR for chord 2 for various frame rates

frame

$\begin{array}{lcccccc}\text { rate } & 50 & 200 & 500 & 2000 & 5000 & 20000 \\ \mathrm{D}_{\alpha} & 726 & 362 & 228 & 111 & 67 & 28\end{array}$

CII

514.7

135

$63 \quad 36$

13

6

2

CIII

229.8

$\begin{array}{lll}770 & 384 & 242\end{array}$

118

72

30

CIV

580.6

5

1

1

0

0

0

CIII

465.0

$1371 \quad 685 \quad 433$

215

134

63

Table 16. Calculated SNR for various frame rates and wavelengths for $20 \mathrm{~mm}$ aperture. 
frame

Calculated SNR for Chord 2 for $5 \mathrm{~mm}$ system aperture

$\begin{array}{lcccccc}\text { rate } & 50 & 200 & 500 & 2000 & 5000 & 20000 \\ \mathrm{D}_{\alpha} & 204 & 99 & 59 & 24 & 12 & 3 \\ \text { CII } & & & & & & \\ 514.7 & 31 & 11 & 5 & 1 & 1 & 0 \\ \text { CIII } & & & & & & \\ 229.8 & 216 & 105 & 63 & 26 & 13 & 4 \\ \text { CIV } & & & & & & \\ 580.6 & <1 & <1 & <1 & <1 & <1 & <1 \\ \text { CIII } & & & & & & \\ 465.0 & 387 & 192 & 119 & 55 & 31 & 11\end{array}$

Table 17. Calculated SNR for various frame rates and wavelengths for $5 \mathrm{~mm}$ aperture

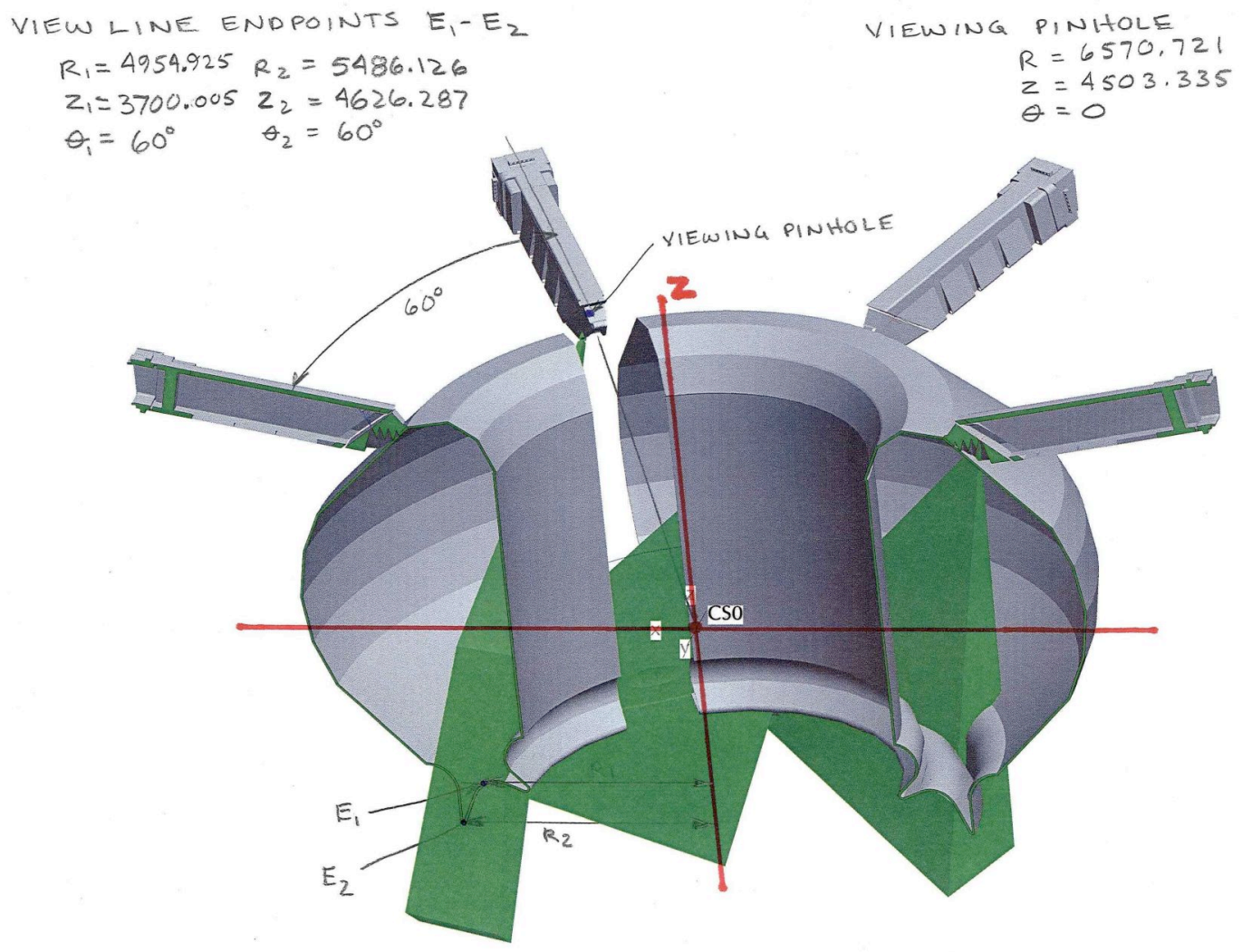

Fig. 54. Two chords were used for integration of visible emission. Chord 1 ended at the private flux baffle, and chord 2 at the bottom of the outer target plate. Endpoints of the two chords are labeled E1 and E2, respectively, in the figure. 


\section{Calibration}

\section{A. IR calibration}

As pointed out in the CEA report, an off-line thermal calibration should be performed before the system is installed on ITER. They have suggested a heated shutter with measured and controlled temperature, which can be closed between the entrance aperture and the mirrors, to provide a thermal signal that can be used to check changes in system transmission.

A related issue is the unknown emissivity of surfaces at the target. This is of some concern with a carbon target, and of great concern with any metal target such as tungsten. The emissivity of tungsten may vary by an order of magnitude depending on the surface preparation and history ${ }^{29}$. A two-color or multi-color system is advisable to help deal with this problem ${ }^{30}$. Measurements at different wavelengths can be fitted to a blackbody curve to arrive at a surface temperature independent of any knowledge of the surface emissivity. A two-color or multi-color system would need the light to be split between different detectors. This is a simple modification to the optical design, but increases the cost, with additional optics and cameras.

The calibration system should be designed so that an automated calibration can be obtained and put into use when desired.

Even the multi-color approach does not eliminate difficulty associated with a metal target plate, in the case where there are nearby objects of higher emissivity which could show reflections in the metal target. This would be the case if the outer target plate were to be made of tungsten and the private flux baffle were covered with carbon tiles. In this case the carbon tiles radiate more efficiently than the tungsten even at a lower temperature, producing a reflection in the tungsten that is brighter than the emission from the hotter tungsten. There may be a possibility of complex background subtraction techniques, but the most reliable solution would be to look in the image for an area that does not show the bright reflection and take temperature measurements there. A hot spot on the tungsten could still be concealed in the area of the bright reflection.

Previous research has shown that roughening techniques such as knurling can increase the emissivity of metal surfaces ${ }^{31,32}$. We note that tests of candidate metals exposed to high heat flux have results in small-scale surface roughness that may enhance the emissivity ${ }^{33,34,35}$.

A spatial calibration is also necessary to make proper use of the data. In an ideally rigid system, the spatial calibration could be measured once on installation and would never change. In practice, the dimensions of the tokamak change with heating and alignment may be disturbed by discharges terminating in disruptions. It will be necessary to have a scheme for checking and re-measuring the spatial calibration as necessary. The interior of the tokamak will provide enough recognizable fiducials to calibrate a wideangle view, perhaps with assistance from pattern-matching image analysis software.

If a narrow-view system is installed, there may be difficulty in the unique identification of landmarks within the field of view. In this case it may be necessary to install fiducials in the target area which are easily identifiable in the camera view. 


\section{B. Visible system calibration}

It is not clear that the visible camera system needs to be absolutely calibrated, and there are significant difficulties associated with maintaining such a calibration. It may be sufficient to reference the visible-light images to another diagnostic which is absolutely calibrated.

In the event that absolute calibration is desired, a calibration should be performed before installation, and a light source should be provided to measure changes in system transmission. Light may be most conveniently introduced on the port interspace in the visible light path. However, this does not test the optics in the port plug, and in particular the mirrors of the optical collection head, which are the most likely to be coated and suffer reduced reflectivity. In this report, we leave calibration of the visible camera system as an area requiring further development.

\section{High-priority R\& D issues}

The issues below must be addressed before construction of the diagnostic, and in some cases before a final design can be completed. Any insoluble problem in any of these areas may need to be addressed by a design change.

\section{A. Large detector for IR, 3000-4000 pixels wide, $18 \mu \mathrm{m}$ pixels}

In order to measure the large area of the outer target with nearly the specified resolution, IR camera detectors much larger with many more pixels than commonly available commercially at the time of this writing must be developed. A few such detectors have been built for space satellite use ${ }^{36}$. These detectors are designed to be read out slowly with much lower frame rates than needed for ITER. The development of an appropriate sensor will be crucial to come near the specified coverage and resolution in the IR.

Considerable time remains before the cameras are needed for taking data on ITER, so an argument can be made to wait as long as possible before purchasing cameras. Otherwise the cameras will be long obsolete before ITER begins operation, and will operate at lower performance than cameras currently available at that time. Even so, at least one high-resolution camera will be needed at the time of construction of the diagnostic to verify performance.

\section{B. Large visible detector, 3300 pixels, $4 \mathrm{~cm}$ long}

Video detectors are in the planning stages today that have the required number of pixels, and some large detectors are on the market ${ }^{26,37}$. However, the pixel sizes are substantially smaller and the frame rates are quite low. The development of a large highspeed, high-resolution detector for visible light is necessary. It is likely that commercial designs will approach this goal in the next few years, and almost certainly before ITER operates. Again, it will be beneficial not to buy the cameras long before they are needed, so as to take advantage of subsequent commercial development. 


\section{Durability of rhodium-coated mirrors under ion bombardment}

Some testing of mirrors has begun, but the specific test of rhodium-plated mirrors in a tokamak environment must be done before committing to their use in diagnostic construction. In our designs we propose, as in the CEA report, to use a GlidCop substrate.

\section{Durability of visible and IR anti-reflection coatings in high neutron environments}

Before construction, data is needed on the durability on anti-reflection coating used for visible and IR under neutron bombardment. The coated optics will be in the port interspace (except for vacuum windows) so that the neutron flux will be lower than in the port plug. The detailed prediction of neutron rates will depend on neutronics calculations yet to be performed.

\section{E. Dependence of IR transmission on neutron fluence for $\mathrm{ZnSe}$ and Ge}

There are some indications that IR transmission through optics is not much affected by neutron bombardment ${ }^{9}$, (compared to visible light transmission reduction, in sapphire) but $\mathrm{ZnSe}$ and Ge must be specifically tested before they are used in a diagnostic. Our designs (except for the $5 \mathrm{~mm}$ aperture design) call for lenses of these materials in the port interspace.

\section{F. Fluorescent emission from optics}

Estimates of the fluorescent emission from optics should be made to determine whether it will pose a problem. Significant amounts of stray light will degrade the system signal-to-noise ratio in any case, but the effect is worse if the dynamic range of the camera is not selected properly.

\section{G. Calibration of the visible system}

If absolute calibration of the visible system is desired, a technique needs to be developed to measure the effects of lens darkening, coating damage, deposition on mirrors, and decrease in mirror reflectivity due to ion bombardment, so that we can maintain calibration. It will be difficult to get calibration light to the collection optics, particularly at a calibrated light level. Optics or fibers used to carry the calibration light could degrade and affect the calibration result in a way that is difficult to quantify.

Rather than putting in additional optics to try to introduce calibration light, which would themselves also be subject to transmission changes, it would be simpler to put a beam splitter near the camera and introduce a calibration beam. The light would travel down the optics of the diagnostic to the machine and be reflected back to the camera by a shutter. The only part of the system in the calibration loop that is not part of the regular optical chain then would be the shutter. The shutter should provide a diffuse reflection rather than a specular reflection so that the alignment of the shutter is not critical in aiming a reflection back through the system.

We still need to monitor changes in reflectivity of the shutter, which we could do by an application of time domain reflectometry. TDR is often used for checking optical fibers, using a commercial instrument built for that purpose ${ }^{38,39}$. The instrument sends fast pulses of light down the fiber which reflect from the far end of the fiber and/or off any defects or fiber breaks along the way. The amplitude vs. time of the reflected pulse is 
displayed on a screen. The time delay between the emitted pulse and the detected reflection are used to determine how far down the fiber the reflection occurred. If the reflection occurs only from the far end at the full length of the fiber, the fiber is good. An example of such an instrument is here: light.

http://www.tequipment.net/TektronixTFP2A.html. Unfortunately it uses near-IR

In our application, we would again put a light pulse into the optical train near the camera and look for the amplitude and timing of the reflections. Each lens surface will create a small reflection, even it is AR coated. There will be a small pulse of scattered light from the surface of each mirror, and a big reflected pulse from the shutter. If we see all the reflections from objects on the far side of a certain lens have dropped off, we know the lens has a problem, probably darkening due to radiation damage. If we see an increase in the reflection from a certain lens, we know the coating is damaged. If we see an increase in the scattered light pulse from a mirror, we know the reflectivity of the mirror is down and the mirror is damaged. If every reflection after a certain mirror is down, we also know the mirror is damaged or has deposits on it. If the intermediate reflections are all the same but the reflection from the shutter is down, we know the reflectivity of the shutter has dropped. The initial TDR signature should be created when the diagnostic is built, and referenced for any changes.

Because of the lens curvatures defocusing the reflections, we would need a brighter light pulse than usually used for TDR checking of fibers. Commercial TDR instruments use near infrared pulses, so modifications would be necessary to check visible light transmission.

\section{H. Rejection of microwave power from gyrotrons}

Current plans call for injection of microwave power into ITER from gyrotrons. During unusual events, it is possible for plasma density to reach cutoff and reflect microwaves into a diagnostic port. IR cameras in particular, because they are designed to detect tiny amounts of heat, need to be shielded from such power. Microwaves can be blocked by the use of electroformed mesh, with accompanying reduction in light throughput simply by the mesh obscuring a fraction of the beam. Attention must be paid in the mechanical design that stray microwave paths to the camera are not allowed.

\section{Acquisition, processing, and storage, and analysis of data}

The IR and visible video systems contemplated here will produce gigantic amounts of data. The pixel counts of the detectors are large, required frame rates are high, and the diagnostics are repeated in separate locations around the tokamak. Even if the detectors operate at only a $50 \mathrm{~Hz}$ frame rate, the data collected in a 400 second discharge is 3 terabytes. For two-color or multicolor IR measurement, the data load increases still more. We may say that computer technology can store such an amount of data by the time of ITER operation, but the data need to be processed in real time to identify threats to the tokamak. Special analysis software is needed to very quickly identify important pieces of data. 


\section{Concluding comments}

Of the many issues that came to the fore in this design process, the most difficult is obtaining adequate spatial resolution in the infrared view. The resolution is severely diffraction-limited by the size of the entrance aperture. The size of the aperture is limited by the size of the optics that will fit in the port. If refractive relay optics were to be used in the outer half of the port tube, this would allow an increase in aperture size as shown is section IV.C. The required optic size can be decreased, or the aperture and hence spatial resolution increased, by decreasing the field of view. This would mean abandoning the requirement of the fullest possible coverage of the outer target plate.

In the event that one of the six upper ports is not available for a camera system, the coverage will be decreased by $1 / 6$, assuming no additions to other ports. It would be quite difficult to fit two high-resolution camera systems in one port. 
${ }^{1}$ ITER.org January 2007, http://www.iter.org/

${ }^{2}$ Y. Corre, et al., CEA Cadarache report: "ITER wide-angle viewing thermographic and visible system", prepared for EFDA

${ }^{3}$ ITER.org January 2007, http://www.iter.org/pics/ITER_col.jpg

${ }^{4}$ ITER.org January 2007, http://www.iter.org/a/index nav 4.htm

${ }^{5}$ S. Clement, A. Chankin, D. Ciric, J.P. Coad, J. Falter, E. Gauthier, J. Lingertat, and S. Pupin, "Power deposition in the JET divertor during ELMs", J. Nucl. Mater, 266-269 (1999) 285

${ }^{6}$ G.D. Porter, private communication to C.J. Lasnier, Sept. 11, 2006

${ }^{7}$ Wikipedia.org. June 2006, http://en.wikipedia.org/wiki/Airy disc

${ }^{8}$ Jenkins, F.A \& White, H.E. (1976). Fundamentals of Optics. New York, NY: McGrawHill Inc.

${ }^{9}$ rohmhaus.com, January 2007, http://www.rohmhaas.com/cvdmaterials/Infrared_Mat/pdfs/Zinc_Selenide.pdf

${ }^{10}$ S. Yamamoto, T. Shikama, V. Belyakov, E. Farnum, E. Hodgson, T. Nishitan, D. Orlinsk, S. Zinkl, S. Kasai, P. Stott, K. Young, V. Zaveriaev, A. Costley, L. deKock, C. Walker and G. Janeschitz, "Impact of irradiation effects on design solutions for ITER diagnostics", J. Nucl. Mater. 283-287, Part I (2000) 60

${ }^{11}$ Spotweldingconsultants.com, January 2007, http://www.spotweldingconsultants.com/GlidCop AL 15.pdf

${ }^{12}$ A. Litnovsky, et al., "Diagnostic mirrors for ITER: a material choice and the impact of erosion and deposition on their performance" presented at the $17^{\text {th }}$ International Conference on Plasma-Surface Interactions in Controlled Fusion Devices, Hefei, China May 23, 2006, http://202.127.205.20/PDF/I-10 Litnovsky.pdf

${ }^{13}$ Thermophysical Properties of Matter, Vol. 7: Thermal Radiative Properties, Y.S. Touloukian, IFI/Plenum, New York, 1970

${ }^{14}$ Pyromtry.com, January, 2007 http://www.pyrometry.com/emissivity.php

${ }^{15}$ Planck, Max, "On the Law of Distribution of Energy in the Normal Spectrum". Annalen der Physik, vol. 4, p. 553 ff (1901).

${ }^{16}$ Wikipedia.org, January 2007 http://en.wikipedia.org/wiki/Planck\%27s law of black body radiation

${ }^{17}$ W.K. Widger and M.P. Woodhall, "Integration of the Planck blackbody radiation function," Bulletin of the American Meteorological Society 57 (10) 1217, 1976

${ }^{18}$ S.D. Gunapala, S.V. Bandara, J.K. Liu, C.J. Hill, S.B. Rafol, J.M. Mumolo, J.T. Trinh, M.Z. Tidrow, and P.D. LeVan, "1024 × 1024 pixel mid-wavelength and long-wavelength infrared QWIP focal plane arrays for imaging applications", Semicond. Sci. Technol. 20 No. 5 (May 2005) 473 
${ }^{19}$ Platinummetalsreviw.com, January 2007

http://www.platinummetalsreview.com/jmpgm/index.jsp (reflectance vs. wavelength graph)

${ }^{20}$ Wikipedia.org, January 2007, http://en.wikipedia.org/wiki/Fresnel_equations

${ }^{21}$ mellesgriot.com, January 2007 , http://www. mellesgriot.com/products/optics/mp 3 5.htm (material properties: sapphire)

22 photonic.saint-gobain.com, January 2007 http://www.photonic. saintgobain.com/Media/Documents/S0000000000000001020/efg properties.pdf

${ }^{23}$ A.S. Kukushkin, private communication to M.E. Fenstermacher, October 10, 2006.

${ }^{24}$ Nist.gov, January 2007, http://www.physics.nist.gov/PhysRefData/ASD/lines_form.html

${ }^{25}$ Microscopyu.com, January 2007, http://www.microscopyu.com/tutorials/java/digitalimaging/signaltonoise/index.html

${ }^{26}$ L.J. Koslowski, Rockwell Scientific, Hdtv.videotechnology.com, January 2007, http://hdtv.videotechnology.com/HDTV-CMOSvsCCD.htm

${ }^{27}$ Ccd.com, January 2007, http://www.ccd.com/apseries.html\#CCDSpecsl

${ }^{28}$ Thermo.com, January 2007, http://www.thermo.com/eThermo/CMA/PDFs/Product/productPDF_26855.pdf

${ }^{29}$ Pyrometry.com, January 2007, http://www.pyrometry.com/emissivity.php

30 e.g. Pyrometry .com, January 2007, http://www.pyrometry.com/ih1995.php

${ }^{31}$ Pyrometry.com, January 2007, http://www.pyrometry.com/ih2003.php

${ }^{32}$ Freshpatents.com, January 2007, http://www.freshpatents.com/System-and-methodfor-increasing-the-emissivity-of-a-material-dt20051215ptan20050274374.php

${ }^{33}$ K. Tokunaga, M.J. Baldwin, R.P. Doerner, N. Noda, Y. Kubota, N. Yoshida, T. Sogabe, T. Kato, B. Schedler, "Blister formation and deuterium retention on tungsten exposed to low energy and high flux deuterium plasma", J. Nucl. Mater. 337-339 (2005) 887

${ }^{34}$ M. Tokitani, M. Miyamoto, D. Koga, K. Tokanaga, T. Fujiwara, N. Yoshida, S. Masuzaki, N. Ashikawa, T. Morisaki, M. Shoji, A. Komori, LHD Experimental Group", 
"Microscopic and macroscopic damage in metals exposed to LHD divertor plasmas", J. Nucl. Mater. 337-339 (2005) 937

${ }^{35}$ Y. Ueda, T. Funabiki, T. Shimada, K. Fukamoto, H. Kurishita, M. Nishikawa, "Hydrogen blister formation and cracking behavior for various tungsten materials", J. Nucl. Mater. 337-339 (2005) 1010

${ }^{36}$ Teledyne-si.com, January 2007, http://www.teledyne-si.com/imaging/products.html

${ }^{37}$ Kodak.com, January 2007, http://kodak.com/US/en/dpq/site/SENSORS/name/ISSFullFrameProductFamily and http://kodak.com/US/en/dpq/site/SENSORS/name/ISSInterlineProductFamily

${ }^{38}$ e.g. tequipment.net January 2007, http://www.tequipment.net/TektronixTFP2A.html

${ }^{39}$ tek.com, January 2007, http://www.tek.com/site/ps/0, 85-17654-INTRO EN,00.html 